\title{
Ethanol Dehydration in a Pressure Swing Adsorption Process Using Canola Meal
}

\author{
A Thesis Submitted to the College of \\ Graduate Studies and Research \\ In Partial Fulfillment of the Requirements \\ For the Degree of Master of Science \\ In the Department of Chemical \& Biological Engineering \\ University of Saskatchewan \\ Saskatoon, Saskatchewan, Canada \\ By \\ Mehdi Tajallipour
}

(C) Mehdi Tajallipour, March 2013. All rights reserved. 


\section{PERMISSION TO USE}

In presenting this thesis in partial fulfillment of the requirements for a Postgraduate degree from the University of Saskatchewan, I agree that the Libraries of this University may make it freely available for inspection. I further agree that permission for copying of this thesis in any manner, in whole or in part, for scholarly purposes may be granted by the professor or professors who supervised my thesis work or, in their absence, by the Head of the Department or the Dean of the College in which my thesis work was done. It is understood that any copying or publication or use of this thesis or parts thereof for financial gain shall not be allowed without my written permission. It is also understood that due recognition shall be given to me and to the University of Saskatchewan in any scholarly use which may be made of any material in my thesis.

Requests for permission to copy or to make other use of material in this thesis in whole or part should be addressed to:

Head of the Department of Chemical \& Biological Engineering

57 Campus Dr.

University of Saskatchewan

Saskatoon, Saskatchewan

Canada

S7N 5A9 


\begin{abstract}
Canola meal was used as an adsorbent in a pressure swing adsorption (PSA) apparatus for ethanol dehydration. The experiments were conducted at different pressures, temperatures, vapor superficial velocities, vapor concentrations and particle sizes. Adsorption experiments were performed at equilibrium and breakthrough points. The results demonstrated that canola meal can break the azeotropic point $95.6 \mathrm{wt} \%$ and produce over $99 \mathrm{wt} \%$ ethanol. At elevated temperature, feed water concentration, and vapor superficial velocity, it was found that the mass transfer rate increased. In addition, the mass transfer rate decreases when either the total pressure or the size of the adsorbent particles are increased. Breakthrough curves were simulated and the overall mass transfer resistance was evaluated at all experimental runs. The internal mass transfer resistance was identified as the relevant mass transfer mechanism.

For canola meal, the equilibrium water/ethanol uptake was achieved at 100, 105, and $110^{\circ} \mathrm{C}$. The Frenkel-Halsey-Hill (FHH) and Guggenheim-Andrson-de-Boer (GAB) models perfectly simulated the water adsorption isotherms. By applying Dubinin-Polanyi model to the experimental data, canola meal was identified as a large pore (non-porous) material.

The heat of adsorption on canola meal with particle size of $0.43-1.18 \mathrm{~mm}$ was determined to be $-32.11 \mathrm{~kJ} / \mathrm{mol}$. The result confirms that the adsorption process is an exothermic phenomenon and is of physical type due to the fact that the value obtained as the heat of adsorption is negative and its magnitude is within the range $20-80 \mathrm{~kJ} / \mathrm{mol}$. The equilibrium water uptake on canola meal was similar to that reported for other starchy and cellulosic adsorbents, while the ethanol uptake was higher.

Water saturated canola meal was successfully regenerated by passing nitrogen at $110^{\circ} \mathrm{C}$ which is lower than that for molecular sieves commonly used in industry for bioethanol dehydration. The canola meal bio-adsorbent was re-used for more than 32 cycles and no significant change in adsorption capacity was observed.
\end{abstract}




\section{ACKNOWLEDGEMENTS}

I would like to express my deepest gratitude to my supervisor, Dr. C. Niu and my cosupervisor Professor A.K. Dalai, and thank them for their guidance and encouragement throughout this research. Without their support, leadership, and friendship this work would not have been possible.

I also would like to thank the members of my advisory committee: Professor M. Nemati and Professor R. Evitts for their help and guidance.

This thesis would not have been possible without the help and support of the members of the Chemical and Biological Engineering Department, particularly Mr. Rlee Prokopishyn, Mr. Richard Blondin, Ms. Heli Eunike, Mr. Dragan Cekic, Ms. Jean Horosko and Ms. Kelly Bader.

I would like to acknowledge the financial assistance from the Department of Chemical and Biological Engineering, the Natural Science and Engineering Research Council of Canada (NSERC), Saskatchewan Canola Development Commission, Saskatchewan Agriculture Ministry and Pounder Maker Investments. 


\section{DEDICATION}

I dedicate this thesis to my parents Mr. Masoud Tajallipour and Ms. Farideh Abbasi and my two brothers Dr. Nima Tajallipour and Mr. Ramin Tajallipour 


\section{TABLE OF CONTENTS}

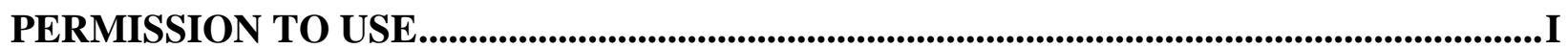

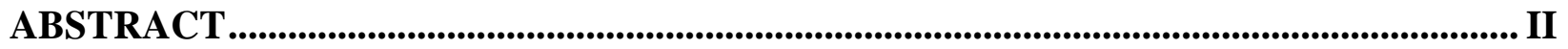

ACKNOWLEDGEMENTS _..........................................................................................

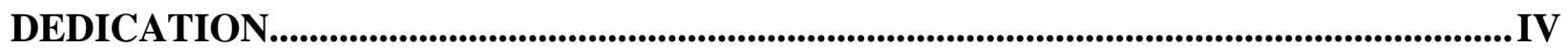

LIST OF TABLES .................................................................................................. VIII

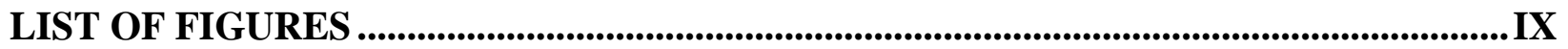

1 INTRODUCTION

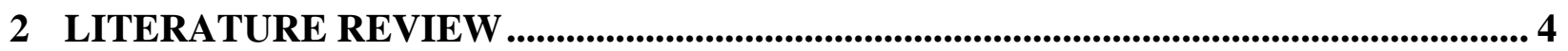

2.1 OVERVIEW OF THE ETHANOL SEPARATION AND PURIFICATION PROCESSES .............................. 4

2.1.1 AZEOTROPIC DiSTILLATION PROCESS ................................................................... 4

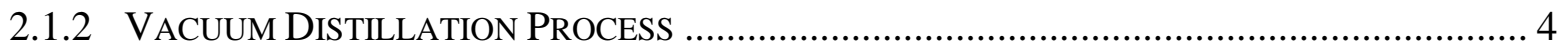

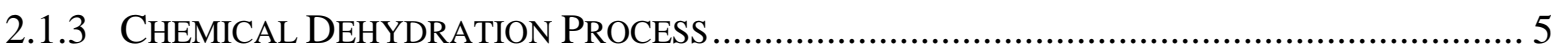

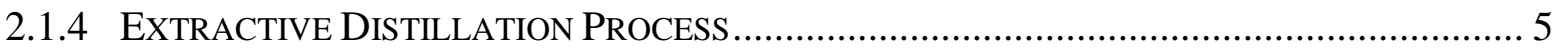

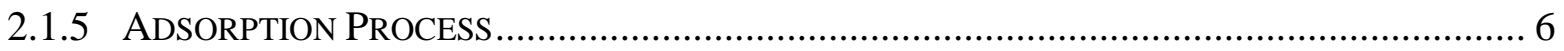

2.2 PRESSURE SWING ADSORPTION FOR ETHANOL DEHYDRATION ……………………….......... 7

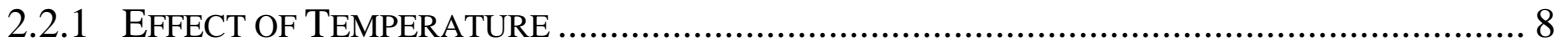

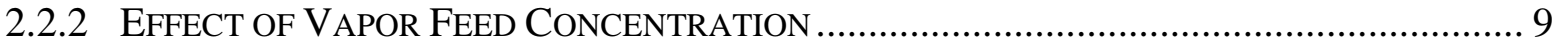

2.2.3 EFFECT OF VAPOR SUPERFICIAL VELOCITY ......................................................... 10

2.2.4 EFFECT OF PARTICLE SIZE ............................................................................. 10

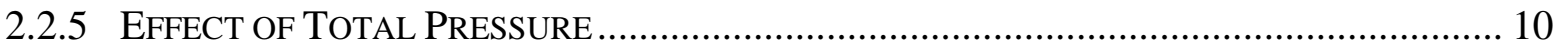

2.2.6 Simulation OF Water Breakthrough CuRVES ................................................... 11

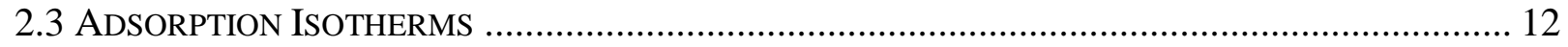

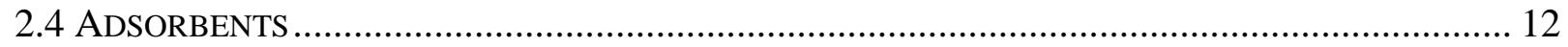

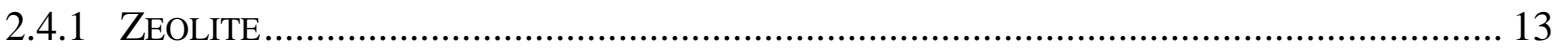

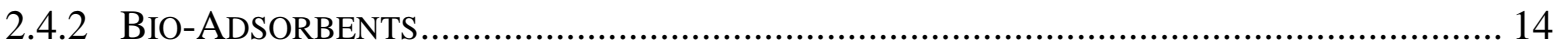

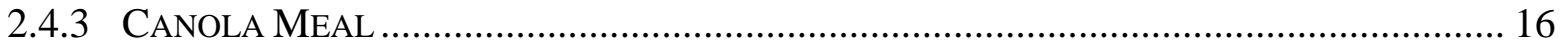

3 MATERIALS AND METHODS........................................................................... 18

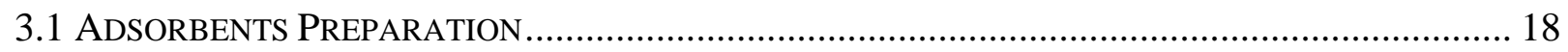

3.1.1 CANOLA MEAL ...................................................................................................... 18

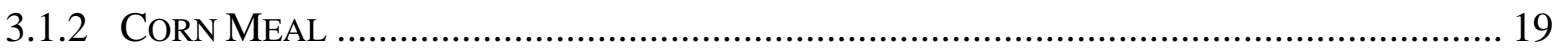




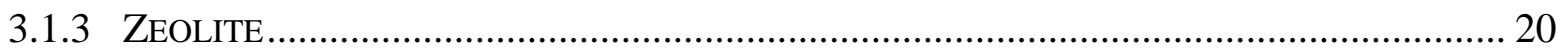

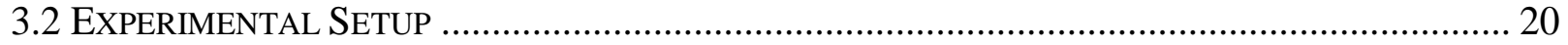

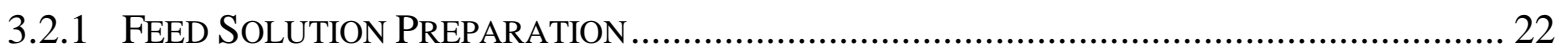

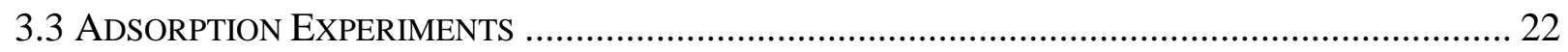

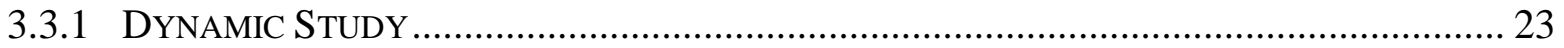

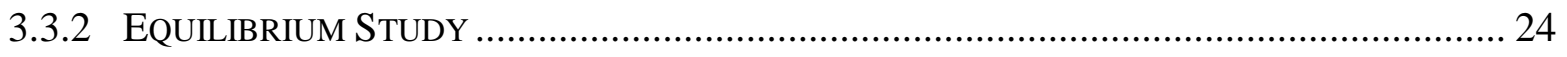

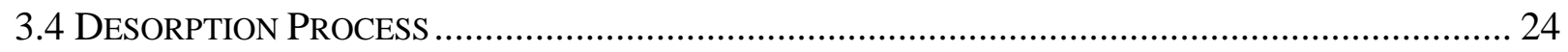

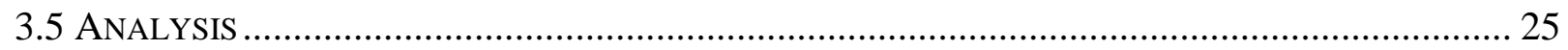

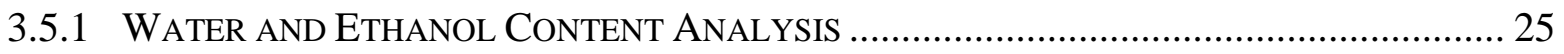

3.5.2 FOURIER-TRANSFORM INFRARED (FTIR) ANALYSIS ………….............................. 25

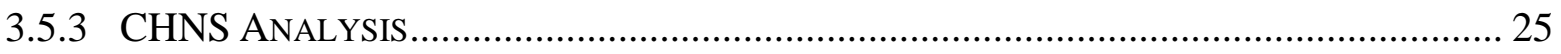

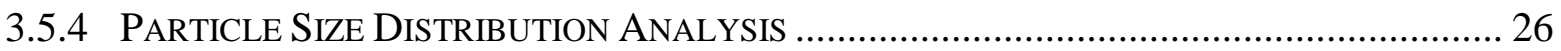

3.5.5 THERMOGRAVIMETRIC ANALYSIS (TG/DTA) …………......................................... 26

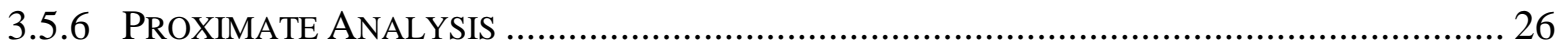

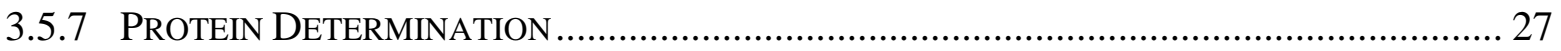

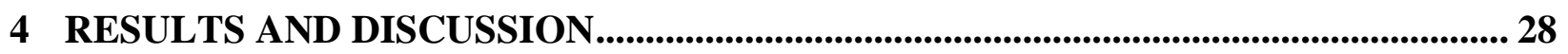

4.1 Characterization of Fresh Canola Meal................................................................. 28

4.1.1 PARTICLE SIZE DistRIBUTION ANALYSIS ............................................................. 28

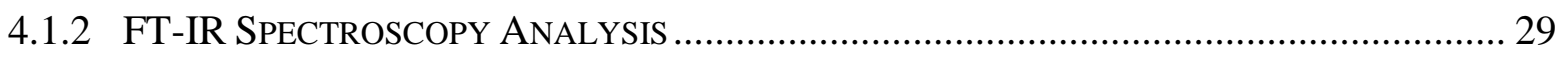

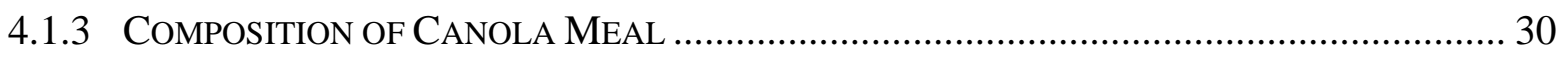

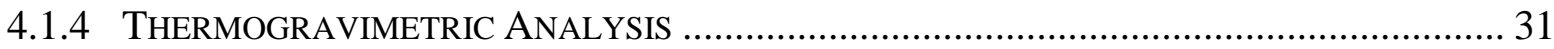

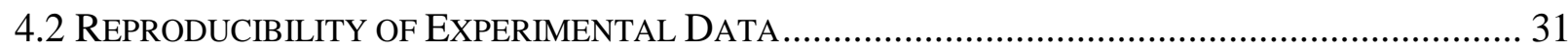

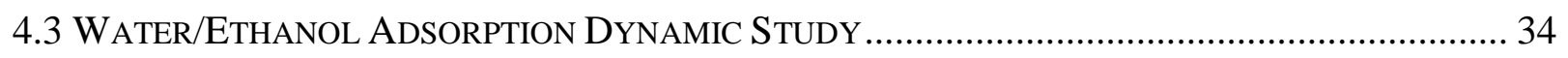

4.3.1 Simulation OF Water Breakthrough CuRVeS .................................................... 36

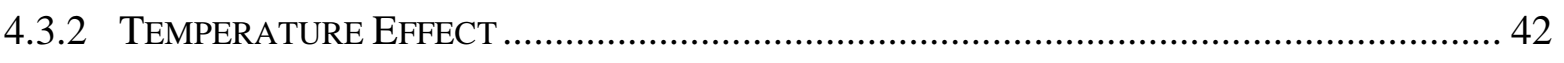

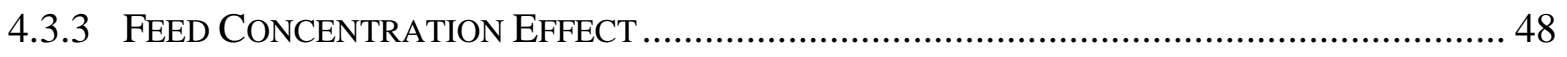

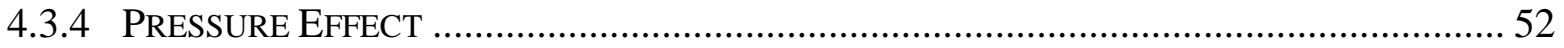

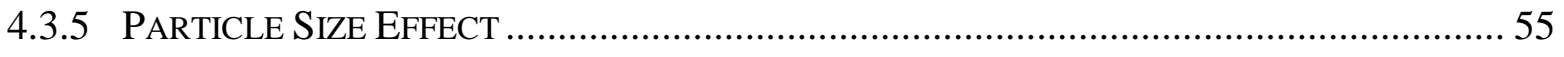

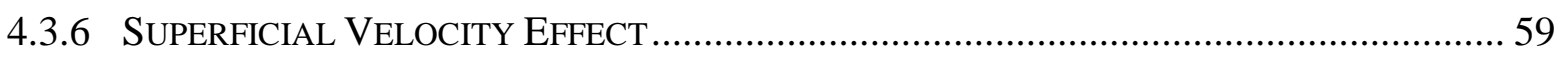

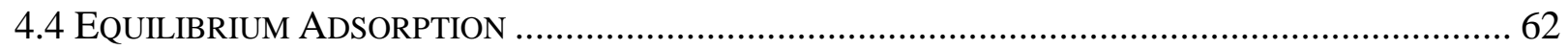

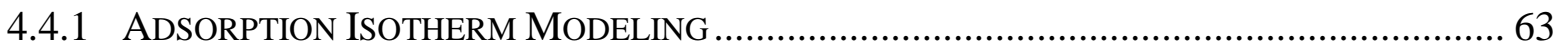




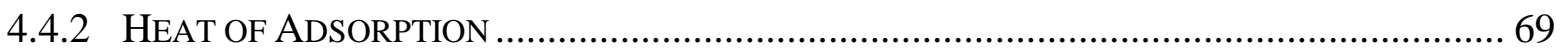

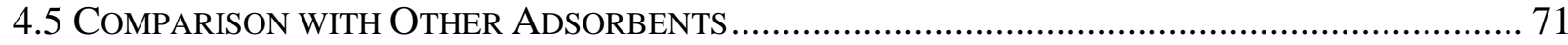

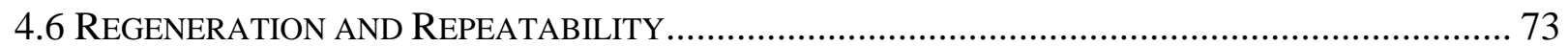

5 CONCLUSIONS AND RECOMENDATIONS .................................................................. 77

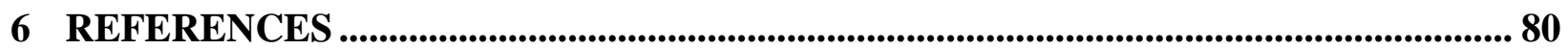

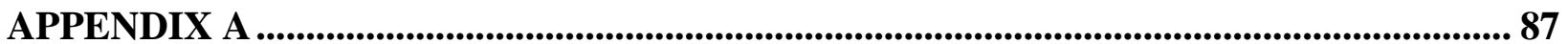




\section{LIST OF TABLES}

Table 2.1. Canola meal composition (Canola Council of Canada, 2011)......................16

Table 4.1. Composition of fresh canola meal....................................................... 30

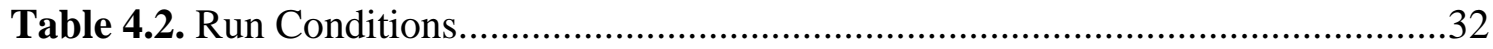

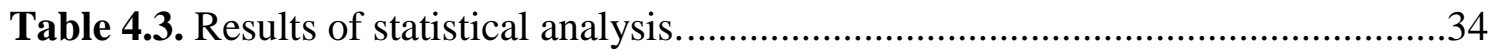

Table 4.4. Equilibrium constants for water adsorption on canola meal.......................39

Table 4.5. Experimental results of water and ethanol adsorption on canola meal for different temperatures...................................................................4 43

Table 4.6. Mass-transfer coefficients for different temperatures. ...............................46

Table 4.7. Experimental results of water and ethanol adsorption on canola meal at $\mathrm{T}=110^{\circ} \mathrm{C}, \mathrm{P}_{\text {total }}=243 \mathrm{kPa}, \mathrm{d}_{\mathrm{p}}=0.43-1.18 \mathrm{~mm}$.

Table 4.8. Mass-transfer coefficients for runs with different water partial pressure at $110^{\circ} \mathrm{C}$ with equilibrium constant $\mathrm{K}=157$

Table 4.9. Experimental results of water/ethanol uptake for different total pressures at $110^{\circ} \mathrm{C}$ and $\mathrm{d}_{\mathrm{p}}=0.43-1.18 \mathrm{~mm}$.

Table 4.10. Mass transfer coefficients for different total pressures with equilibrium constant $\mathrm{K}=157$.

Table 4.11. Experimental results of water/ethanol uptake at $100^{\circ} \mathrm{C}, \mathrm{u}_{0}=0.9 \mathrm{~cm} / \mathrm{s}$ and different particle size. .56

Table 4.12. Mass transfer coefficients for runs at $100^{\circ} \mathrm{C}$ with different particle size.....58

Table 4.13. Experimental results of water/ethanol uptake for different superficial velocities at $\mathrm{T}=110^{\circ} \mathrm{C}$ and $\mathrm{P}_{\text {total }}=243 \mathrm{kPa}$.

Table 4.14. Mass transfer coefficients for different superficial velocities.

Table 4.15. The GAB parameters for water vapor adsorption on canola meal at different temperatures. .65

Table 4.16. Parameter values for the FHH model. 65

Table 4.17. Values of parameters in Dubinin-Polanyi model for equilibrium water adsorption. 68

Table 4.18. Experimental results of water/ethanol uptake on different adsorbents .73

Table 4.19. Experimental results on CHNS analysis of fresh and used canola meal samples. 


\section{LIST OF FIGURES}

Figure 2.1 Experimental setup diagram used in water/ethanol adsorption in zeolites

(Simo et al., 2009) with permission. 7

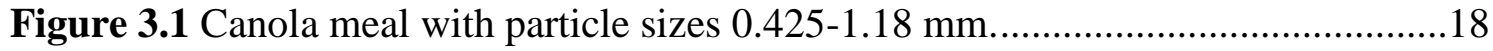

Figure 3.2 Cylindrical pellets with $5 \mathrm{~mm}$ in diameter and $10 \mathrm{~mm}$ in length................19

Figure 3.3 Corn meal with particle sizes $0.425-1.18 \mathrm{~mm}$..........................................19

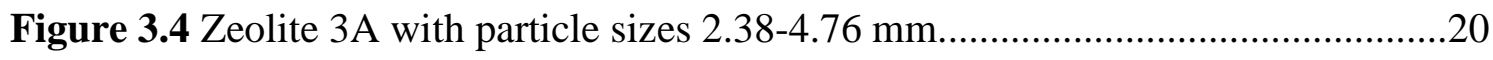

Figure 3.5 Process flow diagram of the PSA set-up............................................22

Figure 4.1 Particle size distributions for fresh canola meal.....................................28

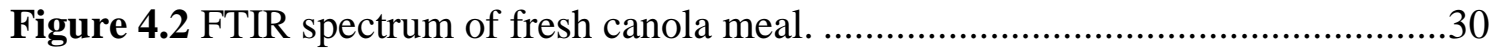

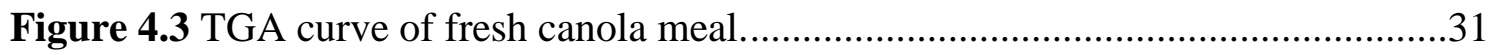

Figure 4.4 Water breakthrough curves and ethanol production profiles for experimental

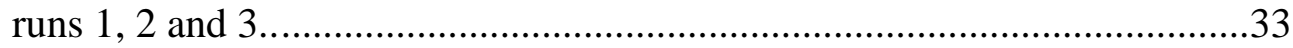

Figure 4.5 Water adsorption isotherms on canola meal.........................................40

Figure 4.6 (a) Ethanol production profiles; (b) Water breakthrough curves. Operating conditions: $\mathrm{P}_{\mathrm{w}}=24 \mathrm{kPa}, \mathrm{u}_{0} \approx 0.9 \mathrm{~cm} / \mathrm{s}$, and $\mathrm{d}_{\mathrm{p}}=0.43-1.18 \mathrm{~mm}$.

Figure 4.7 Variation of temperature with time in the middle of column read from (J-111).

Figure 4.8 Simulation of water breakthrough curves at (a) $110^{\circ} \mathrm{C}$, (b) $105^{\circ} \mathrm{C}$, (c) $100^{\circ} \mathrm{C}$.

Figure 4.9 (a) Ethanol production profiles, (b) Water breakthrough curves.

Figure 4.10 Temperature profiles at middle of column read from (J-111) for runs with different water partial pressure.

Figure 4.11 Simulation of breakthrough curves for runs with water partial pressures 24 , 45 and $85 \mathrm{kPa}$ .52

Figure 4.12 (a) Ethanol production profiles, (b) Water breakthrough curves. .53

Figure 4.13 Simulation of water breakthrough curves for runs at total pressures 243 and

Figure 4.14 (a) Ethanol production profiles, (b) Water breakthrough curves

Figure 4.15 Prediction of water breakthrough curves for runs at different particles size.59

Figure 4.16 (a) Ethanol production profiles, (b) Water breakthrough curves...............61

Figure 4.17 Simulation of breakthrough curve for runs at $\mathrm{u}_{0}$ of 1.5 and $0.9 \mathrm{~cm} / \mathrm{s}$. ..62

Figure 4.18 GAB and FHH isotherms of water adsorption on canola meal at 100, 105, $110^{\circ} \mathrm{C}$. 
Figure 4.19 (a) Dubinin-Polanyi model for the microporous adsorbent (b) DubininPolanyi model for large pore adsorbent................................................69

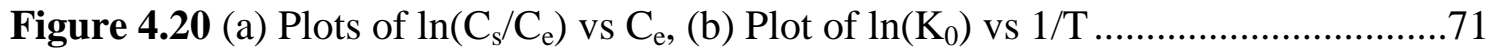

Figure 4.21 (a) Water breakthrough curves, (b) Temperature profiles.........................75

Figure 4.22 Fourrier transform infrared (FTIR) spectra of fresh and used canola meal.76 


\section{ABBREVATIONS AND NOMENCLATURE}

\section{$\underline{\text { Abbreviations }}$}

ads

adsorbent

BET

Brunauer-Emmelt-Teller isotherm model

CEM

control-evaporation-mixing

$\mathrm{D}(\mathrm{v}, 0.5)$

the volume median diameter

Et.

ethanol

$\mathrm{EtOH}$

ethanol

$\mathrm{FHH}$

Frenkel-Halsey-Hill isotherm model

GAB

Guggenheim-Andrson-de-Boer isotherm model

LDF

Linear Driving Force

PSA

pressure swing adsorption

STD

standard deviation

TSA

temperature swing adsorption

\section{Nomenclatures}

$a_{w}$

$a_{s}$

$a_{e}$

C

$\dot{C}$

$\mathrm{C}_{0}$

c

$D_{m}$

$D_{L}$

$D_{p}$

$D_{A B}$

$\operatorname{erf}(\mathrm{x})$

$f$

$f_{S}$

$\Delta G^{\circ}$ water activity (dimensionless)

activity of the adsorbed component

activity of the component in the feed at equilibrium condition

water content at time $\mathrm{t}(\mathrm{wt} \%)$

energy constant (dimensionless)

initial water content (wt \%)

concentration of water at time $\mathrm{t}$ and position $\mathrm{z}$ along the bed (mol/l)

diffusion coefficient for a multi component gas mixture $\left(\mathrm{m}^{2} / \mathrm{s}\right)$

eddy diffusivity $\left(\mathrm{m}^{2} / \mathrm{s}\right)$

equivalent diameter of a spherical particle $(\mathrm{mm})$

diffusion coefficient in binary gas mixture $\left(\mathrm{m}^{2} / \mathrm{s}\right)$

error function

equilibrium fugacity for the adsorbed phase $(\mathrm{kPa})$

saturation fugacity for the liquid sorbate $(\mathrm{kPa})$

standard free energy changes $(\mathrm{kJ} / \mathrm{mol})$ 


\begin{tabular}{|c|c|}
\hline$\Delta \mathrm{H}^{\circ}$ & heat of adsorption $(\mathrm{kJ} / \mathrm{mol})$ \\
\hline$K$ & equilibrium thermodynamic constant (dimensionless) \\
\hline$\dot{K}$ & energy constant (dimensionless) \\
\hline$k_{c}$ & external mass transfer coefficient $(\mathrm{m} / \mathrm{s})$ \\
\hline$k_{L D F}$ & overall mass-transfer coefficient $(1 / \mathrm{s})$ \\
\hline$k_{1}, k_{2}$ & pore constant for micropore and large pore materials (dimensionless) \\
\hline $\mathrm{M}_{\mathrm{A}}, \mathrm{M}_{\mathrm{B}}$ & molecular weights of $\mathrm{a}$ and $\mathrm{b}(\mathrm{g} / \mathrm{mol})$ \\
\hline $\mathrm{n}$ & number of components \\
\hline $\mathrm{P}$ & pressure $(\mathrm{kPa})$ \\
\hline$P_{S}$ & saturation pressure for the liquid sorbate $(\mathrm{kPa})$ \\
\hline$P_{w}^{s t}$ & saturation pressure of water at the isotherm temperature $(\mathrm{kPa})$ \\
\hline$q$ & water uptake ( $\mathrm{mol} \mathrm{H}_{2} \mathrm{O} / \mathrm{kg}$ adsorbent) \\
\hline$q_{0}$ & limiting mass for adsorption (mol $\mathrm{H}_{2} \mathrm{O} / \mathrm{kg}$ adsorbent) \\
\hline $\mathrm{R}$ & universal gas constant $(\mathrm{J} / \mathrm{mol} * \mathrm{~K})$ \\
\hline$R_{e x}$ & external mass transfer resistance $(\mathrm{s})$ \\
\hline$R_{\text {in }}$ & internal mass transfer resistance $(\mathrm{s})$ \\
\hline$R_{p}$ & adsorbent particle radius (mm) \\
\hline$R_{T}$ & overall mass transfer resistance (s) \\
\hline$r_{H}$ & hydraulic radius (mm) \\
\hline $\operatorname{Re}$ & Reynolds number (dimensionless) \\
\hline$\Delta S^{\circ}$ & standard entropy changes $(\mathrm{J} / \mathrm{mol} * \mathrm{~K})$ \\
\hline $\mathrm{Sc}$ & Schmidt number (dimensionless) \\
\hline $\mathrm{Sh}$ & Sherwood number (dimensionless) \\
\hline$T_{b}$ & normal boiling point in kelvin at the atmospheric pressure \\
\hline $\mathrm{u}$ & interstitial velocity of vapor $(\mathrm{cm} / \mathrm{s})$ \\
\hline$V_{b}$ & liquid molar volume at the normal boiling point $\left(\mathrm{cm}^{3} / \mathrm{mol}\right)$ \\
\hline$V_{c}$ & critical volume $\left(\mathrm{cm}^{3} / \mathrm{mol}\right)$ \\
\hline$X$ & water uptake on adsorbent at equilibrium condition $\left(\mathrm{mol} \mathrm{H}_{2} \mathrm{O} / \mathrm{kg}\right.$ adsorbent $)$ \\
\hline$X_{e}$ & mass fraction of ethanol in the adsorbed phase (dimensionless) \\
\hline$X j$ & mole fraction of component $\mathrm{j}$ (dimensionless) \\
\hline
\end{tabular}




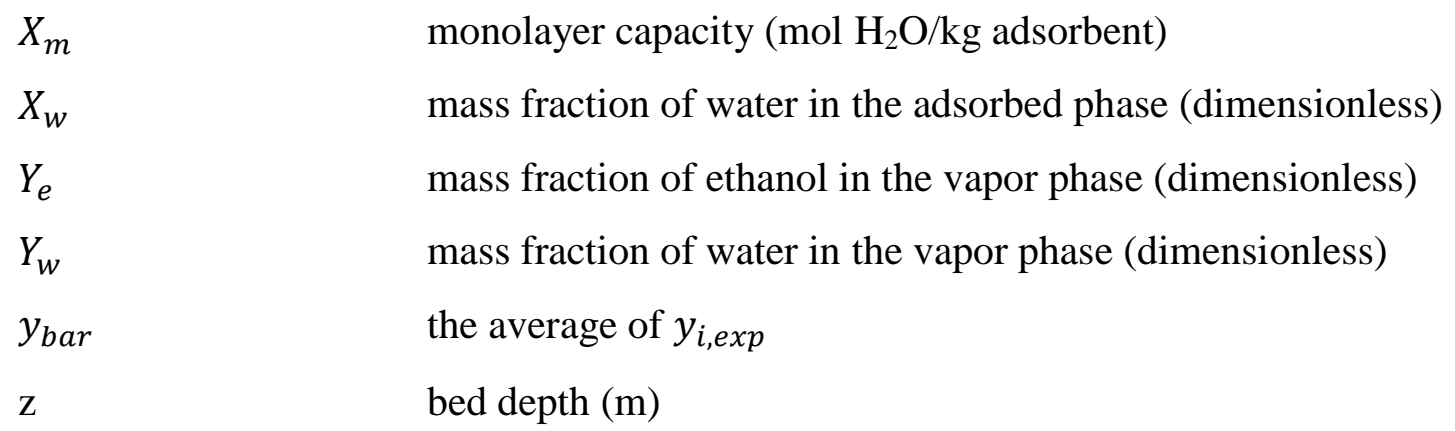

\section{Greek Symbols}

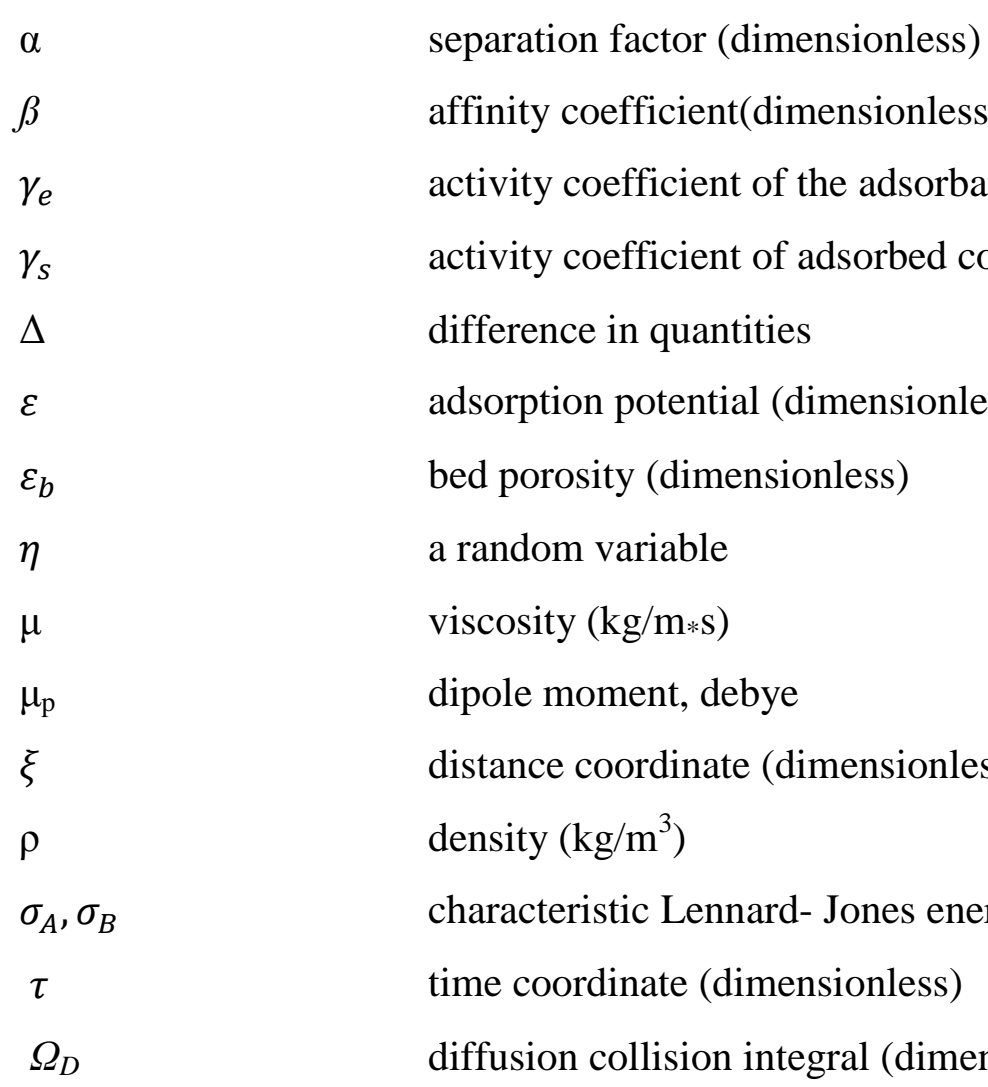

Subscript

$\exp$

experiment

et

i

$\max$

$\min$

W

ethanol

trace component (dimensionless)

maximum

minimum

water 


\section{INTRODUCTION}

The present energy and environmental problems caused by fossil fuels have brought attention to renewable alternatives such as biofuels. Ethanol is a biofuel which has high energy values and can be produced from renewable resources such as starch feedstocks, sugar feedstocks, lignocellulosic feedstocks and agriculture residues (Kumar et al., 2010). Currently, ethanol is added to gasoline as a substitute for methyl tert-butly ether (MTBE) to increase the gasoline's octane number and combustibility (Han et al., 2009). MTBE is an organic compound which is considered as a potential human carcinogen at high doses. The presence of MTBE in groundwater has led to using ethanol as the replacement in gasoline. The usage of ethanol not only improves the combustibility of gasoline but also lowers carbon monoxide levels in the exhaust (Frolkova and Raeva 2010). In addition, the usage of ethanol fuel helps the current global warming issue by reducing the net emissions of carbon dioxide in the atmosphere. This is because the amount of carbon dioxide released during the production and combustion of ethanol fuel is the same as the one bound into the replanted biomass (Kupiec et al., 2008). Another advantage of using ethanol in gasoline is that no anti-freeze is required in the hydrocarbon based fuel containing at least $10 \mathrm{wt} \%$ ethanol (Frolkova and Raeva 2010).

Through many studies, bioethanol based fuel has been reported as a promising alternative to hydrocarbon-based fuels (Kumar et al., 2010). The major concern of blending ethanol with hydrocarbon-based fuels is a completely dry ethanol ( $99.5 \%$ by weight) requirement in order to avoid phase separation (Frolkova and Raeva 2010; Vareli et al., 1998). Bioethanol can be derived from a large number of feed stocks such as sugar, starch, and cellulosic materials by fermentation process, which results in a broth with an ethanol concentration of 6-12\%, by weight (Benson and George 2005; Vareli et al., 1998). This fermented broth can be separated by a conventional distillation process to produce ethanol with a maximum ethanol concentration of $95.5 \mathrm{wt} \%$ due to the formation of an azeotropic mixture at this point (Simo et al., 2009; Vareli et al., 1998). Therefore, other alternative methods must be applied to break the azeotropic point and produce anhydrous ethanol (99.5 wt\% EtOH) such as azeotropic distillation, vacuum distillation, extractive distillation, chemical dehydration, membrane, and adsorption processes (Kumar et al., 2010; Chang et al., 2006b; Ladisch and Dyck 1979). Among these technologies, azeotropic distillation with benzene and extractive distillation with ethylene glycol and potassium acetate (distillation with salt) are mostly applied to break the azeotropic point of ethanol-water mixture 
in ethanol plants but the energy consumption for all these methods is significant because they require another distillation process for the recovery of the solvent ( $\mathrm{Hu}$ and Xie 2001). The azeotropic distillation technology was replaced by the adsorption process using zeolite in the late 1980s due to the lower energy consumption of the new method which in addition gives a very dry product (Simo et al., 2009; Tindall and Natarajan 1987).

Pressure swing adsorption process is known as a common technology in purification and bulk separation of gases (Arumugam et al., 1999). In the pressure swing adsorption (PSA) cycle, adsorption is performed at an elevated pressure, while desorption takes place at near-ambient pressure. Among the above mentioned methods used to produce anhydrous ethanol, pressure swing adsorption process (PSA) has been found to be much more efficient in terms of energy consumption (Simo et al., 2008). Although the PSA process is a reasonable method to produce fuel grade ethanol, there is still a need to search for a suitable substance as the adsorbent. Currently, the pressure swing process using 3A molecular sieve or corn grits as the adsorbent is widely employed in the ethanol industry for ethanol dehydration (Beery and Ladisch 2001). It has been reported that the usage of biomass derived adsorbents is more beneficial compared to other types of adsorbents regarding the energy demand (Boonfung and Rattanaphanee 2010). For example, the energy requirement for the dehydration of ethanol with $\mathrm{CaO}$ was reported to be $3669 \mathrm{~kJ} / \mathrm{kg} \mathrm{EtOH}$, while the energy consumed by the adsorption with cellulose was $2873 \mathrm{~kJ} / \mathrm{kg}$ EtOH (Ladisch and Dyck 1979). In addition, bio-adsorbents require moderate temperature of only $90-110^{\circ} \mathrm{C}$ at desorption stage while zeolite requires $190-210^{\circ} \mathrm{C}$.

Bio-adsorbents are environment friendly materials (Boonfung and Rattanaphanee 2010). Furthermore, bio-adsorbents can be reused as a fermentation feedstock to produce either ethanol or biogas when they are exhausted. Bio-based adsorbents are cheaper than zeolites which are the most commonly industrial adsorbents.

Bio-adsorbents that have been extensively studied for ethanol dehydration purposes, include cassava (Boonfung and Rattanaphanee 2010; Liu et al., 2010; Quintero and Cardona 2009), cornmeal (Chang et al., 2006b; Hu and Xie 2001; Vareli et al., 1998), wood chips (Boonfung and Rattanaphanee 2010; Benson and George 2005) natural corncobs, natural and activated palm stone and oak (Al-Asheh et al., 2004). However, other bio-based adsorbent such as canola meal have not been systematically investigated for this purpose. After the oil extraction of canola/rapeseed, what remains is referred to as canola meal which is highly rich in protein 
even up to 50\% on a dry basis (Aider and Barbana 2011). Canola meal in Canada, and especially in Saskatchewan, is accessible in abundance. In addition, canola meal has been proven to have high water adsorption capacity, which makes it a good option to be employed in adsorption processes for ethanol dehydration and this is of interest of this research.

As mentioned earlier, some research has been done on using bio based adsorbents for ethanol dehydration with the pressure swing adsorption process, which is a common process used in industry for ethanol dehydration. However, systematic investigation on ethanol dehydration using canola meal based adsorbent in a pressure swing adsorption process has not been done. In addition, no study has been conducted regarding the mechanisms of water/ethanol adsorption on canola meal. Therefore, there is a knowledge gap in applying canola meal in PSA process as the adsorbent for the dehydration of ethanol.

Based on the knowledge gap the overall objective of this research is to develop a pressure swing adsorption process (PSA) using canola meal as the adsorbent to adsorb water from ethanol-water vapor mixture and produce fuel grade ethanol, and to investigate the dynamics, equilibrium and mechanisms of the adsorption process. The specific objectives of this M.Sc. thesis are listed as follows:

- To characterize canola meal in terms of composition, the functional groups, particle size distribution, and devolatilization behavior with temperature.

- To investigate the dynamics of ethanol dehydration by canola meal in a Pressure Swing Adsorption (PSA) process at different pressures, temperatures, vapor superficial velocities and feed concentrations as well as bio-adsorbent particle sizes.

- To analyze the adsorption capacity of water/ethanol on canola meal in a PSA process.

- To determine the equilibrium uptake of water/ ethanol on the bio-adsorbent as well as the isotherms of water adsorption on canola meal.

- To simulate the water breakthrough profiles and evaluate the mechanism of the adsorption.

- To evaluate the regeneration process and stability of canola meal as an adsorbent. 


\section{LITERATURE REVIEW}

\subsection{Overview of the Ethanol Separation and Purification Processes}

Anhydrous ethanol is known as absolute ethanol which is clear, colorless and it contains at least $99.5 \%$ ethanol by volume at $15.6^{\circ} \mathrm{C}$. In general, the conversion of biomass into anhydrous ethanol through fermentation involves 3 steps: first, the biomass is converted into a fermentable form of sugar, next the sugars are fermented using yeast and bacteria to produce ethanol yielding a broth with $10-12 \%$ ethanol by weight and finally anhydrous ethanol is produced by separation and purification of the fermentation product (Kumar et al., 2010).

There are various processes used for producing anhydrous ethanol, most of which contain distillation. In general, the fermentation broth is distilled by the conventional distillation tower to concentrate ethanol up to 75-95 wt\% which then is further purified by a different number of processes to remove the remaining water and produce anhydrous ethanol. These processes are listed as follows: 1) Azeotropic distillation process, 2) Vacuum distillation process, 3) Chemical dehydration process, 4) Extractive distillation process and 5) Adsorption process.

\subsubsection{Azeotropic Distillation Process}

In azeotropic distillation, a third chemical component (such as benzene, n-pentane, hexane, cyclohexane, n-heptane, isooctane, or acetone) is added to the water-ethanol mixture to alter the distillation equilibrium and form homogeneous azeotropes with the initial components (water and ethanol). This leads to a change in the value of the activity coefficient of the components in the mixture and therefore the relative volatility of the components is altered (Frolkova and Raeva 2010). To produce pure ethanol through this method, a lot of energy is required in terms of maintaining and recirculating a large quantity of the additional (third) component (Kumar et al., 2010; Gomis et al., 2005).

\subsubsection{Vacuum Distillation Process}

In the vacuum distillation process, pressure is reduced to increase the concentration of ethanol in the ethanol-water azeotrope since the concentration of ethanol in the azeotropic mixture changes with pressure (Black and Distler 1972). This prevents ethanol and water from 
forming an azeotrope; thus, the components can be easily separated by distillation (Kumar et al., 2010). This process requires two distillation columns. Ethanol is concentrated in the first column at moderate pressure to the near azeotropic composition and then, the near-azeotropic mixture is further dehydrated in the second column at low pressure (below $11.5 \mathrm{kPa}$ ) (Kumar et al., 2010). This method requires a condensation temperature of $24.5^{\circ} \mathrm{C}$ at $9.3 \mathrm{kPa}$ which is considered as the drawback of this method (Kumar et al., 2010).

\subsubsection{Chemical Dehydration Process}

The chemical dehydration process is the oldest method of anhydrous ethanol production. It is based on exposing either ethanol liquors or ethanol vapors to hygroscopic substances such as calcium chloride, potassium carbonate or quicklime (Pleeth 1949). In this method, water is removed from the water-ethanol mixture by a chemical reaction in which water reacts with hygroscopic substances and forms an insoluble substance in ethanol (Kumar et al., 2010). Then, filtration is used to separate the ethanol from the suspended particles.

\subsubsection{Extractive Distillation Process}

Extractive distillation method includes extractive distillation with liquid solvent or soluble salt (Kumar et al., 2010). In the first approach, a non-volatile liquid solvent is used to alter the volatility of the feed components on the trays of a distillation column so that the volatility of one component is altered much more than the other component. There are several liquid solvents such as ethylene glycol, diethyl ether, and toluene that enhance the volatility of ethanol more than water. In both cases, the component with higher volatility shows up at the top as the product stream. In extractive distillation with soluble salt, a soluble salt is fed into the distillation column at the top tray. On each tray salt is dissolved into the ethanol-water mixture to form liquid phase associations or complexes with the less volatile component of the solution. This in turn increases the relative volatility of the more volatile component of the solution. There are several salts which are used for extractive distillation of ethanol-water system such as calcium and chlorides, sodium and potassium iodides (Frolkova and Raeva 2010; Kumar et al., 2010). 


\subsubsection{Adsorption Process}

In this process, which is currently used in industry, the distilled 90-95 wt \% ethanol vapor is passed through an adsorption column to remove the remaining water and produce anhydrous ethanol. This method is often preferred as compared to the aforementioned techniques since it has lower energy demands. It has been reported that $50-80 \%$ of the overall energy used in a typical ethanol plant is consumed by distillation processes (Vareli et al., 1997; Ghose and Tyagi 1979). Ladish and Dyck proposed an alternative approach; first the fermentation broth is distilled up to 75-90 wt\% EtOH, and then the remaining water is removed by the adsorption process (Ladisch and Dyck 1979). The energy consumption of this combined process was reported to be about $3.9 \mathrm{MJ} / \mathrm{kg}$ which is considerably less than the method involving only distillation processes (6-9 MJ/kg) (Vareli et al., 1997).

Adsorption is referred to as the diffusion of molecules in liquid or gas to the surface of a solid, where they form chemical bonds with the surface (chemical adsorption) or are held on the surface of a solid through weak intermolecular forces (physical adsorption) (Seader and Henley 1998). The adsorbed molecules on the surface of a solid are known as the adsorbate and the solid substance is referred to as the adsorbent (Seader and Henley 1998). The adsorption process has been developed for producing anhydrous ethanol, in which adsorbents act similarly to molecular sieves that selectively adsorb water molecules and yield anhydrous ethanol.

In general, there is a need to regenerate the adsorbents (desorption step) after the adsorption process is accomplished and the adsorbents are saturated. The regeneration process is performed by either increasing temperature or decreasing pressure during desorption cycles; the former method is called temperature swing adsorption (TSA), the latter is pressure swing adsorption (PSA) (Huang et al., 2008; Ribeiro et al., 2008; Hu and Xie 2001). In thermal swing adsorption cycles, the bed is heated to desorb the adsorbed species after which the bed is cooled to be prepared for the next adsorption cycle. A typical cycle time for TSA is between several hours to several days since heating and cooling of the bed take time while, the cycle time for PSA is between several seconds to several minutes (Seader and Henley 1998). Ruthven (1984) reported that TSA process is suitable for the regeneration of strongly adsorbed species but PSA process is generally used for the regeneration of weakly adsorbed species. As a result, PSA is popularly used in industry for ethanol dehydration. 


\subsection{Pressure Swing Adsorption for Ethanol Dehydration}

In this method, desorption is accomplished by reducing pressure while the temperature is kept constant and then the bed or adsorption column is purged at low pressure. This method is mainly applied for gaseous systems (Ruthven 1984). The pressure swing adsorption process has advantages over the other methods of regenerations in that it lowers the adsorbent inventory and the capital cost, subsequently (Ruthven 1984).

Several research projects have been conducted using molecular sieves zeolites (Jeong et al., 2009; Pruksathorn and Vitidsant 2009; Simo et al., 2009; Carmo and Gubulin 2002) and biobased adsorbents (Boonfung and Rattanaphanee 2010; Beery et al., 1998) in PSA processes to dehydrate ethanol. For example, Simo and his co-workers (Simo et al., 2009) investigated the adsorption/desorption of water and ethanol on 3A zeolite in PSA process in near adiabatic fixed bed. The simplified process flow diagram was used for the experiments presented in Figure 2.1.

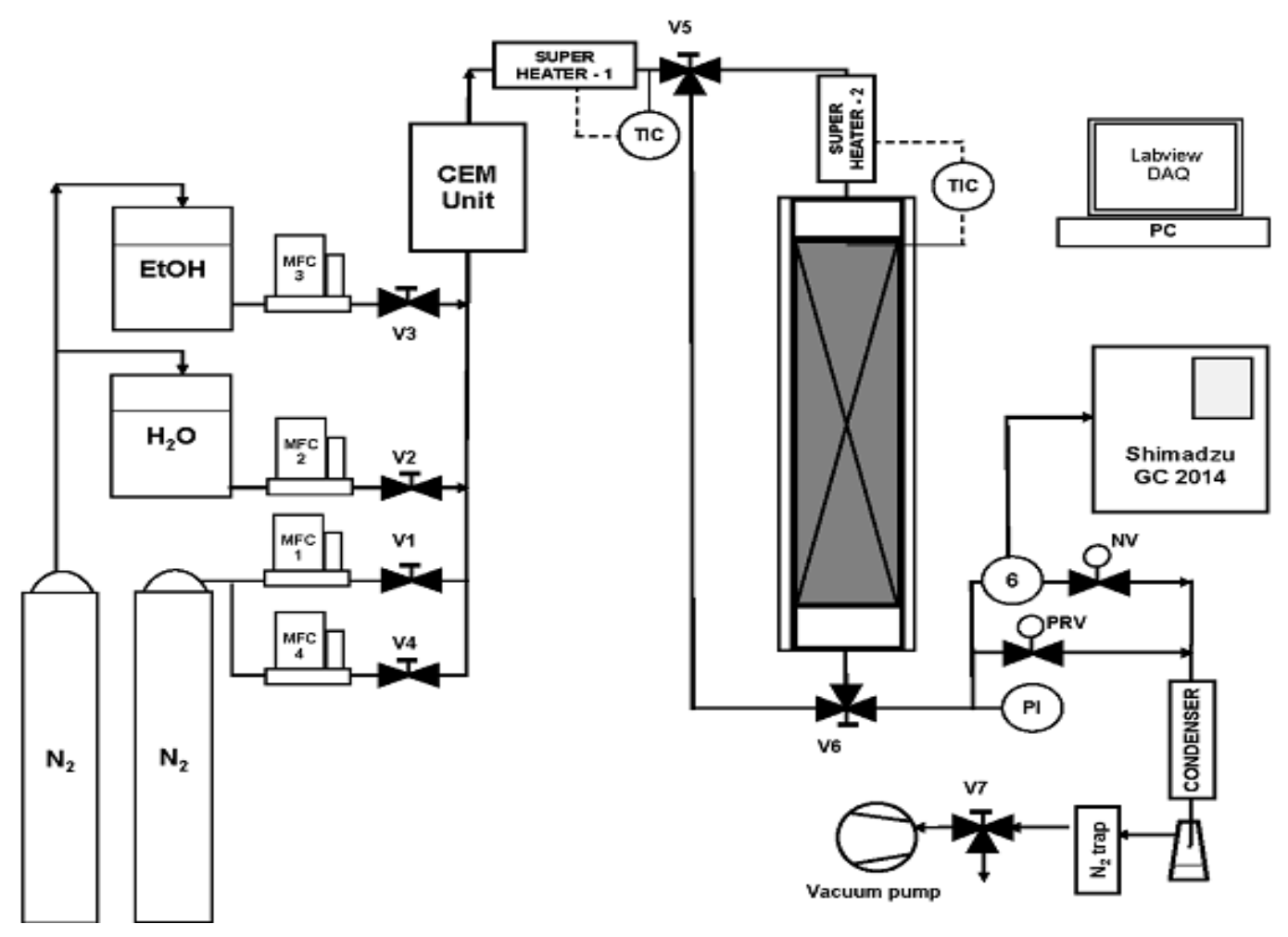

Figure 2.1 Experimental setup diagram used in water/ethanol adsorption in zeolites (Simo et al., 2009) with permission. 
As it can be seen from Figure 2.1, water and ethanol is mixed with nitrogen gas (carrier gas) in the CEM (control-evaporation-mixing) unit, which is a vapor generating system. Then, the temperature of the produced vapor can be further adjusted using Super Heater-1 and Super Heater-2. After that, the vapor enters into the adsorption column from the top. The column was equipped with six band heaters to ensure constant axial temperature profile. To keep the column under adiabatic conditions, the adsorption column was insulated with a thick layer of ceramic insulation. In addition, all lines were insulated to avoid any vapor condensation. One back pressure regulator was placed at the end of the setup to provide the isobaric condition in the system. The composition of the components in the effluent was determined using online gas chromatographic method. After the adsorption step was accomplished the bed was saturated and regenerated before the next adsorption cycle. The desorption step occurred under the following conditions: temperature in the range of $220-240^{\circ} \mathrm{C}$, absolute pressure of $6-10 \mathrm{kPa}$ and nitrogen purge of $200 \mathrm{~cm}^{3} / \mathrm{min}$. Simo and his co-workers investigated the effects of operating conditions such as the water concentration, temperature $\left(100-200^{\circ} \mathrm{C}\right)$, pressure $(200-670 \mathrm{kPa})$, pellet size (3.6 and $1.8 \mathrm{~mm}$ ), and carrier gas flow rate on the adsorption/desorption of water and ethanol on zeolite. Further, the equilibrium data was obtained through breakthrough runs and the water breakthrough curves were simulated using a mathematical model to obtain the overall mass transfer coefficient (Simo et al., 2009).

In the PSA process, operational parameters such as temperature, pressure, feed concentration, vapor superficial velocity and the size of adsorbent particles play an important role for the adsorption performance. They are discussed as follows.

\subsubsection{Effect of Temperature}

Temperature is known as an important parameter in the ethanol dehydration process because at higher temperature the vibrational energy of the adsorbate increases resulting in less adsorbtion at equilibrium (Okewale et al., 2011). However, the diffusion rate of the adsorbate within the solid increases when the temperature is increased, resulting in an increase of the adsorption rate (Sowerby and Crittenden 1988).

Chang et al., (2006b) investigated the adsorption capacity of water and ethanol on corn meal at temperatures of $82,87,91$, and $94^{\circ} \mathrm{C}$ and vapor feed concentration of $93.8 \mathrm{wt} \% \mathrm{EtOH}$. They reported that the separation factor for water increased while the adsorbed masses of water 
and ethanol decreased when the temperature was increased. Further, the adoption favored ethanol as the temperature of the bed was decreased.

The effect of temperature on bed performance and the adsorption/desorption kinetics was studied by Simo et al., (2009). They used temperatures of $100,146,167$, and $200^{\circ} \mathrm{C}$ to study the adsorption of water on zeolite. They concluded that the water breakthrough curves had a strong dependence on temperature, thus the breakthrough time decreased with an increase in temperature which is due to the decrease in the bed capacity. The observation of the strong temperature dependency of water breakthrough curves confirmed the presence of the activated micropore diffusion mechanisms. Further, at lower temperatures, the adsorption capacity of zeolite for water increased; the isotherm became more unfavorable and desorption profile became more dispersed.

Pruksathorn and Vitidsant (2009) investigated the effect of temperature in an ethanolwater adsorption system at 100 and $120^{\circ} \mathrm{C}$ and feed concentration of $90 \mathrm{wt} \% \mathrm{EtOH}$. They found that lower initial temperature led to higher breakthrough time and water adsorption capacity. They concluded that this phenomenon is due to the exothermic nature of adsorption processes which performs better at lower temperature.

\subsubsection{Effect of Vapor Feed Concentration}

Vapor feed concentration affects partial pressure of the species of interest in the vapor feed stream. Simo et al., (2009) studied the effect of water partial pressure in the feed stream at $167^{\circ} \mathrm{C}$ on adsorption/desorption kinetics. As the water partial pressure was increased, the slope of water breakthrough curves increased and the bed saturated faster. Further, the water equilibrium uptake increased with the increasing water content in the feed stream. They also reported that the favorable isotherm affected the kinetic parameters which resulted in sharper water breakthrough profiles with an increase in partial pressure of water in the feed stream.

In the work carried out by Pruksathorn and Vitidsant (2009), breakthrough time decreased as the ethanol feed concentration was reduced. Sowerby and Crittenden (1988) explained that the reason for this observation was that the adsorbent was subjected to more adsorbate per unit time.

Wang et al., (2010) studied the effect of feed concentration on separation of ethanol/water azeotrope using compound starch-based adsorbents. They found that as the feed 
concentration was increased from 82.1 to $92.5 \mathrm{wt} \% \mathrm{EtOH}$, the concentration of ethanol in the product significantly increased and the curve plateau length became longer.

\subsubsection{Effect of Vapor Superficial Velocity}

Vapor superficial velocity is another important parameter affecting the adsorption process. The external mass transfer resistance becomes greater as the flow rate is decreased. In the work of Baylak and his colleagues (Baylak et al., 2012), the slope of water breakthrough curves increased greatly when vapor superficial velocity was increased from 0.6 to $1.3 \mathrm{~cm} / \mathrm{s}$. Afterwards, a slight increase was observed when the velocity was further increased up to 2.1 $\mathrm{cm} / \mathrm{s}$. These results support the conclusion made by Simo et al., (2009) that film mass transfer resistance becomes insignificant at higher flow rates. Similar results were reported by Wang et al., (2010); Simo et al., (2009); Westgate and Ladisch (1993a).

\subsubsection{Effect of Particle Size}

Vareli and his colleagues (Vareli et al., 1998) studied the effect of adsorbent particle sizes of $0.18-0.25,0.16-0.18$, and $0.125-0.16 \mathrm{~mm}$ on water-ethanol separation by starchy materials. It was discovered that adsorbents with greater particle sizes had a smaller separation factor.

In the work done by Kim and her co-workers (Kim et al., 2011), two particle sizes of cassava pearls (1 and $0.5 \mathrm{~mm}$ ) were investigated for drying ethanol. The pearl with smaller particle size achieved a slightly higher adsorption capacity for water at both breakthrough and equilibrium. At breakthrough, the separation factor decreased as the particle size was increased, while the separation factor at equilibrium increased with the increase of the particle size.

\subsubsection{Effect of Total Pressure}

Boonfung and Rattanaphanee (2010) investigated the effect of adsorption pressure at 200 and $300 \mathrm{kPa}$ and presented the ethanol profiles obtained from the pressure swing adsorption process. They found that the concentration of ethanol increased with an increase in the adsorption pressure. Thus, the optimum adsorption pressure was identified at $300 \mathrm{kPa}$ (absolute). However, they did not report that the partial pressure of the components in the vapor feed stream was kept constant when total pressure was increased which may explain the reported increase in the concentration of ethanol in the product. 
Simo et al., (2009) studied the effect of total pressure on the shape of water breakthrough curves and found out that the slope of water breakthrough profiles decreased as the total pressure was increased. Further, they concluded that among different rates of diffusion, only the rate of diffusion in macropores was affected by the change in total pressure. The key point of this work is that they conducted experiments at different total pressures, while the other operating conditions, partial pressure of water in the feed stream, vapor superficial velocity, temperature, and the pellet size, were kept constant. They carefully planned the experimental runs because of the unique dependence of the mass transfer mechanism on each operating parameter.

Carmo and Gubulin (2002) used three adsorption pressures of 200, 400 and $600 \mathrm{kPa}$ for ethanol-water separation in the PSA process. They reported that an increase in the adsorption pressure led to a decrease in the ethanol productivity at a fixed flow rate.

\subsubsection{Simulation of Water Breakthrough Curves}

Although bio-adsorbents have been used in the pressure swing adsorption process (PSA) for ethanol dehydration in a number of papers, very limiting information is available regarding the mathematical modeling of water breakthrough curves in literatures.

Chang et al., (2006c) simulated the water breakthrough curves of a bed packed with corn meal (adsorbent). They performed the experiments at temperatures $82-100^{\circ} \mathrm{C}$. The water isotherms were obtained and subsequently used in the simulation of water breakthrough curves. The mathematical model considers axial dispersion, and uses the Linear Driving Force (LDF) adsorption rate model. Klinkenberg analytical solution was used to solve the mathematical model and the overall mass transfer resistance coefficient was estimated to be $2.7813 \times 10^{-3} 1 / \mathrm{s}$. It was shown that Klinkenberg model successfully simulated the water breakthrough profiles at different superficial velocities and bed depths. However, the model did not give a good simulation for water breakthrough profiles at water vapor contents higher than $12 \mathrm{wt} \%$. Further, it was found that the adsorption process was dominated by internal mass transfer resistance.

Simo et al., (2009) developed a mathematical model to simulate water breakthrough curves on zeolite which considers the LDF adsorption rate, and variation of axial velocity. Using the model, they identified the overall mass transfer coefficient which was subsequently used in the evaluation of the external film, macropore and micropore mass transfer resistances. The 
results showed that macropore and micropore diffusions were the relevant mass transfer mechanisms.

\subsection{Adsorption Isotherms}

To obtain the adsorption isotherms, the adsorption column must reach the equilibrium state in which the concentration of the components in the inlet and outlet streams is equal and the temperature of the bed has restored its initial state. Then, the adsorbed amount of absorbable components can be calculated by using the overall mass balance.

There are many isotherm models used to describe the adsorption isotherms including Langmuir, Freundlich, linear, Dubinin-Polanyi (potential theory), Brunauer-Emmelt-Teller (BET), Guggenheim-Andrson-de-Boer (GAB), Frenkel-Halsey-Hill (FHH) model (Al-Asheh et al., 2009; Ruthven 1984).

Langmuir model was used by Simo et al., (2009) to describe the adsorption isotherms at $100-200^{\circ} \mathrm{C}$ on zeolite $3 \mathrm{~A}$. Kim et al., (2011) found that the adsorption isotherms of cassava pearls showed a linear behavior similar to Henry's law, at feed concentration range of 88-97 wt\% $\mathrm{EtOH}$ and bed temperature of $90^{\circ} \mathrm{C}$.

Chang et al., (2006a) used BET, Dubinin-Polanyi, Sircar models to describe the adsorption isotherms at temperatures $82-100^{\circ} \mathrm{C}$ on corn meal. They stated that water adsorption isotherms were of type II according to Brunauer's classification. In addition, Dubinin-Polanyi and Sircar's model fitted the experimental data at all temperatures very well.

Al-Asheh et al., (2009) used GAB and FHH model to represent the isotherms for water adsorption on natural zeolite (phillipsite). The GAB model represented a better fit to the experimental data compared to FHH model in all cases. The relevant adsorbents for ethanol dehydration are discussed in the following section.

\subsection{Adsorbents}

There are a number of adsorbents that can be employed to dry ethanol: zeolite (Jeong et al., 2009; Simo et al., 2009), silica gel, activated alumina, cassava (Boonfung and Rattanaphanee 2010; Liu et al., 2010; Quintero and Cardona 2009), cornmeal (Chang et al., 2006b; Hu and Xie 2001; Vareli et al., 1998), wood chips (Boonfung and Rattanaphanee 2010; Benson and George 
2005), potato starch (Hu and Xie 2001), natural corncobs, natural and activated palm stone, oak (Al-Asheh et al., 2004). Among these adsorbents, 3A zeolite and corn grit are currently used in ethanol plants to dry ethanol (Kim et al., 2011; Simo et al., 2009). The other adsorbents are still at the research stage. In addition, several researchers have investigated the feasibility of applying bio-based adsorbents as an alternative to zeolite since bio-adsorbents are derived from renewable sources, they are cheaper and require moderate desorption temperature compared to $3 \mathrm{~A}$ zeolite (Hu and Xie 2001).

\subsubsection{Zeolite}

Zeolite is the most commonly used adsorbent in industry for ethanol dehydration. 3A zeolite has pores in diameter of $0.3 \mathrm{~nm}$ which enable it to selectively adsorb water molecules while excluding ethanol molecules (Carmo and Gubulin 2002). This phenomenon happens because of the difference in polarity and molecular size of water and ethanol; water and ethanol molecules have a diameter of approximately $0.28 \mathrm{~nm}$ and $0.44 \mathrm{~nm}$, respectively (Huang et al., 2008; Ribeiro et al., 2008).

Pruksathorn and Vitidsant (2009) studied the production of pure ethanol in the PSA using zeolite. They reported that higher breakthrough time and water adsorption capacity were achieved for runs with lower initial temperature and explained this with the observation that adsorption processes are exothermic phenomena. They reported that higher cycle time resulted in higher ethanol recovery.

Jeong et al., (2009) used zeolite in their experiments and reported a production of about 2 $\mathrm{kl} /$ day of dehydrated ethanol $(99.5 \mathrm{wt} \% \mathrm{EtOH})$ with a product recovery of $72 \%$ at feed concentration of $93.2 \mathrm{wt} \% \mathrm{EtOH}$.

Simo et al., (2009) investigated equilibrium and kinetic adsorption of water and ethanol on 3A zeolite using a PSA process. The operating conditions were selected similarly to the industrial ones: pressure of $400 \mathrm{kPa}$, temperature in the range $100-167^{\circ} \mathrm{C}$ and the bed was kept under adiabatic conditions. They reported adsorbent selectivity of 900 and the Langmuir isotherm model gave a perfect fit to the water equilibrium adsorption data.

Ribeiro et al., (2008) studied the adsorption equilibrium and kinetics of water vapor on activated carbon, activated alumina and zeolite at $303 \mathrm{~K}$ using a gravimetric system. It was 
shown that zeolite had the highest adsorption capacity $(11 \mathrm{~mol} / \mathrm{kg})$ at low pressure. However, the alumina sample achieved the highest adsorption capacity $(35 \mathrm{~mol} / \mathrm{kg})$ at high relative humidity.

Sowerby and Crittenden (1988) examined 3A, 4A, 5A and 10A zeolite to dry an ethanolwater azeotropic mixture. They concluded that zeolite 5A and 10A were not suitable for ethanol dehydration processes because they reacted with ethanol and formed undesirable products. They also showed that a $4 \mathrm{~A}$ molecular sieve had a greater water adsorption capacity than a $3 \mathrm{~A}$ molecular sieve at similar operating conditions.

Al-Asheh et al., (2004) used 3A, 4A and 5A zeolite in their experiments. Their results indicated that type $3 \mathrm{~A}$ zeolite has better breakthrough time and outlet water concentration compared to the other types.

The high temperature requirement $\left(200-250^{\circ} \mathrm{C}\right)$ for zeolite regeneration has led to a growing interest for the search of more energy efficient alternatives such as biomass-derived adsorbents (Okewale et al., 2011; Boonfung and Rattanaphanee 2010; Simo et al., 2008; Beery and Ladisch 2001). Moreover, the use of bio-adsorbents offers additional advantages compared to synthetic adsorbents. For example, bio-adsorbents can easily be deposited in the environment and they can be reused as the fermentation feedstock to produce either ethanol or biogas when their regeneration does not seem feasible (Boonfung and Rattanaphanee 2010).

\subsubsection{Bio-Adsorbents}

Bio-adsorbents are adsorbents made of natural biomaterials or by-products of related industries, such as cellulose and starchy materials. Bio-adsorbents adsorb water due to the polar attraction between water molecules and the polar groups (such as hydroxyl and carboxyl) in the biomaterials (Quintero and Cardona 2009). Sun et al., (2007) used different adsorbents to study water and ethanol adsorption in liquid phase. They studied barely straw, wheat straw and acidwashed crab shells at room temperature in a batch system. Among these adsorbents the highest ratio of ethanol to water uptake was achieved for barley straw (4.31) followed by wheat straw (3.22) and crab shells (0.79).

For vapor phase adsorption, Hong et al., (1982) utilized a gas chromatographic elution method to explore the capacity of certain adsorbents in vapor phase adsorption. Adsorption and desorption was performed at $80^{\circ} \mathrm{C}$ and $\mathrm{He}$ gas was used as the carrier gas at velocity of 94 
$\mathrm{cm} / \mathrm{min}$. The adsorption capacity of the adsorbents was reported in the following order: potato and corn starch > xylan > cornmeal > avicel > bagasse, corn residue, and wheat straw.

Vareli et al., (1998) applied the IGC method to identify chromatographic retention data for cornmeal, wheat flour, and wheat straw. The experiments were performed at temperatures in the range 50 to $90^{\circ} \mathrm{C}$ with particle sizes $0.18-0.25,0.16-0.18$ and $0.13-0.16 \mathrm{~mm}$. The highest separation factor was achieved for wheat flour at $50^{\circ} \mathrm{C}$ and particle size $0.13-0.16 \mathrm{~mm}$. For all adsorbents, the separation factor decreased by increasing the temperature and the absorbents with smaller particle size showed a higher separation factor due to their greater specific surface area.

Chang et al., (2006b) investigated the feasibility of using corn meal for the separation of water-ethanol mixtures and production of anhydrous ethanol. To study the kinetic of water and ethanol adsorption, several experimental runs were performed. The concentration and temperature were kept constant while varying the vapor superficial velocities and operating time. They reported that the selectivity of water adsorption at breakthrough point was slightly higher than that at equilibrium conditions.

Quintero and Cardona (2009) also utilized a fixed bed column to examine the adsorption capacity of starchy and cellulosic materials. Expecting to achieve higher adsorption capacity, they applied an enzymatic hydrolysis to the adsorbents in order to modify the adsorbents. The results showed an increase in the adsorption capacity of the tested materials after the enzymatic hydrolysis treatment, but no increase in specific surface area. This was explained by the fact that the enzymatic hydrolysis treatment modified the adsorbents in a way that more hydroxyl groups were exposed to water molecules. Among the tested adsorbents, the highest water adsorption capacity was achieved for corn starch and the lowest was reported for elephant ear starch.

Al-Asheh et al., (2004) applied the same method as was used in the work of Quintero and Cardona (2009). They found that palm gave the best results in separation of ethanol-water mixture compared to natural corncobs, activated palm stone, oak, and activated oak.

Wang et al., (2010) used gravimetric method to investigate the water vapor isotherms on 3A zeolite, potato starch, corn starch, cassava starch, and cellulose at room temperature. Their results indicated that at relative pressure of 0.6, the highest value of water-ethanol adsorption ratio was achieved for potato starch (64.2). The adsorption ratios they obtained were in the following order: potato starch>cellulose >corn starch>cassava starch>3A zeolite. 
Many researchers have justified that the adsorption of water or ethanol by bio based adsorbents is mainly controlled by mass transfer resistances. In addition, the adsorption on bioadsorbents was explained by the polar attraction between their polar groups (hydroxyl, carboxyl, and protein) and water or ethanol molecules. Since the polarity of water is higher than ethanol, water molecules are selectively adsorbed by bio-adsorbents (Quintero and Cardona 2009). This indicates that bio-adsorbents have a potential for industrial application in ethanol dehydration.

\subsubsection{Canola Meal}

Canola is known as a promising source for biodiesel production and the second largest supply of edible oil in the world (Aider and Barbana 2011). According to Statistics Canada, the share of Saskatchewan in canola production was 3.4 million tons in 2006, which was increased up to 5 and 7 million tons in 2010, and 2011, respectively. Canola meal is known as a by-product of canola oil extraction and contains up to $50 \%$ protein on a dry basis which is mainly used as the protein source in animal feed (Aider and Barbana 2011; Canola Council of Canada, 2011). The composition of canola meal is summarized in Table 2.1. In addition, the protein in canola meal is mainly composed of albumin and globulin (Manamperi et al., 2007).

Table 2.1. Canola meal composition (Canola Council of Canada, 2011).

\begin{tabular}{cc}
\hline Component & wt\% on a dry basis \\
\hline Moisture & 7.1 \\
Crude protein & 36.3 \\
Crude fat (ether extract) & 11.1 \\
Ash & 6.3 \\
Free sugars & 9.8 \\
Neutral detergent (cellulose, hemicellulose, lignin) & 24.1 \\
Non-starch polysaccharides & 13.7 \\
\hline
\end{tabular}

The ability of canola meal to adsorb water has been measured by several studies. They reported water adsorption capacity values of canola meal between 218 and $382 \%$ of its initial weight (Aider and Barbana 2011). These values mainly are attributed to canola meal containing a considerable amount of fiber which improves its water holding capacity (Aider and Barbana 2011). 
In a preliminary study, Baylak and his co-workers (Baylak et al., 2012) used canola meal to produce fuel grade ethanol (over $99 \mathrm{wt} \%$ ). They used a fixed bed apparatus in their experiments to separate water-ethanol mixtures and demonstrated that canola meal has a potential for ethanol dehydration. However, a systematic investigation on ethanol dehydration in pressure swing adsorption has not been done. 


\section{MATERIALS AND METHODS}

\subsection{Adsorbents Preparation}

\subsubsection{Canola Meal}

The canola meal used in this work was produced by Federated Co-Operatives Limited (Saskatoon, Canada). Canadian Standard Sieves Series (Combustion Engineering Canada Inc.) was applied to sieve canola meal particles; the collected samples had particle sizes in the range 0.425-1.18 mm (Figure 3.1).

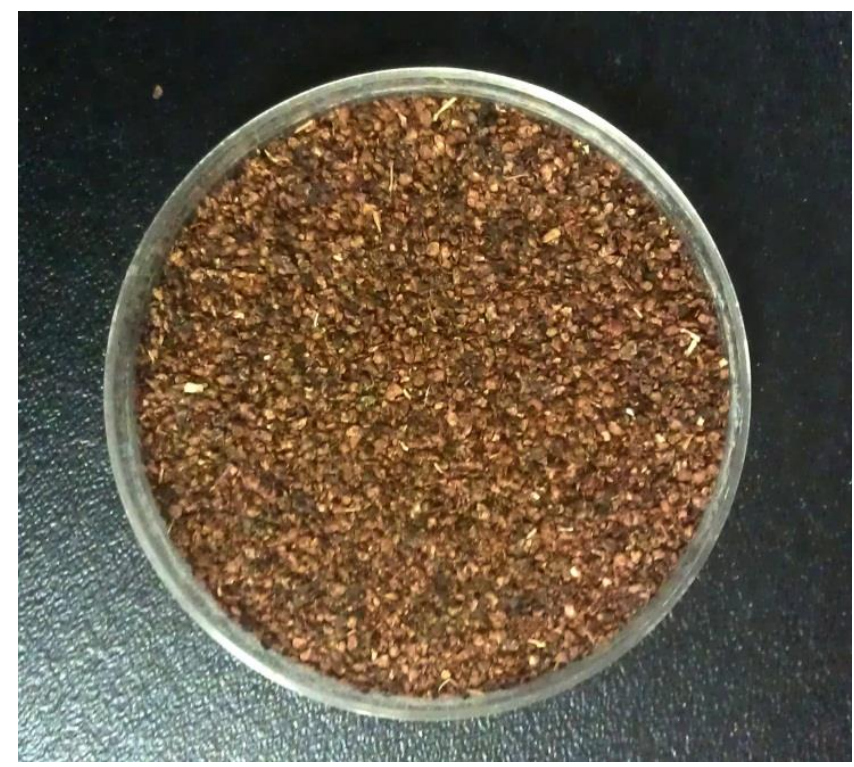

Figure 3.1 Canola meal with particle sizes $0.425-1.18 \mathrm{~mm}$.

Canola meal was also used to prepare cylindrical pellets. California Pellet Mill (CPM-Laboratory Model CL-5, California Pellet Mill Co., Crawfordsville, IN) was used to make cylindrical pellets with the uniform size of about $5 \mathrm{~mm}$ in diameter and $10 \mathrm{~mm}$ in length (Figure 3.2). Canola meal samples were dried in an oven at $110^{\circ} \mathrm{C}$ for $24 \mathrm{hrs}$, and then were ready for use in the column. 


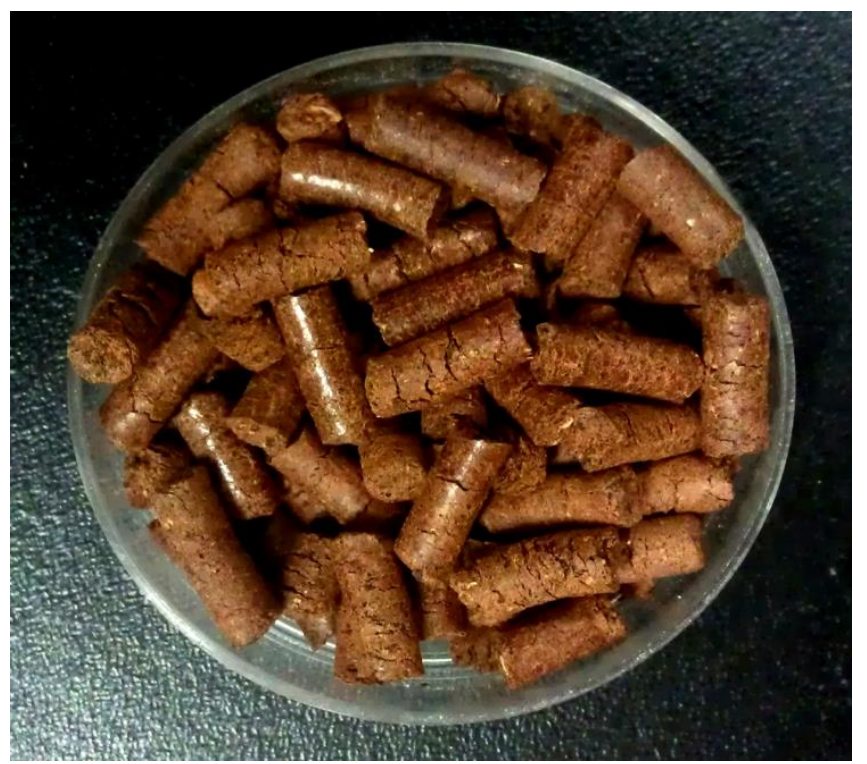

Figure 3.2 Cylindrical pellets with $5 \mathrm{~mm}$ in diameter and $10 \mathrm{~mm}$ in length.

\subsubsection{Corn Meal}

The corn meal used in this work was produced by BUNGE MILLING, INC. (Kansas, USA). Upon receiving, the corn meal was sieved and samples with particle sizes in the range of 0.425-1.18 mm were collected (Figure 3.3). Corn meal was dried in an oven at $110^{\circ} \mathrm{C}$ for $24 \mathrm{hrs}$, and then was ready for use in the column.

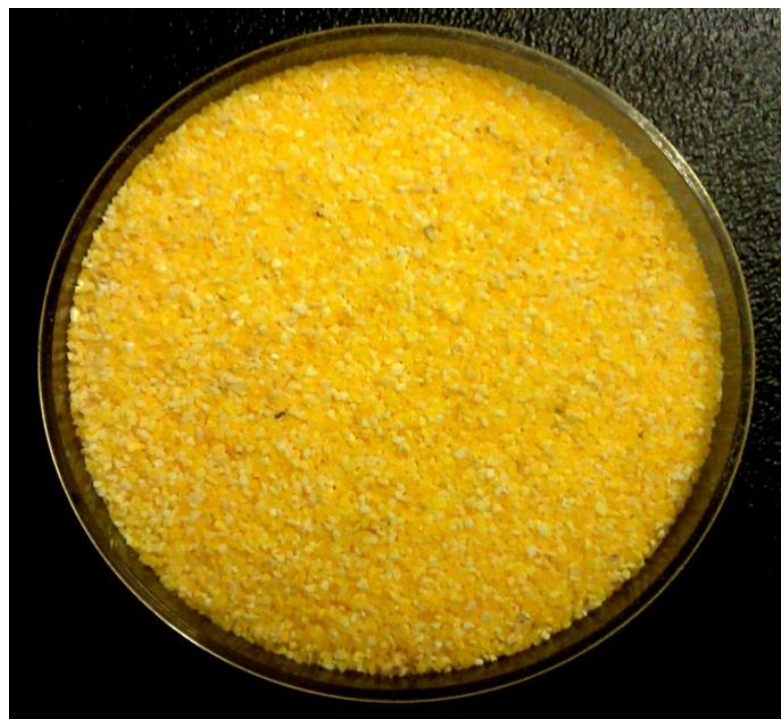

Figure 3.3 Corn meal with particle sizes $0.425-1.18 \mathrm{~mm}$. 


\subsubsection{Zeolite}

Zeolite 3A pellets with particle sizes $2.38-4.76 \mathrm{~mm}$ were provided by EMD Chemicals Inc. (Pamstadt, Germany) (Figure 3.4). Zeolite similar to other adsorbents was kept in an oven at $110{ }^{\circ} \mathrm{C}$ for $24 \mathrm{hrs}$, and then was ready for use in the column.

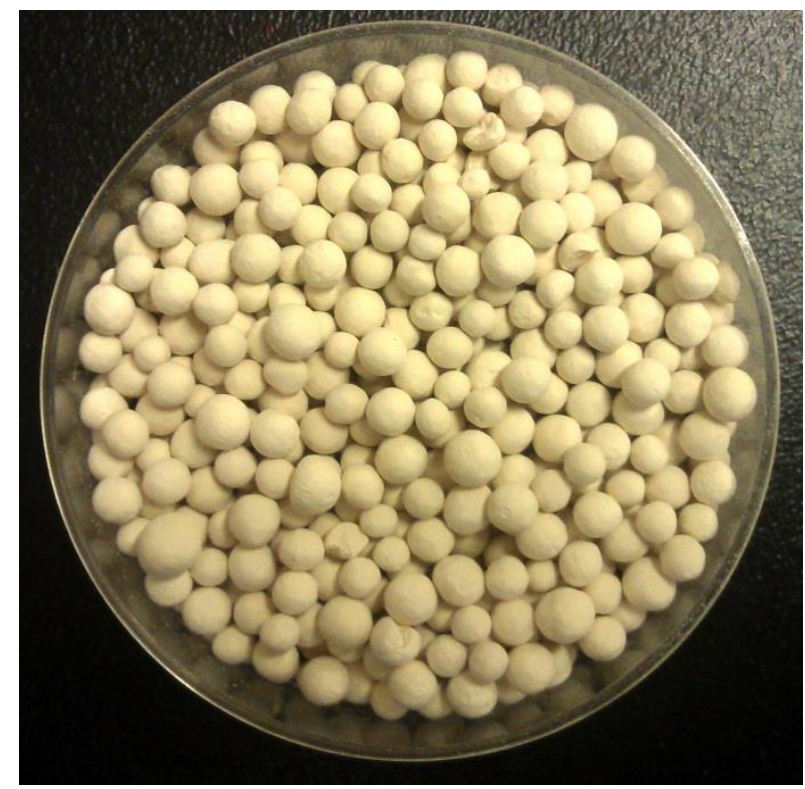

Figure 3.4 3A zeolite with particle sizes 2.38-4.76 mm.

\subsection{Experimental Setup}

The schematic diagram of the experimental set-up is shown in Figure 3.5. It includes:

- A pump (Cole-Parmer, RK-74930-05) to transfer the prepared mixture of water and ethanol to the Nebulizer.

- A gas tank $\left(\mathrm{N}_{2}\right)$.

- A gas flow meter (Cole-Parmer, PMR1-010360) to adjust the flow rate of the carrier gas $\left(\mathrm{N}_{2}\right)$.

- A preheater (heated piping line).

- An evaporator which is an approximately $15 \mathrm{~m}$ long copper tube coiled and immersed in a hot oil bath.

- A stainless steel adsorption column $501 \mathrm{~mm}$ long and $46 \mathrm{~mm}$ ID equipped with a jacket. 
- A heated pipe line connecting the outlet of the adsorption column to a back pressure regulator valve to ensure no condensation happens in the stream before entering to the back pressure regulator.

- A back pressure regulator valve (Parker Hannifin Corp, US) which was used to pressurize the system according to the operating conditions.

- Three glassware condensers to cool down the effluent and consequently separate water and ethanol from the carrier gas $\left(\mathrm{N}_{2}\right)$.

The temperature of the preheater in the setup was controlled by temperature controllers (Cole-Parmer, 89000-00, Canada) connected with a heating tape. The temperatures of the vapor stream and the bed were monitored at different points by four thermocouples (Omega K type, US) labeled J-111, J-114, J-115, and J-126. The thermocouples J-115 and J-126 were placed inside the tube, where J-115 read the temperature of the vapor stream at the inlet of the column and J-126 read the temperature of the vapor stream entering the back pressure regulator valve. J111 and J-114 were inserted at the middle and bottom of the column to monitor the bed temperature. Two pressure transducers (Honeywell, US) were used to monitor pressure at the top and bottom of the adsorption column (J-112 and J-113). The pressure transducers were attached to Omega DPiS32 outputs. The thermocouples J-115 and J-126 were connected to Omega DPi32 outputs, while the thermocouples $\mathrm{J}-111$ and $\mathrm{J}-114$ were attached to Omega UTC-USB Connectors and temperature data was recorded using TRH Central Measurement and Data Logging Program (Omega). 


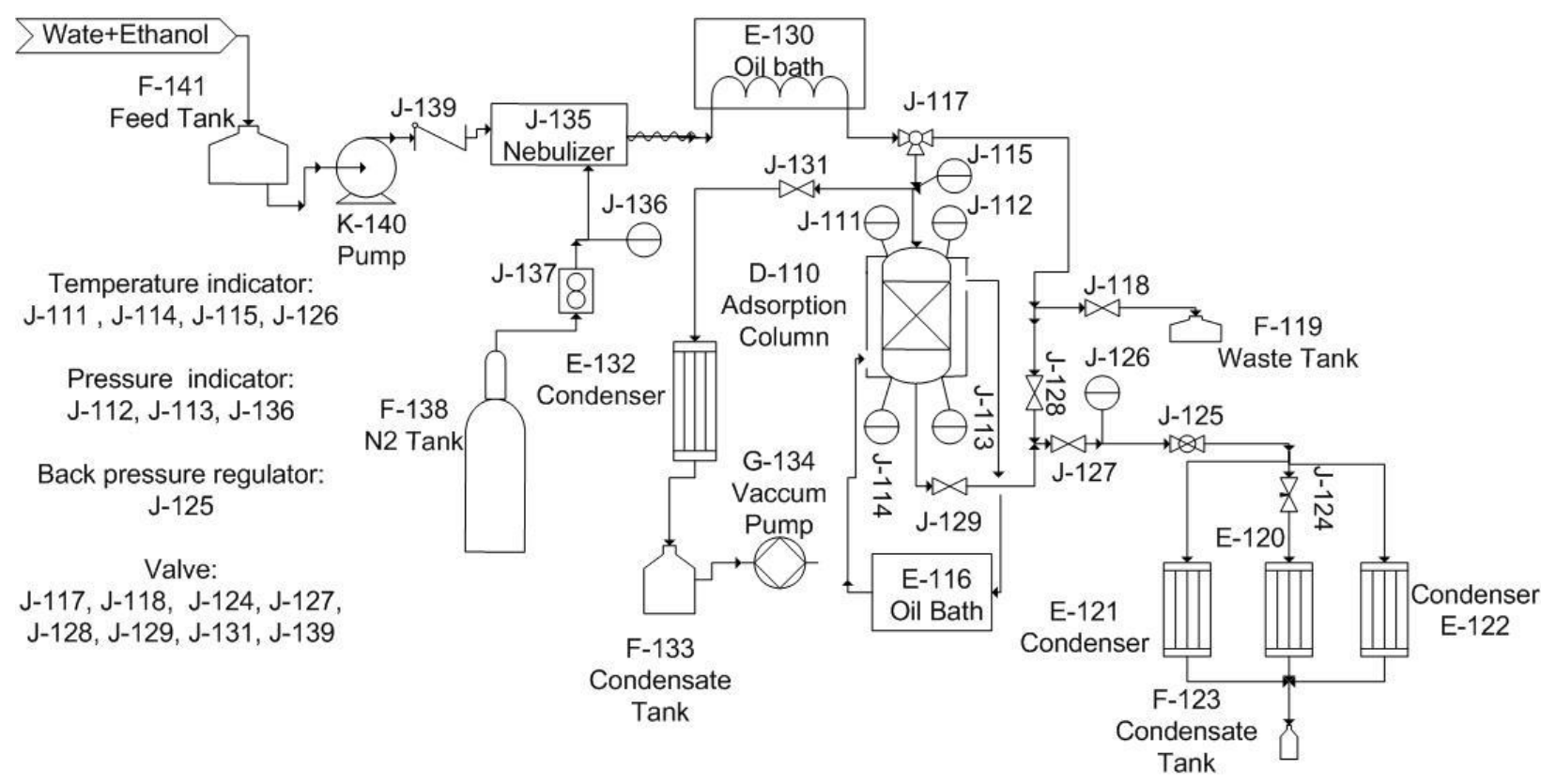

Figure 3.5 Process flow diagram of the PSA set-up.

\subsubsection{Feed Solution Preparation}

The ethanol-water solution was prepared by mixing 200 proof ethanol (reagent grade, Commercial Alcohol Inc., Canada) with distilled water.

\subsection{Adsorption Experiments}

Prior to the adsorption step, the column (D-110) was kept under vacuum condition (25 $\mathrm{kPa}$ ) at $110^{\circ} \mathrm{C}$ and purged with nitrogen gas at a flow rate of $756 \mathrm{~cm}^{3} / \mathrm{min}$ calibrated at standard conditions $\left(\mathrm{T}=25^{\circ} \mathrm{C}\right.$ and $\left.\mathrm{P}=101 \mathrm{kPa}\right)$ from the bottom for $15 \mathrm{hrs}$ to ensure the bed is free of any moisture. In the adsorption step, the prepared mixture of ethanol and water is pumped into the nebulizer (J-135), where the mixture is broken into small aerosol droplets with the aid of $\mathrm{N}_{2}$ gas (Figure 3.5). After that the mixture enters into the preheater where the tube is wrapped with heat tapes to warm up the mixture before entering into the evaporator (E-130). The mixture in the evaporator turns into vapor and reaches the desired temperature corresponding to the operating conditions (at this point the temperature is monitored by thermocouple (J-115)). After the bed temperature has reached the desired point, the adsorption step can begin. The temperature of the bed is kept constant corresponding to the operating conditions using an oil bath (E-116) which 
circulates the heating oil through the jacket of the adsorption column. This results in isothermal conditions for the adsorption process.

The adsorption process begins once the vapor stream enters into the column (D-110) from the top. As the vapor stream passes through the bed, water and/or ethanol molecules are adsorbed on the adsorbent and the vapor stream including unabsorbed materials along with $\mathrm{N}_{2}$ gas leaves the column from the bottom. The back pressure regulator valve (J-125) pressurized the system according to the operating conditions. The pressure drop along the column during the adsorption process was 2.1-3.4 $\mathrm{kPa}$, which is negligible. The tube between the column and back pressure regulator was wrapped with heat tapes to keep the vapor temperature at $103^{\circ} \mathrm{C}$ and avoid any condensation of the vapor stream before going into the pressure regulator. The effluent of the adsorption column is distributed between 3 condensers (E-120, E-121, and E-122), which were placed in a parallel pattern in order to separate the ethanol and water content of the vapor from the $\mathrm{N}_{2}$ gas. The condensed liquid was collected in sample tubes (F-123) in intervals of 2 min for the first $10 \mathrm{~min}, 5 \mathrm{~min}$ for $30 \mathrm{~min}, 10 \mathrm{~min}$ for $40 \mathrm{~min}$, and $20 \mathrm{~min}$ for the rest of the experiment. The collected samples were weighed and then analyzed to determine their water and ethanol contents.

The adsorption process was terminated when the bed was saturated and the temperatures at the middle (J-111) and bottom (J-114) of the column (D-110) had reached the inlet temperature of the vapor.

\subsubsection{Dynamic Study}

To study the effect of temperature, pressure, flow rate, pellet size, and feed concentration on the dynamic adsorption of water/ethanol on canola meal, water breakthrough curves and ethanol production profiles were generated. Water breakthrough curves were generated by plotting $\mathrm{C} / \mathrm{C}_{0}$ (dimensionless) versus time, where $\mathrm{C}$ is water content in effluent at specified time intervals and $\mathrm{C}_{0}$ represents the water content in the feed stream. Ethanol production profiles were also generated by plotting the ethanol content of the effluent versus time. By breakthrough point is meant, the point where the water content in the effluent reaches $1 \mathrm{wt} \%$ corresponding to 99 wt\% ethanol. At breakthrough point, water/ethanol uptake was determined as the ratio of the difference between the total mass of water/ethanol input into the column and the accumulated mass of water/ethanol in the effluent, and the dry net weight of the adsorbent in the column. 
The operating conditions for this research were as follows: bed temperatures of 100, 105, and $110^{\circ} \mathrm{C}$, water partial pressures of 24,45 , and $85 \mathrm{kPa}$, superficial velocities of 0.9 and 1.5 $\mathrm{cm} / \mathrm{s}$, total pressures of 243 , and $312 \mathrm{kPa}$, adsorbent particle sizes in the range $0.43-1.18 \mathrm{~mm}$ and cylindrical pellets of $5 \mathrm{~mm}$ diameter. These conditions were investigated on canola meal and the optimum conditions for ethanol production with concentration of over $99 \mathrm{wt} \%$ EtOH were determined. For comparison, canola meal, corn meal, and 3A zeolite adsorbents were tested in this work as well.

Water breakthrough curves were modeled to evaluate the overall, external, and internal water mass transfer resistances (Seader and Henley 1998) and determine the mechanism controlling the mass transfer rate.

\subsubsection{Equilibrium Study}

For the equilibrium study, the adsorption breakthrough experiments were run continuously until the bed reached equilibrium conditions. At equilibrium, the bed reached its saturation point, at which the water content in the effluent equals its feed value, and the bed temperature has restored its initial value.

Equilibrium isotherms were determined at temperatures 100,105 , and $110^{\circ} \mathrm{C}$ by plotting the equilibrium uptake versus the relative humidity. The narrow temperature range was chosen to avoid burning canola meal at higher temperatures, and condensing water or ethanol in the vapor feed stream at lower temperatures. At equilibrium, water/ethanol uptake was calculated as the ratio of the difference between the total mass of water/ethanol input into the column and the accumulated mass of water/ethanol in the effluent, and the dry net weight of the adsorbent in the column.

To find a model that can represent the adsorption isotherms in this system, the equilibrium data were fitted by the Dubinin-Polanyi, the Guggenheim-Andrson-de-Boer (GAB) and the Frenkel-Halsey-Hill (FHH) models (Al-Asheh et al., 2009; Ruthven 1984).

\subsection{Desorption Process}

The first step in the desorption stage was the depressurization step at which the pressure of the column was decreased to the atmospheric one by opening the valve (J-131) located on the top of the adsorption column (D-110). Next, the pressure of the column was reduced to $25 \mathrm{kPa}$ 
and kept constant using a vacuum pump (G-134). After that, the temperature of the bed was kept constant $\left(\right.$ at $110^{\circ} \mathrm{C}$ ) and the column was purged with nitrogen gas at flow rate $756 \mathrm{~cm}^{3} / \mathrm{min}$ for 5 hrs. Nitrogen gas was directed by a bypass to enter the column from the bottom and leave from the top. Finally, the outlet stream went through a condenser (E-132) to separate water/ethanol from the nitrogen gas and prevent them from entering the vacuum pump (G-134).

\subsection{Analysis}

\subsubsection{Water and Ethanol Content Analysis}

The water content for each collected sample was analyzed by an automated Karl Fischer Coulometer (METLER TOLEDO DL32). The ethanol mass fraction for each sample was determined as the difference between unity and the mass fraction of water. The ethanol mass fraction evaluated using this approach was consistent with the one analyzed by HPLC (Agilent, 1100 Series, Refractive Index Detection).

\subsubsection{Fourier-Transform Infrared (FTIR) Analysis}

Information regarding the functional groups of canola meal was obtained using FTIR analysis (Jasco FT/IR-4100). A 1-2 mg sample of canola meal was mixed with $100 \mathrm{mg}$ of a solid infrared transparent substance (potassium bromide) and then pressed into a $7 \mathrm{~mm}$ disc. Then, the prepared disc was used for FTIR analysis in the IR range of 450-3500 1/cm at a resolution of 16 $1 / \mathrm{cm}$.

\subsubsection{CHNS Analysis}

The elemental components (carbon, hydrogen, nitrogen and sulfur) of canola meal samples were determined using Perkin Elmer Elemental CHNS analyzer. Approximately 4-6 mg of each sample was taken and placed in a tin boat. Then, the tin boat was folded and placed in the instrument used in the analysis. Each analysis was repeated twice and the results were presented in average of the duplicates. 


\subsubsection{Particle Size Distribution Analysis}

The Mastersizer particle size analyzer (Mavlern Mastersizer-s long bench size distributor) was used to determine the size distribution of canola meal particles sieved in the range of 0.425 $1.18 \mathrm{~mm}$. Canola meal samples were manually placed into the dry feeder system. Then, a jet of compressed air delivered the sample from the feeder to the measurement area. The sample cell was located in front of the range lens, and the sample passed through the laser beam by flowing through the cell. The Mastersizer analyzes the size of each particle by using its optical unit to capture the actual scattering pattern from a field of particles. A $1000 \mathrm{~mm}$ lens was used for the analysis as the particle sizes were in the range of $0.0042-3.480 \mathrm{~mm}$.

\subsubsection{Thermogravimetric Analysis (TG/DTA)}

To study the pyrolytic behavior of canola meal, thermogravimetric analysis (TGA) was carried out using a PerkinElmer instrument, Pyris Diamond TG/DTA. The depolarization of the canola meal samples was performed in argon gas in a temperature range of $22-400^{\circ} \mathrm{C}$ and a temperature increase rate of $5^{\circ} \mathrm{C} / \mathrm{min}$.

\subsubsection{Proximate Analysis}

ASTM methods were applied to analyze the moisture, ash, and volatile contents of canola meal. The moisture and the ash content was determined according to procedures in ASTM 317378 (2003) and ASTM 3174-04 (2004) methods, respectively. For the ash content analysis, a $5 \mathrm{~g}$ canola meal sample was put in a crucible which in turn was placed in a muffle furnace (Holpack, US) at $575 \pm 10^{\circ} \mathrm{C}$ for $4 \mathrm{hrs}$. Then, the crucible was placed in a desiccator to cool down. The ash content was calculated as ratio of the sample residue in the crucible and its initial weight.

The volatile content was analyzed using the ASTM D3175-07 (2007) method. A $5 \mathrm{~g}$ sample was put in a crucible and placed in the muffin furnace at $950 \pm 10^{\circ} \mathrm{C}$ for $7 \mathrm{~min}$. Then, the crucible was placed in a desiccator to cool down. The volatile content was determined as the ratio of the sample's weight loss and its initial weight. 


\subsubsection{Protein Determination}

The protein content of canola meal was determined according to AACC Method 46-30.

First nitrogen content was determined by CHNS analysis. Then, the protein content was calculated by multiplying nitrogen content by 6.25 (Hassas-Roudsari et al., 2009). 


\section{RESULTS AND DISCUSSION}

\subsection{Characterization of Fresh Canola Meal}

\subsubsection{Particle Size Distribution Analysis}

To study the size distribution of sieved canola meal particles, the Mastersizer particle size analyzer was used. Figure 4.1 shows the size distribution of sieved canola meal particles in the size range of $0.425-1.18 \mathrm{~mm}$. The particle size analysis was duplicated and the average value of the volume median diameter $\mathrm{D}(\mathrm{v}, 0.5)$ was determined.

The volume median diameter $\mathrm{D}(\mathrm{v}, 0.5)$ of fresh canola meal particles is approximately $0.571 \pm 0.002 \mathrm{~mm}$. This means that $50 \mathrm{v} \%$ of the distribution is above $0.571 \pm 0.002 \mathrm{~mm}$ and 50 $\mathrm{v} \%$ is below $0.571 \pm 0.002 \mathrm{~mm}$.

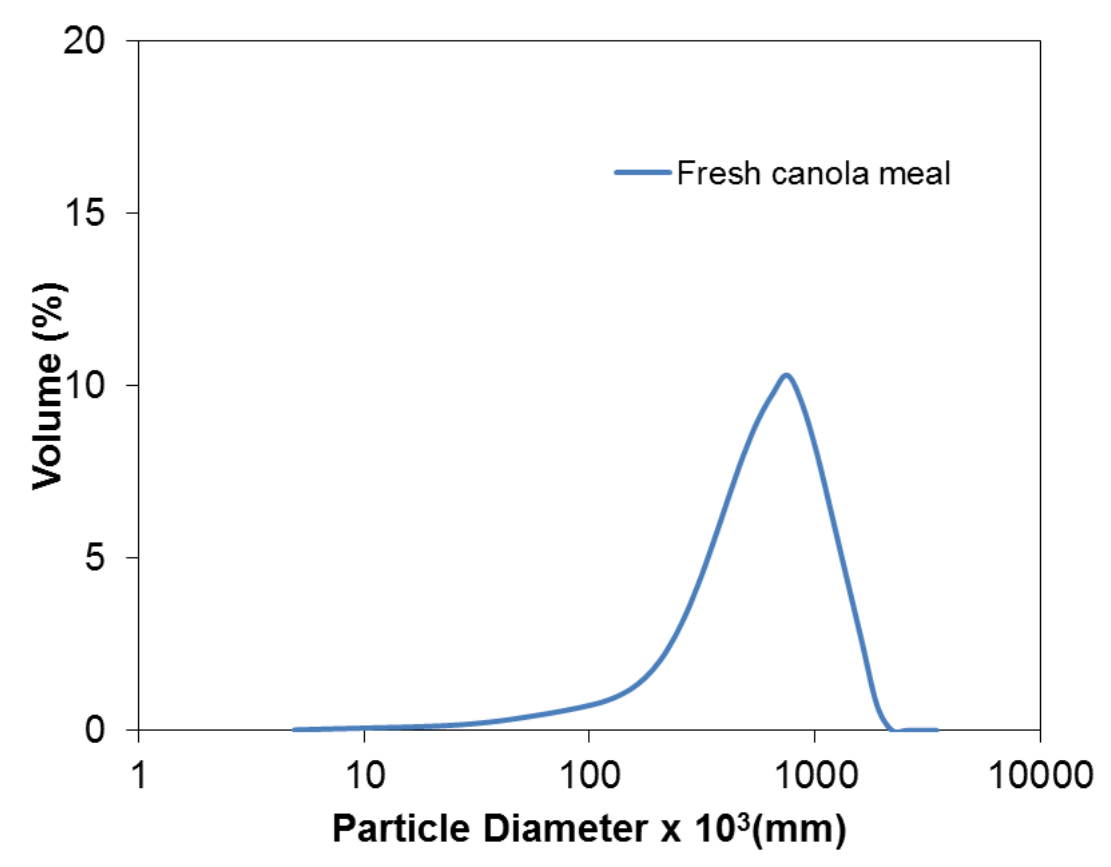

Figure 4.1 Particle size distributions for fresh canola meal. 


\subsubsection{FT-IR Spectroscopy Analysis}

The FT-IR spectroscopies of fresh canola meal showed peaks at 3372, 2926, 2855, 1655, 1542, 1241 and 1052 1/cm (Figure 4.2). The analysis of FT-IR bands demonstrated the presence of the functional groups amino, hydroxyl and carbonyl in canola meal. The band $33721 / \mathrm{cm}$ was assigned to O-H and N-H stretching vibration, while the bands 2926 and $28551 / \mathrm{cm}$ represented $\mathrm{CH}_{2}$ asymmetric and symmetric stretching vibrations, respectively. The presence of amide I was confirmed by the $\mathrm{C}=\mathrm{O}$ (peptide $\mathrm{C}=\mathrm{O}$ bond) stretching vibration band of $16551 / \mathrm{cm}$ and the $\mathrm{N}-\mathrm{H}$ bending vibration band of $15421 / \mathrm{cm}$. Band $12411 / \mathrm{cm}$ demonstrated the presence of hemicellulose and cellulose in canola meal, while band 1052 1/cm indicated the total $\mathrm{CHO}(\mathrm{Yu}$ et al., 2005). Carbohydrate band peaks between 1025-1100 1/cm represent non-structural carbohydrate such as starch (Yu et al., 2005; Wetzel et al., 1998), while the observation of a peak at $12421 / \mathrm{cm}$ is indicative of a structural carbohydrate such as hemicellulose and cellulose ( $\mathrm{Yu}$ et al., 2005).

Moreover, the presence of secondary amine was confirmed by observing $\mathrm{N}-\mathrm{H}$ stretch band in the range 3250-3400 1/cm and N-H bend wavelength in the range 1450-1550 1/cm (Mahmoodi et al., 2010; Yu et al., 2005; Pavia et al., 2000). The polar interaction between water molecules and the functional groups hydroxyl, carbonyl and amine could be identified as the mechanism of the intrinsic water adsorption on canola meal (Beery and Ladisch 2001; Kapoor and Viraraghavan 1997). 


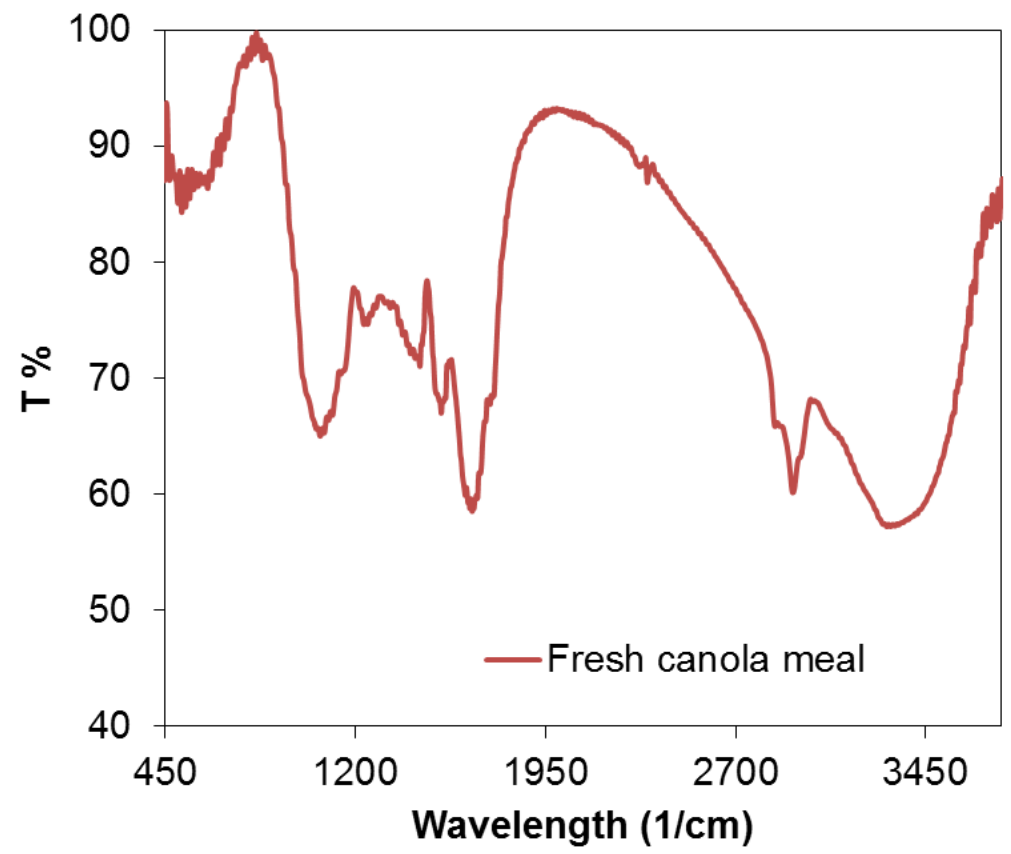

Figure 4.2 FTIR spectrum of fresh canola meal.

\subsubsection{Composition of Canola Meal}

The composition of canola meal was determined through CHNS and proximate methods. The results are shown in Table 4.1. The major components of canola meal were shown to be volatile matter and protein.

Neutral detergent fiber, free sugars, and non-starch polysaccharides comprise up to 24.1, 9.8, 6.2, and $13.7 \%$ of canola meal, respectively. Canola expeller meal contains up to $7.1 \%$ moisture, $6.3 \%$ ash, $36.3 \%$ crude protein and $10.8 \%$ non-degradable protein (Canola Council of Canada, 2011).

Table 4.1. Composition of fresh canola meal.

\begin{tabular}{lcccc}
\hline Adsorbent & $\begin{array}{c}\text { Moisture content } \\
(\mathrm{wt} \%)\end{array}$ & $\begin{array}{c}\text { Ash content } \\
(\mathrm{wt} \%)\end{array}$ & $\begin{array}{c}\text { Volatile matter } \\
(\mathrm{wt} \%)\end{array}$ & $\begin{array}{c}\text { Protein* } \\
(\mathrm{wt} \%)\end{array}$ \\
\hline Fresh CM & $8.6 \pm 0.1$ & $6.9 \pm 0.1$ & $78.9 \pm 0.9$ & $40.7 \pm 0.9$ \\
\hline
\end{tabular}

* Protein content was determined by the Kjeldahl method 


\subsubsection{Thermogravimetric Analysis}

To study the pyrolytic behavior of canola meal, thermogravimetric analysis (TGA) was carried out in inert argon gas. The TGA curve of fresh canola meal is presented in Figure 4.3. As it can be seen from the figure, the weight of the sample remained unchanged until $200^{\circ} \mathrm{C}$ while the maximum weight loss occurred in the range $290-350^{\circ} \mathrm{C}$. A slower weight loss was observed in the range $380^{\circ} \mathrm{C}$ to $480^{\circ} \mathrm{C}$. The results demonstrated that over $60 \mathrm{wt} \%$ of the volatile matter was devolatilized in the temperature range of $200-500^{\circ} \mathrm{C}$ (Carrier et al., 2011). In addition, Carrier et al., (2011) reported that the degradation of hemicelluloses, $\alpha$-cellulose and lignin occurred in the temperature intervals of $200-300^{\circ} \mathrm{C}, 250-350^{\circ} \mathrm{C}$, and $200-500^{\circ} \mathrm{C}$, accordingly. Based on the above, it was assumed that canola meal will remain stable in an ethanol dehydration process as long as the temperature of the bed remains lower than $200^{\circ} \mathrm{C}$. In this work, all ethanol dehydration experiments were done at $100-110^{\circ} \mathrm{C}$.

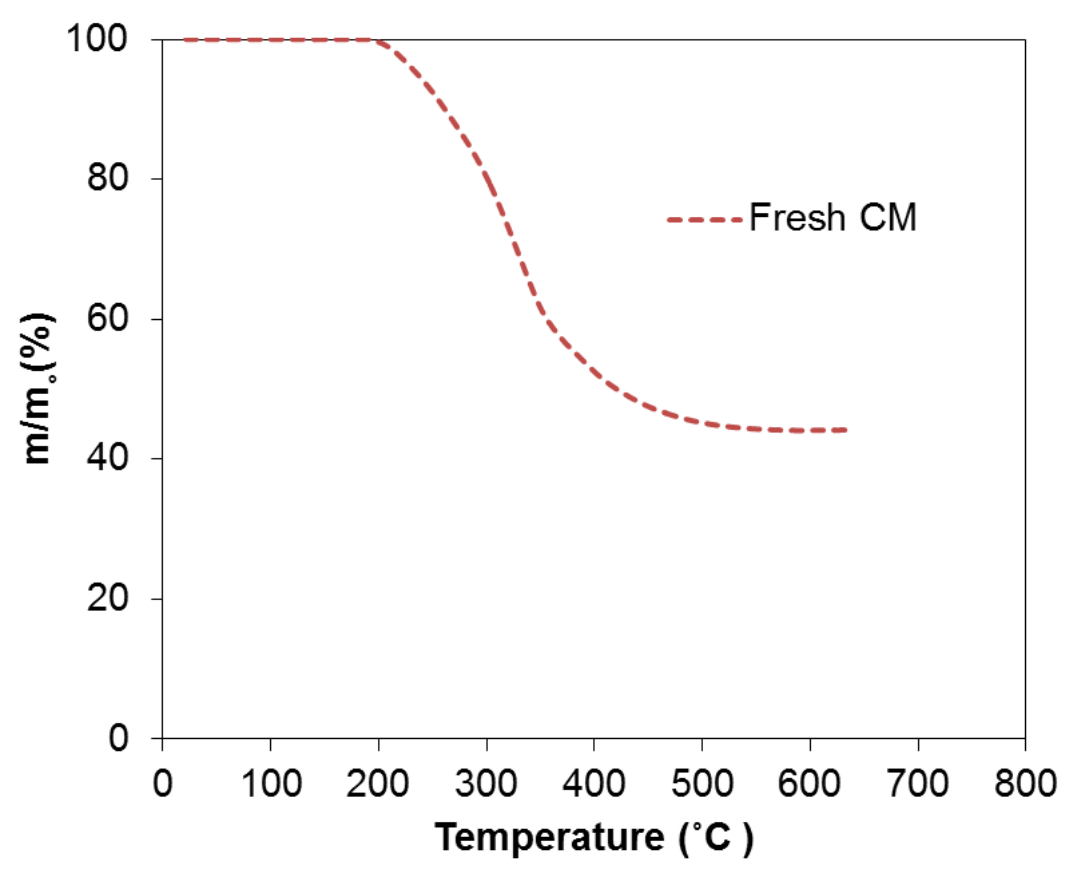

Figure 4.3 TGA curve of fresh canola meal.

\subsection{Reproducibility of Experimental Data}

Ethanol dehydration forms the central part of this thesis; hence the reproducibility of the experimental data of ethanol dehydration was investigated. Several experimental runs were 
performed and each run was repeated twice. Three random experimental runs, with different operating conditions, are presented here. Table 4.2 displays the operating conditions of the replicated runs. The results of the replicates are presented in Figure 4.4 in terms of their water breakthrough curves and ethanol production profiles. The data represents the average values of the repeated runs. The error bars represent the range of the obtained highest and lowest values for each data point.

Table 4.2. Run Conditions.

\begin{tabular}{cccccc}
\hline Run \# & $\mathrm{T}\left({ }^{\circ} \mathrm{C}\right)$ & $\mathrm{P}_{\text {total }}(\mathrm{kPa})$ & $\mathrm{P}_{\mathrm{w}}(\mathrm{kPa})$ & $\mathrm{d}_{\mathrm{p}}(\mathrm{mm})$ & $\mathrm{u}_{0}(\mathrm{~cm} / \mathrm{s})$ \\
\hline 1 & 110 & 243 & 24 & $0.43-1.18$ & 1.5 \\
2 & 100 & 243 & 45 & 5.00 & 0.9 \\
3 & 100 & 243 & 85 & $0.43-1.18$ & 0.9 \\
\hline
\end{tabular}



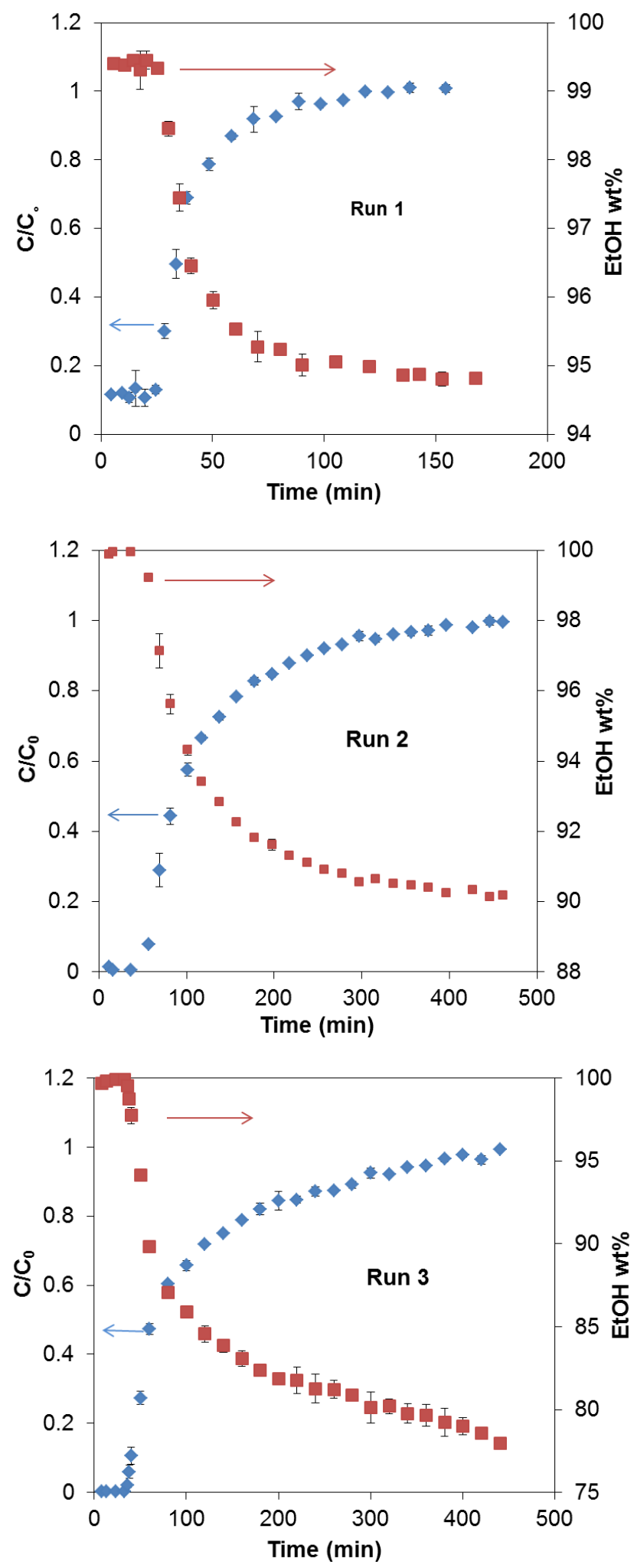

Figure 4.4 Water breakthrough curves and ethanol production profiles for experimental runs 1, 2 and 3. Error bars represent the range of the obtained highest and lowest values for each data point. 
The average equilibrium water/ethanol uptake was calculated for each run as the ratio of the adsorbed amount and the weight of dry canola meal packed in the bed. The results are listed in Table 4.3. The equilibrium water/ethanol uptake represents the average value obtained through the replicates. The standard deviation (STD) and error of the data were calculated as well. As it can be seen from Table 4.3., the calculated error for all runs is less than 5\%. The results demonstrated that the experimental data were reproducible.

Table 4.3. Results of statistical analysis.

\begin{tabular}{ccccccc}
\hline & \multicolumn{2}{c}{$\begin{array}{c}\mathrm{H}_{2} \mathrm{O} \text { uptake } \\
\text { (mol/kg adsorbent) }\end{array}$} & \multicolumn{3}{c}{$\begin{array}{c}\text { EtOH uptake } \\
\text { (mol/kg adsorbent) }\end{array}$} \\
\hline Run \# & Average & STD & Error (\%) & Average & STD & Error (\%) \\
\hline 1 & 0.94 & 0.03 & 3.62 & 2.41 & 0.08 & 3.54 \\
2 & 3.34 & 0.16 & 4.88 & 4.10 & 0.14 & 3.45 \\
3 & 7.26 & 0.35 & 4.78 & 4.25 & 0.21 & 4.99 \\
\hline
\end{tabular}

\subsection{Water/Ethanol Adsorption Dynamic Study}

To study the effects of temperature, pressure, flow rate, pellet size and feed concentration on the dynamic adsorption of water/ethanol on canola meal, water breakthrough curves and ethanol production profiles were generated. As explained in Chapter 3, water breakthrough curves were generated by plotting the dimensionless water content $\left(\mathrm{C} / \mathrm{C}_{0}\right)$ versus time, where $\mathrm{C}$ is water content (wt\%) in the effluent at given time intervals and $\mathrm{C}_{0}$ represents water content (wt\%) in the feed. The slopes of the curves represent the water mass transfer rate (Simo et al., 2009). Ethanol production profiles represent the ethanol concentration in the output stream at the given time intervals. Breakthrough point refers to the point where the concentration of water in the effluent reaches $1 \mathrm{wt} \%$, which corresponds to $99 \mathrm{wt} \%$ ethanol.

The water/ethanol uptake on canola meal at equilibrium conditions was determined. The equilibrium conditions in each run were identified by considering both the water breakthrough curve and the temperature profile. At equilibrium, the bed reached its saturation point, at which the water content in the effluent equals its feed value, and the bed temperature has restored its initial value. At breakthrough and equilibrium, water/ethanol uptake was calculated as the ratio of the difference between the total mass of water/ethanol input into the column and the 
accumulated mass of water/ethanol in the effluent, and the dry net weight of the canola meal in the column.

The selectivity of water adsorption by the adsorbent was determined by calculating the separation factor $\alpha$ as follows:

$\alpha=\frac{X_{w} / X_{e}}{Y_{w} / Y_{e}}$

where $X_{w}$ and $Y_{w}$ are the mass fractions of water in the adsorbed and vapor phases, respectively, while $X_{e}$ and $Y_{e}$ are the corresponding ethanol mass fractions (Chang et al., 2006b).

Furthermore, by simulating water breakthrough curves, the overall water mass transfer coefficient was evaluated. This coefficient was used to calculate the overall mass transfer resistance. In addition, the external and internal mass transfer resistances were determined since they have a unique dependence on the operating conditions (Simo et al., 2009).

In general, there are three steps for the adsorption of a adsorbate (solute) onto the surface of a porous adsorbent. The first step is external transport (interphase), which is the mass transfer of a adsorbate from the bulk fluid to the external surface of the adsorbent (pore mouth) by means of diffusion. The second step is internal transport (intraphase), in which the adsorbate diffuses from the pore mouth to the inner surface of the internal porous structure. The third step is adsorption, when the adsorbate is adsorbed onto the porous surface (Simo et al., 2009; Fogler 1999; Seader and Henley 1998). For physical adsorption the rate of the third kinetic step is almost instantaneous due to its dependency on the collision frequency and the orientation of the molecules with the porous surface (Seader and Henley 1998). However, for chemisorption, step 4 may be slow and even controlling due to the formation of chemical bonds between the adsorbate and the adsorbent (Seader and Henley 1998). In this work, the assumption was that the rate controlling step is mass transfer and the intrinsic water adsorption rate (step 3) on canola meal is fast since water adsorption is physical in nature. To identify the controlling mechanism of the mass transfer rate, the total water mass transfer, external mass transfer and internal mass transfer resistances were determined. 


\subsubsection{Simulation of Water Breakthrough Curves}

The aim of a mathematical modeling of the water adsorption dynamics is to simulate the experimentally obtained breakthrough curves and determine the mass transfer resistance. This in turn enables us to get more insight into the mass transfer mechanism governing the adsorption process. In general, the mathematical models used to describe the dynamic behavior of adsorption systems involve a set of partial differential and algebraic equation, the overall mass balance equation, component mass balance equations, adsorption rate equation and the momentum balance equation (Chahbani and Tondeur 2000; Ruthven 1984) which usually require complex computation. A simplified model has been developed by applying mass balance of fluid phase on a differential element of the bed $(d z)$, in which the fluid stream contains an adsorbate with concentration varying with axial position $\mathrm{z}$ and time $\mathrm{t}, \mathrm{c}(\mathrm{z}, \mathrm{t})$ (Ruthven 1984):

$\frac{\partial c}{\partial t}=D_{L} \frac{\partial^{2} c}{\partial z^{2}}-\frac{\partial(u c)}{\partial z}-\frac{\left(1-\varepsilon_{b}\right)}{\varepsilon_{b}} \frac{\partial \bar{q}}{\partial t}$

The term on the left hand side represents accumulation rate of the adsorbate. The first term on the right hand side accounts for axial dispersion with eddy diffusivity $D_{L}$, the second one represents the convection term, and the third one is adsorption rate based on $\bar{q}$, the volume average adsorbent loading per unit mass (uptake). Thus, the last term accounts for the variation of q throughout the adsorbent particle, due to internal mass transfer resistance, by averaging the rate of adsorption over the adsorbent particle. $\varepsilon_{b}$ is bed porosity, $\mathrm{z}$ is the bed depth (m), and $\mathrm{u}$ is the interstitial velocity of vapor. Equation (4.2) gives the concentration of the adsorbate in the fluid as a function of time and location in the bed (Seader and Henley 1998; Sereno and Rodrigues 1993). To achieve the analytical solution, the following assumptions were further made (Seader and Henley 1998; Sereno and Rodrigues 1993) :

1) The solute in the bulk fluid is in instantaneous equilibrium with the one adsorbed on the adsorbent;

2) Axial dispersion is negligible;

3) Mass transfer is the controlling mechanism of the overall water adsorption rate and the Linear Driving Force (LDF) model is applied to describe the overall mass transfer rate.

Under the above assumptions, equation (4.2) becomes:

$\frac{\partial c}{\partial t}+\frac{\partial(u c)}{\partial z}+\frac{\left(1-\varepsilon_{b}\right)}{\varepsilon_{b}} \frac{\partial \bar{q}}{\partial t}=0$ 
Then, the LDF model introduced by Glueckauf (Seader and Henley 1998; Glueckauf 1955; Glueckauf and Coates 1947), was applied to replace the adsorption rate in equation (4.3) by:

$\frac{\partial \bar{q}}{\partial t}=k_{L D F}\left(q^{*}-\bar{q}\right)$

To correlate the adsorbate uptake in the solid phase with its concentration in the fluid phase, a linear adsorption equilibrium model was used (Seader and Henley 1998; Sereno and Rodrigues 1993).

$q^{*}=K c^{*}$

$\bar{q}=K c$

where $q^{*}$ is the saturated adsorbate loading in equilibrium with the sorbate concentration, $\mathrm{c}^{*}$ in the bulk fluid, $c$ is adsorbate concentration in equilibrium with average loading $\bar{q}$ and $K$ is the adsorption equilibrium constant.

Combining equations (4.4), (4.5), and (4.6) gives:

$\frac{\partial \bar{q}}{\partial t}=k_{L D F} K\left(c^{*}-c\right)$

where $k_{L D F}$ is the overall mass-transfer coefficient $(1 / \mathrm{s})$, which includes both external and internal transport resistances.

Combining equations (4.3) and (4.7) gives:

$\frac{\partial c}{\partial t}+u \frac{\partial c}{\partial z}+\frac{\left(1-\varepsilon_{b}\right)\left(k_{L D F} K\right)}{\varepsilon_{b}}\left(c^{*}-c\right)=0$

The initial and boundary conditions for an initially dry bed that was exposed to a step change in sorbate concentration at the inlet at time zero are (Ruthven 1984):

$t=0, \quad \bar{q}(0, Z)=c(0, Z)=0$

$t>0, \quad c(t, 0)=c_{0}, c(t, l)=c_{i}$

where $\mathrm{z}$ (bed depth) varies from 0 to $l$, and $c_{i}$ is the concentration of the adsorbate in the effluent.

The simulation of a breakthrough curve requires solving equation (4.8) subject to initial and boundary conditions (equations (4.9) and (4.10)). The following approximate solution to equation (4.8) was obtained (Klinkenberg 1954). 
$\frac{c_{i}}{c_{0}} \approx \frac{1}{2}\left[1+\operatorname{erf}\left(\sqrt{\tau}-\sqrt{\xi}+\frac{1}{8 \sqrt{\tau}}+\frac{1}{8 \sqrt{\xi}}\right)\right]$

where $c_{i}$ and $c_{0}$ are the concentration of the adsorbable species in the effluent and feed stream, respectively, while $\xi$ is the dimensionless distance coordinate and $\tau$ is the dimensionless time coordinate corrected for displacement. The equations for $\xi$ and $\tau$ are:

$\xi=\frac{k_{L D F} K z}{u}\left(\frac{1-\varepsilon_{b}}{\varepsilon_{b}}\right)$

$\tau=k\left(t-\frac{z}{u}\right)$

$\xi$ and $\tau$ are defined as coordinate transformations for $\mathrm{z}$ and $\mathrm{t}$ in order to convert the equations to an equation with a much simpler form of the error function $\operatorname{erf}(x)$. Recall that the error function is defined by:

$$
\begin{aligned}
& \operatorname{erf}(-x)=-\operatorname{erf}(x) \\
& \operatorname{erf}(x)=\frac{2}{\sqrt{\pi}} \int_{0}^{x} e^{-\eta^{2}} d \eta
\end{aligned}
$$

In this work, equation (4.11) was used to fit the experimentally obtained water breakthrough curves. The adsorption column worked under isobaric conditions because of the negligible pressure drop (2.1-3.4 $\mathrm{kPa}$ ) along the bed. While treating the experimental data, the fed vapor is considered to have an ideal gas behavior due to the low operating pressure. $\mathrm{u}$ in the model was presented by the average interstitial velocity of vapor across the adsorption column.

Through determination of $k_{L D F}$ by fitting equation (4.11) to the experimental data, the overall mass transfer resistance $R_{T}$, measured in s, was calculated (Gorbach et al., 2004):

$$
R_{T}=\frac{1}{K_{L D F}}
$$

The overall mass transfer resistance is also correlated to the external $\left(R_{\text {ex }}\right)$ and internal $\left(R_{\text {in }}\right)$ mass transfer resistances by (Gorbach et al., 2004):

$R_{T}=R_{\text {ex }}+R_{\text {in }}$

The external mass transfer resistance was evaluated by (Gorbach et al., 2004) using:

$$
R_{e x}=\frac{R_{p} K}{3 k_{c}}
$$


where $k_{c}$ is the external mass-transfer coefficient $(\mathrm{m} / \mathrm{s}), R_{p}$ is adsorbent particle radius $(\mathrm{m})$ and $K$ is the equilibrium constant at temperature $\mathrm{T}$. Thus the internal mass transfer resistance is evaluated as the difference of the external mass transfer resistance and the overall mass transfer resistance.

The parameters in equations (4.11), (4.12) and (4.13), used to fit the water breakthrough curves are determined.

Equilibrium constant $K$ : As mentioned earlier, in order to achieve the analytical solution (equation (4.11)), the water adsorption isotherms were fit by the linear model equation (4.5) to determine $K$ at different temperatures and particle sizes. The results are shown in Figure 4.5 and Table 4.4. Further, the values of the correlation coefficient $\mathrm{R}^{2}$ were determined using:

$R^{2}=1-\frac{\sum_{i=1}^{n}\left(y_{i, \exp }-y_{i, \text { model }}\right)^{2}}{\sum_{i=1}^{n}\left(y_{i, \exp }-y_{b a r}\right)^{2}}$

where $y_{i}=\left(\frac{c_{i}}{c_{0}}\right)$ and $y_{b a r}$ is the average of $\left\{y_{i, \exp } \mid i=1, \ldots, n\right\}$.

As can be seen in Table 4.4, the values of coefficient of determination $\mathrm{R}^{2}$ were greater than or equal to 0.95 with an average of 0.97 . The results confirmed that the linear isotherm model gave acceptable fitting to the experimental data.

More sophisticated isotherms models will be discussed in Section 4.4 in terms of their capabilities to fit the equilibrium isotherms of water adsorption on canola meal.

Table 4.4. Equilibrium constants for water adsorption on canola meal.

\begin{tabular}{cccc}
\hline $\mathrm{T}\left({ }^{\circ} \mathrm{C}\right)$ & $\mathrm{d}_{\mathrm{p}}(\mathrm{mm})$ & $\mathrm{K}$ & $\mathrm{R}^{2}$ \\
\hline 100 & $0.425-1.18$ & 269 & 0.96 \\
100 & 5 & 273 & 0.95 \\
105 & $0.425-1.18$ & 198 & 0.96 \\
110 & $0.425-1.18$ & 157 & 0.99 \\
\hline
\end{tabular}




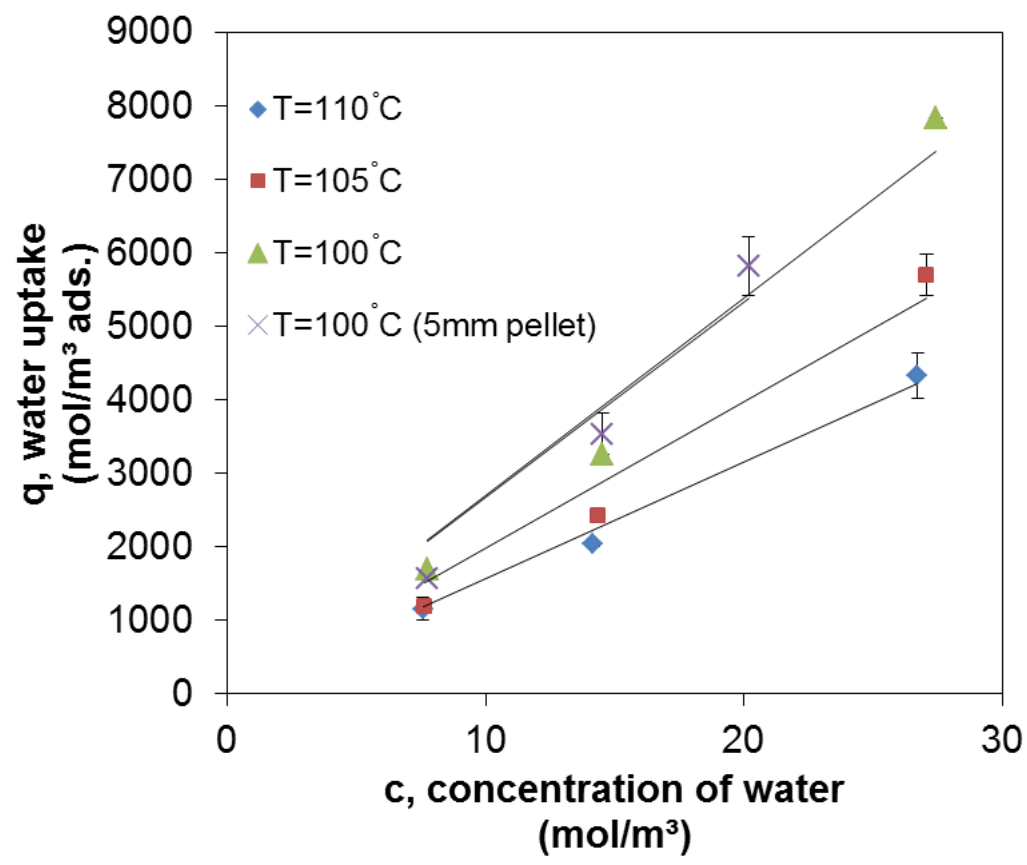

Figure 4.5 Water adsorption isotherms on canola meal. For particle size 0.43-1.18 mm, data was obtained at $100,105,110^{\circ} \mathrm{C}$ and for pellet $5 \mathrm{~mm}$ at $100^{\circ} \mathrm{C}$. The solid lines represent the linear model fit, while the error bars represent the range of the obtained highest and lowest values for each data point.

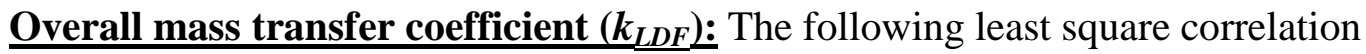

$\min f(k)=\sum\left[\left(\frac{c_{i}}{c_{0}}\right)-\left(\frac{c_{i}}{c_{0}}\right)_{\exp }\right]^{2}$

was used to fit equations (4.11), (4.12) and (4.13) to the experimental data and was used to estimate the optimum values for the overall mass transfer coefficient $\mathrm{k}_{\mathrm{LDF}}$. As it can be seen from equation (4.11), the ratios $\frac{c_{i}}{c_{0}}$ become a function of the overall mass transfer coefficient only, once the remaining parameters are known. The value of the bed depth $\mathrm{z}$ was $0.5 \mathrm{~m}$ for all experimental runs. The effective velocity $u$ of vapor is calculated by:

$u=\frac{u_{0}}{\varepsilon_{b}}$

where $u_{0}$ is the superficial velocity in the column $(\mathrm{m} / \mathrm{s})$.

In the simulation of the water breakthrough curves using equation (4.11), the coefficient $\mathrm{R}^{2}$ was also calculated to evaluate how well the model fits the experimental data. In order to 
determine the mass transfer resistance in equation (4.19), the following parameters were determined:

External mass coefficient $\left(\boldsymbol{k}_{c} \underline{\underline{ }} \underline{i}\right.$ To evaluate the external mass transfer coefficient $k_{c}$, it was necessary to calculate Reynolds number Re and Schmidt number Sc:

$R e=\frac{D_{p} \rho u_{0}}{\mu\left(1-\varepsilon_{b}\right)}$

$S c=\frac{\mu}{p D_{m}}$

where $\mu$ is viscosity of vapor in $\mathrm{kg} / \mathrm{m} * \mathrm{~s}, \rho$ is vapor density in $\mathrm{kg} / \mathrm{m}^{3}, D_{p}$ is the equivalent diameter of a spherical particle in $\mathrm{m}, u_{0}$ represents the superficial velocity of vapor in $\mathrm{m} / \mathrm{s}$, and $D_{m}$ is molecular diffusivity for a gas mixture in $\mathrm{m}^{2} / \mathrm{s}$. The detailed calculation of $D_{m}$ has been described in Appendix A.

Then, using the values of Re and Sc, the Sherwood number Sh was calculated through equation (4.24) (Ruthven 1984):

$S h=2+1.1 S c^{1 / 3} R e^{0.6}$

The external mass transfer coefficient $k_{c}$ of particles in the fixed-bed in equation (4.20) was determined from the following correlation:

$S h=\frac{D_{p} k_{c}}{D_{m}}$

In the correlations mentioned earlier, $\mathrm{D}_{\mathrm{p}}$ was introduced as the equivalent diameter of a spherical particle. There are some correlations used to calculate $D_{p}$ from the geometric properties of the particles. A short cylinder with diameter D, equal to its length, was used to describe the geometry of the particles. In this work, two different sizes of adsorbents were investigated and the corresponding equivalent diameters were calculated as follows (Seader and Henley 1998):

1) For particles with $\mathrm{D}$ in the range $0.425-1.18 \mathrm{~mm}, \mathrm{D}_{\mathrm{p}}$ equals 4 times the hydraulic radius $r_{H}$, where for a packed bed $4 r_{H}=1.0 D$. Thus,

$D_{p}=1.0 D$

This correlation is commonly used for crushed particles of irregular surface, with no obvious longer or shorter dimension (Seader and Henley 1998). 
2) For $5 \mathrm{~mm}$ pellets, $D_{p}$ was taken to equal the diameter of a sphere with the same volume as the above mentioned cylinder. Thus,

$D_{p}=1.145 D$

Once $k_{c}$ was calculated, the external mass transfer resistance was determined by equation (4.18), and the internal resistance was calculated as the difference between the total resistance and the external resistance. The results of the mathematical modeling and the effect of the operating conditions on the mass transfer resistances are discussed in detail in the subsequent sections.

\subsubsection{Temperature Effect}

The effect of the bed temperature on water/ethanol adsorption was investigated at 100, 105 , and $110^{\circ} \mathrm{C}$, while the water partial pressure in vapor stream was kept constant at $24 \mathrm{kPa}$. The water breakthrough curves and ethanol production profiles are shown in Figure 5.6. As it can be seen from Figure 4.6, canola meal broke the azeotropic point (95 wt\% EtOH) at different temperatures and produced ethanol with concentration greater than $99 \mathrm{wt} \%$. As it presented in Figure 4.6(b), breakthrough time decreased as the temperature was increased. The breakthrough times of $60,54.8$, and 41.9 min were observed at 100,105 and $110^{\circ} \mathrm{C}$, respectively. Further, the slope of water breakthrough curves increased as the temperature was increased, which shows greater mass transfer rates at elevated temperatures.

Table 4.5 summarizes the uptake, production of $99 \mathrm{wt} \%$ ethanol, and separation factor at different bed temperatures. At breakthrough point, water uptake decreased as the temperature was increased. Water uptake for runs at 100,105 , and $110^{\circ} \mathrm{C}$ was $0.85,0.79,0.58(\mathrm{~mol} / \mathrm{kg}$ adsorbent), respectively. In the case of ethanol, the uptake decreased from 1.74 to 1.16 (mol/kg ads) when the temperature was increased from 100 to $110^{\circ} \mathrm{C}$. Furthermore, Table 4.5 , shows that an increase in temperature caused a decrease in the amount of ethanol production with concentration over $99 \mathrm{wt} \% \mathrm{EtOH}$; the values were 4.7, 4.4, 4 (mol EtOH/kg adsorbent) for runs at 100,105 , and $110^{\circ} \mathrm{C}$, respectively. The results indicated that water/ethanol adsorption is an exothermic process.

Comparison of water/ethanol uptake at the breakthrough and equilibrium points indicated that the uptake was higher at equilibrium for both components. The separation factor for all runs at equilibrium was lower compared to the one at breakthrough point. Thus, ethanol dehydration is to be operated till the breakthrough point (Baylak et al., 2012). 
Table 4.5. Experimental results of water and ethanol adsorption on canola meal for different temperatures at total pressure of $243 \mathrm{kPa}$ with particle sizes of $0.43-1.18 \mathrm{~mm}$.

\begin{tabular}{|c|c|c|c|c|c|c|c|c|c|c|}
\hline \multicolumn{4}{|c|}{ Operating condition } & \multicolumn{3}{|c|}{ Equilibrium adsorption } & \multicolumn{4}{|c|}{$\begin{array}{l}\text { Adsorption until breakthrough point } \\
\text { (99 wt } \% \text { EtOH) }\end{array}$} \\
\hline $\begin{array}{c}\mathrm{T} \\
\left({ }^{\circ} \mathrm{C}\right) \\
\end{array}$ & $\begin{array}{c}\mathrm{u}_{0} \\
(\mathrm{~cm} / \mathrm{s}) \\
\end{array}$ & $\begin{array}{c}\mathrm{Pw} \\
(\mathrm{kPa})\end{array}$ & $\begin{array}{c}\mathrm{P}_{\mathrm{Et}} \\
(\mathrm{kPa})\end{array}$ & $\begin{array}{c}\mathrm{H}_{2} \mathrm{O} \\
\text { uptake* }\end{array}$ & $\begin{array}{c}\text { EtOH } \\
\text { uptake* }\end{array}$ & $\alpha^{* *}$ & $\begin{array}{c}\mathrm{H}_{2} \mathrm{O} \\
\text { uptake* }\end{array}$ & $\begin{array}{c}\text { EtOH } \\
\text { uptake* }\end{array}$ & $\alpha^{* *}$ & $\begin{array}{c}\mathrm{EtOH} \\
\text { mass*** }\end{array}$ \\
\hline 100 & 0.9 & 24 & 178 & 1.43 & 3.17 & 3.35 & 0.85 & 1.74 & 3.60 & 4.7 \\
\hline 105 & 0.9 & 24 & 178 & 1.19 & 2.67 & 3.30 & 0.79 & 1.58 & 3.69 & 4.4 \\
\hline 110 & 0.9 & 24 & 178 & 1.10 & 2.52 & 3.34 & 0.58 & 1.16 & 3.65 & 4.0 \\
\hline
\end{tabular}



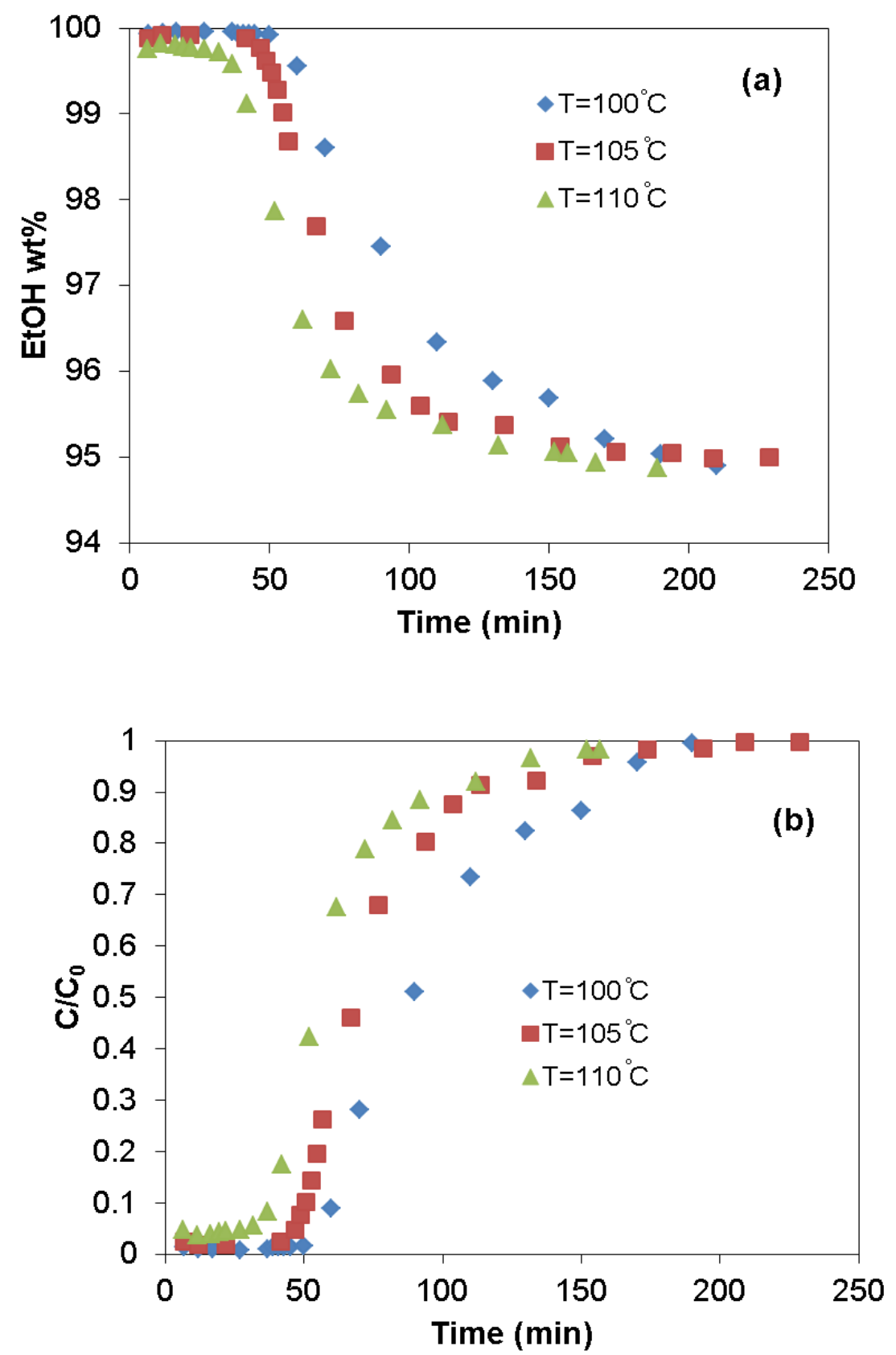

Figure 4.6 (a) Ethanol production profiles; (b) Water breakthrough curves. Operating conditions: $\mathrm{P}_{\mathrm{w}}=24 \mathrm{kPa}, \mathrm{u}_{0} \approx 0.9 \mathrm{~cm} / \mathrm{s}$, and $\mathrm{d}_{\mathrm{p}}=0.425-1.18 \mathrm{~mm}$.

Due to the exothermic nature of adsorption processes, greater water adsorption by the adsorbent results in higher heat generation. This fact can be further observed from the temperature profile presented in Figure 4.7; the temperature rise $\Delta \mathrm{T}=\mathrm{T}_{\max }-\mathrm{T}_{\text {inlet }}$ (or hot spot) 
increased as the temperature was decreased (Simo, et al., 2009), where $T_{\max }$ is peak temperature profile, and $\mathrm{T}_{\text {inlet }}$ is temperature of vapor stream at the inlet.

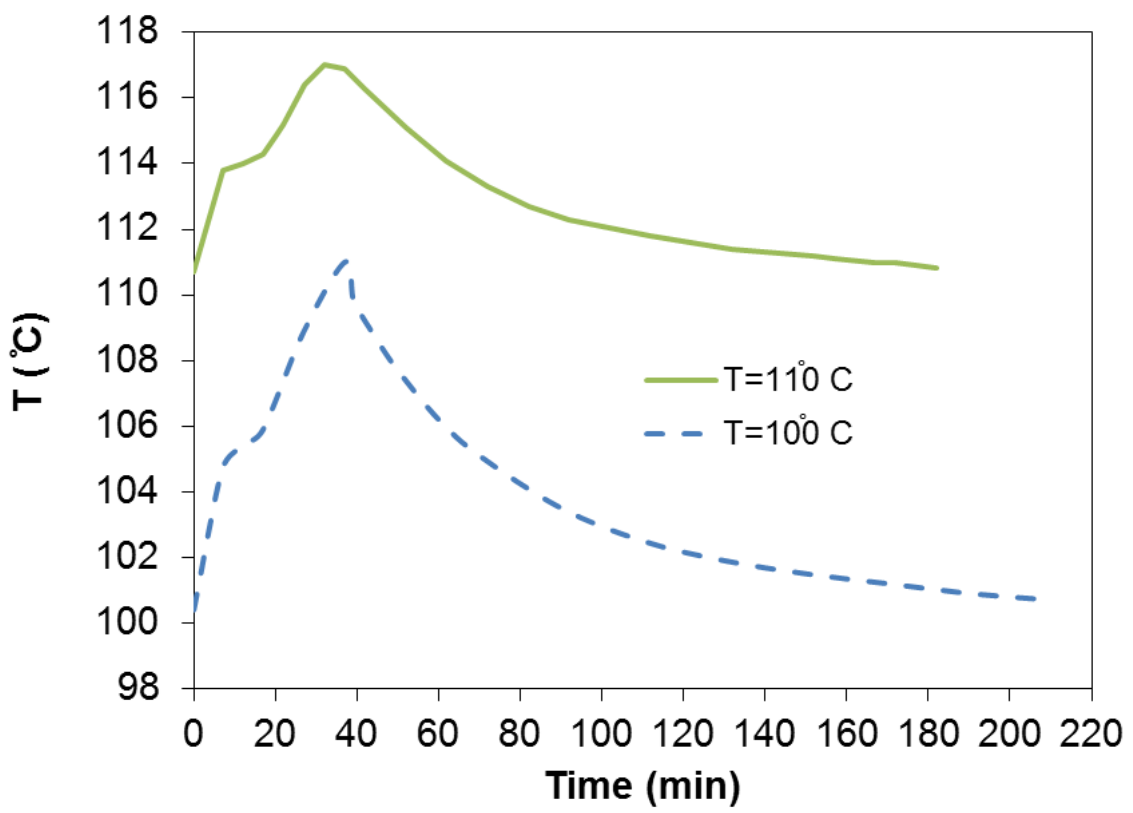

Figure 4.7 Variation of temperature with time in the middle of column read from (J-111).

As it was explained earlier, equation (4.11) was applied to simulate the water breakthrough curves at various operating conditions. The simulated breakthrough curves for the experimental runs at temperatures $100,105,110^{\circ} \mathrm{C}$ are presented in Figure 4.8. The obtained values for $\mathrm{R}^{2}$ at 100,105 , and $110^{\circ} \mathrm{C}$ were $0.99,0.98$, and 0.98 , respectively. The results show that the model accurately described the experimental breakthrough curves. The deviation can be attributed to the assumptions of the model (isothermal condition, ignorance of axial dispersion and liner behavior of adsorption isotherms).

The obtained values of the overall mass transfer coefficient $\mathrm{k}_{\mathrm{LDF}}$, presented in Table 4.6, increased from 2.9 to $4\left(\times 10^{3} 1 / \mathrm{s}\right)$ as the temperature was elevated from 100 to $110^{\circ} \mathrm{C}$. This indicates that the mass transfer rate increased as the temperature was increased. This is reflected by the slight increase in the slope of water breakthrough curves as can be seen in Figure 4.8 (b). The larger slope suggests a higher mass transfer rate (Chang et al., 2006c).

The overall mass transfer coefficient obtained from the modeling was further used to calculate the overall mass transfer resistance using equation (4.17). The calculated values for 
different resistances are presented in Table 4.6. The results show that the overall, the external and the internal mass transfer resistances, decreased as the temperature was increased. Simo and his co-workers (Simo et al., 2009) reported the similar decreasing trend of the resistances with an increase in the temperature for water adsorption on molecular sieves.

From Table 4.6 can be seen that more than $98 \%$ of the overall mass transfer resistance was due to the internal region, which indicates that the internal mass transfer resistances governed the adsorption process.

Table 4.6. Mass-transfer coefficients for different temperatures with particle size $0.425-1.18 \mathrm{~mm}$ and $\mathrm{P}_{\mathrm{w}}=24 \mathrm{kPa}$.

\begin{tabular}{cccccccccc}
\hline $\mathrm{T}\left({ }^{\circ} \mathrm{C}\right)$ & $\begin{array}{c}\mathrm{D}_{\mathrm{m}} \times 10^{6} \\
\left(\mathrm{~m}^{2} / \mathrm{s}\right)\end{array}$ & $\mathrm{Re}$ & $\mathrm{Sc}$ & $\mathrm{Sh}$ & $\begin{array}{c}\mathrm{k}_{\mathrm{LDF}} \\
\left(\times 10^{2} 1 / \mathrm{s}\right)\end{array}$ & $\begin{array}{c}\mathrm{k}_{\mathrm{c}} \\
(\times 10 \mathrm{~m} / \mathrm{s})\end{array}$ & $\begin{array}{c}\mathrm{R}_{\mathrm{T}} \\
(\mathrm{s})\end{array}$ & $\begin{array}{c}\mathrm{R}_{\mathrm{ex}} \\
(\mathrm{s})\end{array}$ & $\begin{array}{c}\mathrm{R}_{\text {in }} \\
(\mathrm{s})\end{array}$ \\
\hline 100 & 9.03 & 3.57 & 0.33 & 3.64 & 0.29 & 0.64 & 370.37 & 0.36 & 370.01 \\
105 & 9.28 & 3.51 & 0.33 & 3.62 & 0.39 & 0.65 & 256.41 & 0.26 & 256.15 \\
110 & 9.52 & 3.45 & 0.33 & 3.61 & 0.40 & 0.67 & 250.00 & 0.20 & 249.80 \\
\hline
\end{tabular}



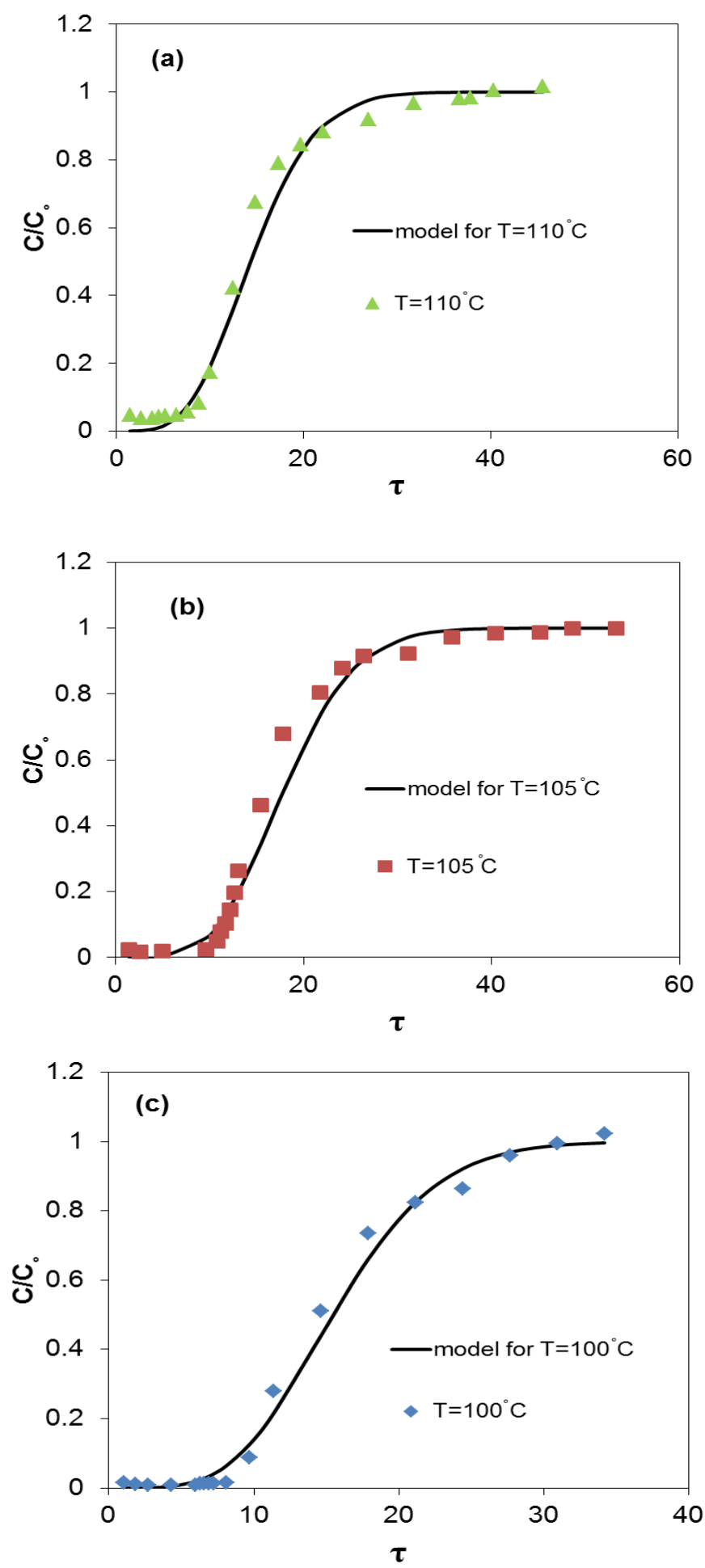

Figure 4.8 Simulation of water breakthrough curves at (a) $110^{\circ} \mathrm{C}$, (b) $105^{\circ} \mathrm{C}$, (c) $100^{\circ} \mathrm{C}$.

Operating conditions: $\mathrm{P}_{\mathrm{w}}=24 \mathrm{kPa}, \mathrm{d}_{\mathrm{p}}=0.425-1.18 \mathrm{~mm}, \mathrm{u}_{0} \approx 0.9 \mathrm{~cm} / \mathrm{s} . \tau$ is the dimensionless time coordinate corrected for displacement $\left(\tau=k\left(t-\frac{z}{u}\right)\right)$. 


\subsubsection{Feed Concentration Effect}

The effect of water/ethanol feed concentration on adsorption performance was investigated by varying the water/ethanol partial pressure in the feed stream at temperature $110^{\circ} \mathrm{C}$, total pressure $243 \mathrm{kPa}$ and superficial velocity $0.9 \mathrm{~cm} / \mathrm{s}$. Ethanol production profiles and water breakthrough curves for runs with different feed concentrations are shown in Figure 4.9. The calculated values for water and ethanol uptake at breakthrough and equilibrium are listed in Table 4.7.

From Figure 4.9 (a) can be seen that the breakthrough time decreased as the water concentration was increased in the feed stream. Breakthrough times of 42, 30.6, and 21.3 min were achieved for experimental runs with water partial pressure 24, 45, and $85 \mathrm{kPa}$, respectively. The corresponding ethanol productions (with concentration over $99 \mathrm{wt} \% \mathrm{EtOH}$ ) were 4, 2.1, and 1.3 (mol EtOH/kg adsorbent) indicating decreased $99 \mathrm{wt} \%$ ethanol production as the ethanol partial pressure in the feed stream was decreased (see Table 4.7).

It can be seen from the water breakthrough curves in Figure 4.9 (b) that an increase in water partial pressure of the feed stream (corresponding to higher water content in the feed) resulted in an increase in the slope of the profiles. This is indicative of a higher mass transfer rate. The same information can be obtained from the temperature profiles in Figure 4.10, where higher and steeper temperature curves correspond to runs with more water content in the feed stream and higher water uptake. This behavior was expected due to the exothermic nature of adsorption processes.

Table 4.7. Experimental results of water and ethanol adsorption on canola meal at $\mathrm{T}=110^{\circ} \mathrm{C}$, $P_{\text {total }}=243 \mathrm{kPa}, \mathrm{d}_{\mathrm{p}}=0.43-1.18 \mathrm{~mm}$.

\begin{tabular}{|c|c|c|c|c|c|c|c|c|c|c|}
\hline \multicolumn{4}{|c|}{ Operating conditions } & \multicolumn{3}{|c|}{ Equilibrium adsorption } & \multicolumn{4}{|c|}{$\begin{array}{l}\text { Adsorption until breakthrough point } \\
(99 \% \text { wt EtOH) }\end{array}$} \\
\hline $\begin{array}{c}\mathrm{T} \\
\left({ }^{\circ} \mathrm{C}\right)\end{array}$ & $\begin{array}{c}\mathrm{u}_{0} \\
(\mathrm{~cm} / \mathrm{s})\end{array}$ & $\begin{array}{c}\mathrm{Pw} \\
(\mathrm{kPa})\end{array}$ & $\begin{array}{c}\mathrm{P}_{\mathrm{Et}} \\
(\mathrm{kPa})\end{array}$ & $\begin{array}{c}\mathrm{H}_{2} \mathrm{O} \\
\text { uptake* }\end{array}$ & $\begin{array}{c}\text { EtOH } \\
\text { uptake* }\end{array}$ & $\alpha^{* *}$ & $\begin{array}{l}\mathrm{H}_{2} \mathrm{O} \\
\text { uptake* }\end{array}$ & $\begin{array}{c}\text { EtOH } \\
\text { uptake* }\end{array}$ & $\alpha^{* *}$ & $\begin{array}{c}\mathrm{EtOH} \\
\text { mass } * * *\end{array}$ \\
\hline 110 & 0.9 & 24 & 178 & 1.10 & 2.52 & 3.34 & 0.58 & 1.16 & 3.65 & 4.0 \\
\hline 110 & 0.9 & 45 & 160 & 2.03 & 1.64 & 4.38 & 0.89 & 0.99 & 3.17 & 2.1 \\
\hline 110 & 0.9 & 85 & 125 & 4.31 & 1.59 & 4.04 & 1.32 & 0.64 & 3.10 & 1.3 \\
\hline
\end{tabular}



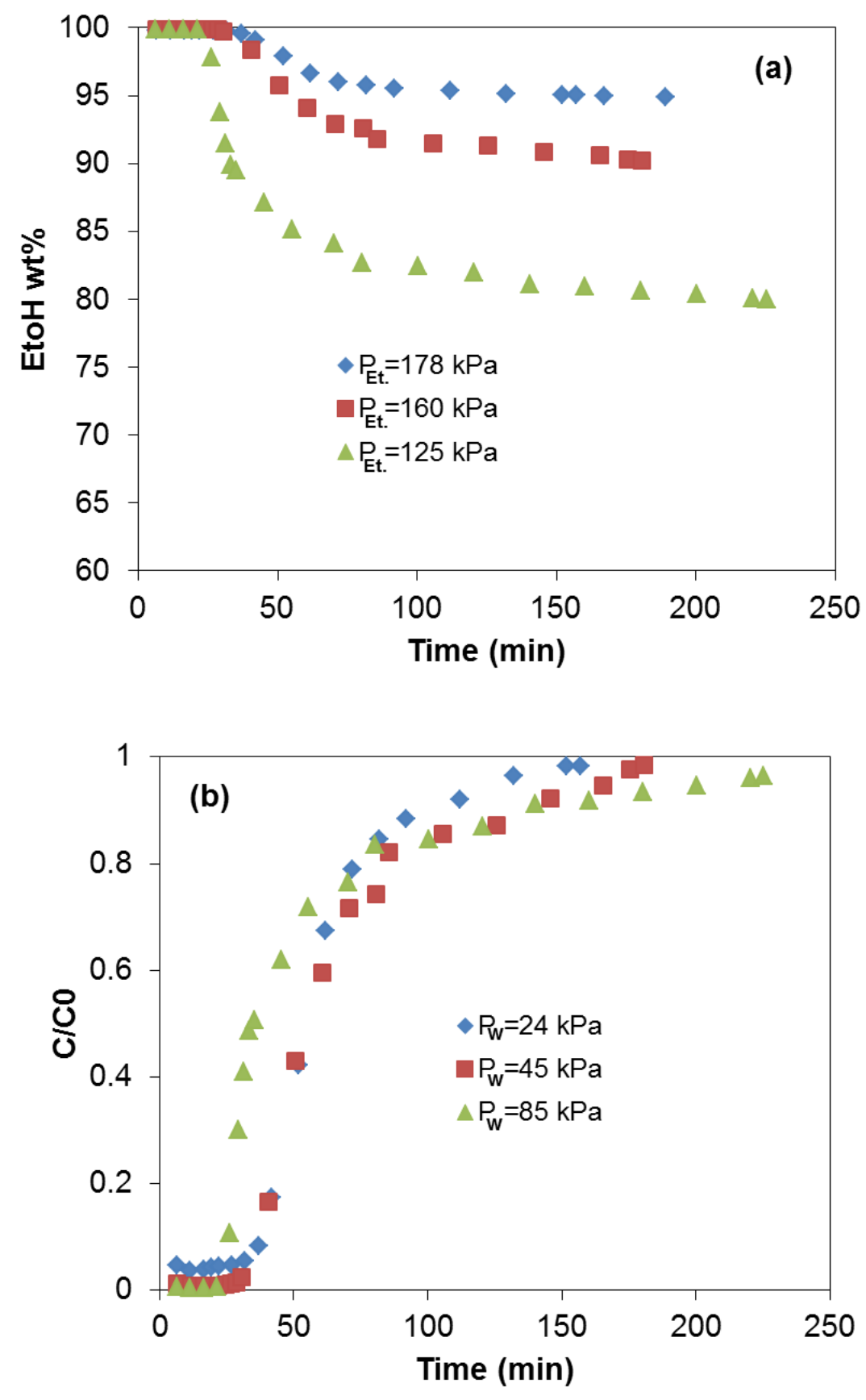

Figure 4.9 (a) Ethanol production profiles, (b) Water breakthrough curves. Operating conditions: $\mathrm{T}=110^{\circ} \mathrm{C}, \mathrm{u}_{0}=0.9 \mathrm{~cm} / \mathrm{s}, \mathrm{d}_{\mathrm{p}}=0.425-1.18 \mathrm{~mm}$. 


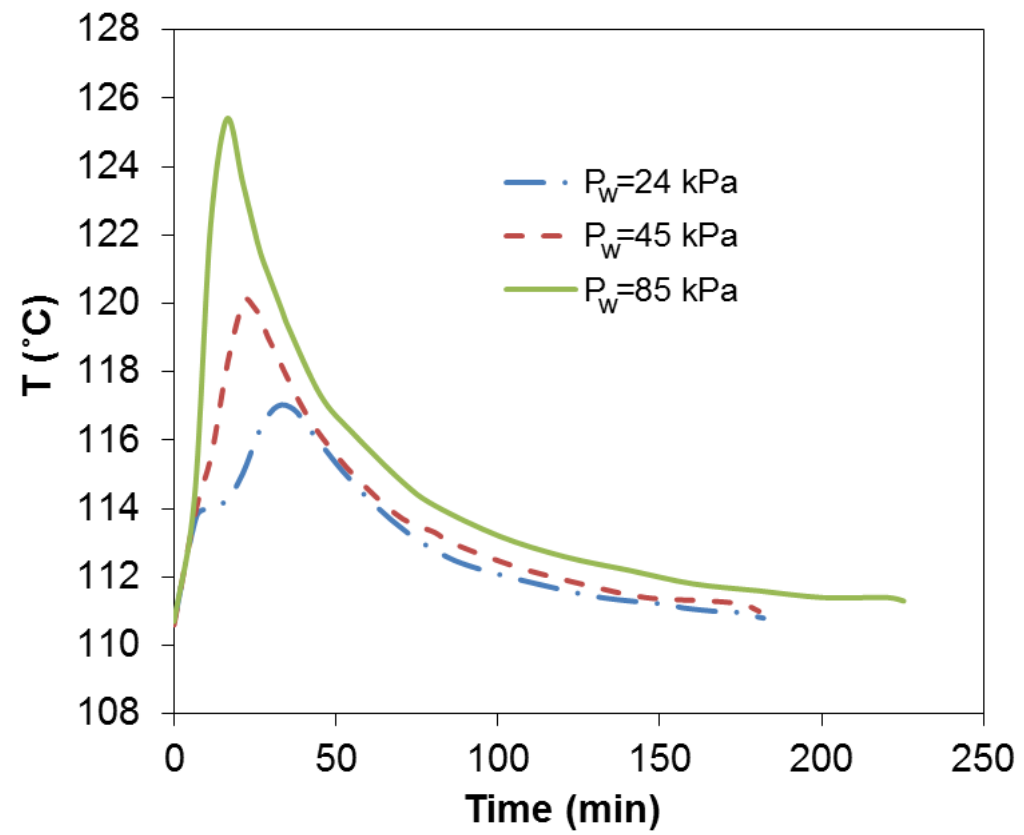

Figure 4.10 Temperature profiles at middle of column read from (J-111) for runs with different water partial pressure.

Table 4.7, shows that the water uptake at breakthrough increases as the water content is increased in the feed stream, while the ethanol uptake decreases. At breakthrough, water uptake of $0.58,0.89$, and 1.32 (mol/ $/ \mathrm{kg}$ adsorbent) was obtained at runs with water partial pressure of 24 , 45 , and $85 \mathrm{kPa}$. In case of ethanol uptake at breakthrough, corresponding values were 1.16, 0.99, and 0.64 (mol/kg adsorbent), respectively. At equilibrium, higher values for water and ethanol uptake were achieved compared to that at breakthrough point. In addition, an increase was observed in separation factor at equilibrium as the water concentration was increased in the feed stream, but it is insignificant.

The simulation of water breakthrough curves using equation (4.11), for runs with different water content, is shown in Figure 4.11. The calculated regression coefficient $\mathrm{R}^{2}$ for runs with water partial pressure of 24,45 , and $85 \mathrm{kPa}$, corresponding to 5,10 and $21 \mathrm{wt} \%$ water, were 0.99, 0.97, and 0.89, respectively. It is evident that the simulation does not give a good approximation as the water concentration is increased in the feed stream. Similar results were reported by Chang and his co-workers (Chang et al., 2006c) stating that Klinkenberg's model does not give a satisfactory fit for runs with feed water content over $12 \mathrm{wt} \%$. 
Table 4.8, shows the determined overall mass transfer coefficient $\mathrm{k}_{\mathrm{LDF}}$ for different runs at temperature $110^{\circ} \mathrm{C}$. Recall that the values for $\mathrm{k}_{\mathrm{LDF}}$ are calculated from the simulations. As mentioned earlier, equation (4.11) did not fit the experimental data well for the run with water partial pressure of $85 \mathrm{kPa}$. Therefore, $\mathrm{k}_{\mathrm{LDF}}=1.7\left(\times 10^{3} 1 / \mathrm{s}\right)$ cannot be used to calculate the mass transfer resistances for this run. For runs with water partial pressure of 24 and $45 \mathrm{kPa}$, values of 4 and $4.3\left(\times 10^{3} 1 / \mathrm{s}\right)$ were obtained for $\mathrm{k}_{\mathrm{LDF}}$, respectively. The increase in the overall mass transfer coefficient $\mathrm{k}_{\mathrm{LDF}}$ at higher water content led to a decrease in the overall mass transfer resistance which resulted in an increase in the adsorption rate. This was confirmed by the increasing slope of the water breakthrough curves as the water content in the feed stream was increased (Figure 4.9 b). Similar results were reported by Simo et al., (2009) stating that the overall mass transfer coefficient of water adsorption on zeolite $3 \mathrm{~A}$ increased with an increase in water concentration of the vapor stream.

As it can be seen from Table 4.8, the molecular diffusivity, $\mathrm{D}_{\mathrm{m}}$, of water in the gas mixture increased with an increase in the water content in the vapor stream. This caused the external mass transfer coefficient $\mathrm{k}_{\mathrm{c}}$ to rise from 0.062 to $0.067 \mathrm{~m} / \mathrm{s}$ due to the fact that the external mass transfer coefficient is proportional to the molecular diffusivity (Fogler 1999).

Furthermore, a decreasing trend was observed in the external and internal mass transfer resistances as the water content in the feed stream was increased. The internal mass transfer resistance had the greater contribution to the overall mass transfer resistance compared to the external one. This again confirmed that the water adsorption process was governed by the internal mass transfer resistance.

Table 4.8. Mass-transfer coefficients for runs with different water partial pressure at $110^{\circ} \mathrm{C}$ with equilibrium constant $\mathrm{K}=157$.

\begin{tabular}{cccccccccc}
\hline $\begin{array}{c}\mathrm{P}_{\mathrm{w}} \\
(\mathrm{kPa})\end{array}$ & $\begin{array}{c}\mathrm{D}_{\mathrm{m}} \times 10^{6} \\
\left(\mathrm{~m}^{2} / \mathrm{s}\right)\end{array}$ & $\mathrm{Re}$ & $\mathrm{Sc}$ & $\mathrm{Sh}$ & $\begin{array}{c}\mathrm{k}_{\mathrm{LDF}} \\
\times 10^{2} \\
1 / \mathrm{s})\end{array}$ & $\begin{array}{c}\mathrm{k}_{\mathrm{c}} \\
(\times 10 \\
\mathrm{m} / \mathrm{s})\end{array}$ & $\mathrm{R}_{\mathrm{T}}(\mathrm{s})$ & $\mathrm{R}_{\mathrm{ex}}(\mathrm{s})$ & $\mathrm{R}_{\text {in }}(\mathrm{s})$ \\
\hline 24 & 9.53 & 3.45 & 0.33 & 3.61 & 0.40 & 0.67 & 250.00 & 0.20 & 249.80 \\
45 & 10.59 & 3.22 & 0.32 & 3.52 & 0.43 & 0.73 & 232.56 & 0.18 & 232.37 \\
\hline
\end{tabular}




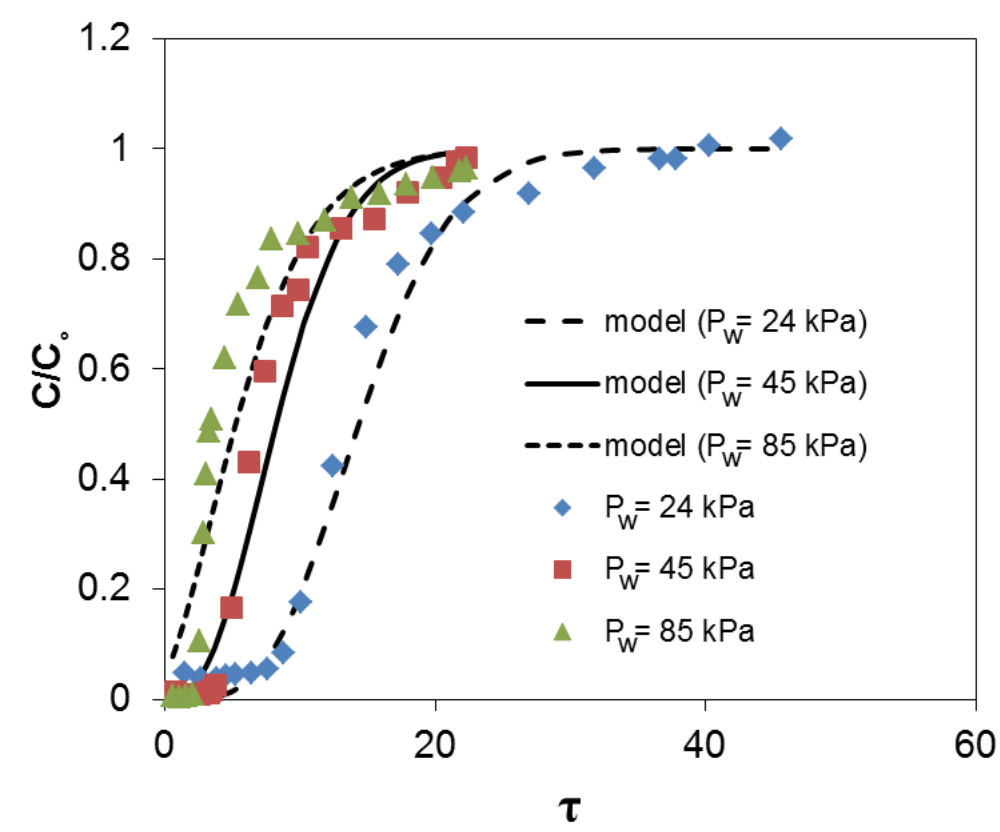

Figure 4.11 Simulation of breakthrough curves for runs with water partial pressures 24,45 and $85 \mathrm{kPa}$. Operating conditions: $\mathrm{P}_{\text {total }}=243 \mathrm{kPa}, \mathrm{d}_{\mathrm{p}}=0.425-1.18 \mathrm{~mm}, \mathrm{~T}=110^{\circ} \mathrm{C}, \mathrm{u}_{0}=0.9 \mathrm{~cm} / \mathrm{s} . \tau$ is the dimensionless time coordinate corrected for displacement $\left(\tau=k\left(t-\frac{z}{u}\right)\right)$.

\subsubsection{Pressure Effect}

To study the effects of the total pressure on the adsorption performance, two experimental runs were carried out at total pressures 243 and $312 \mathrm{kPa}$, while the partial pressure of water/ethanol, temperature, and superficial velocity were kept constant (Table 4.9).

The ethanol profiles presented in Figure 4.12 (a), show a decrease in the breakthrough time from 42 to 21 min once the total pressure was increased from 243 to $312 \mathrm{kPa}$. As a consequence, the production of ethanol (99 wt\%) dropped from 4 to 1.5 (mol EtOH/kg adsorbent).

From Figure 4.12 (b) can be observed that with an increase in pressure the slope of the water breakthrough curves did not change significantly, while the bed saturated faster. At breakthrough, the water/ethanol uptake decreased as the total pressure was increased due to the fact that the overall mass transfer resistance increased when total pressure was increased (Table 4.9). Similarly, at equilibrium, the water/ethanol uptake decreased as the total pressure was increased. Pruksathorn and Vitidsant (2009) reported similar results for 3A zeolite. 

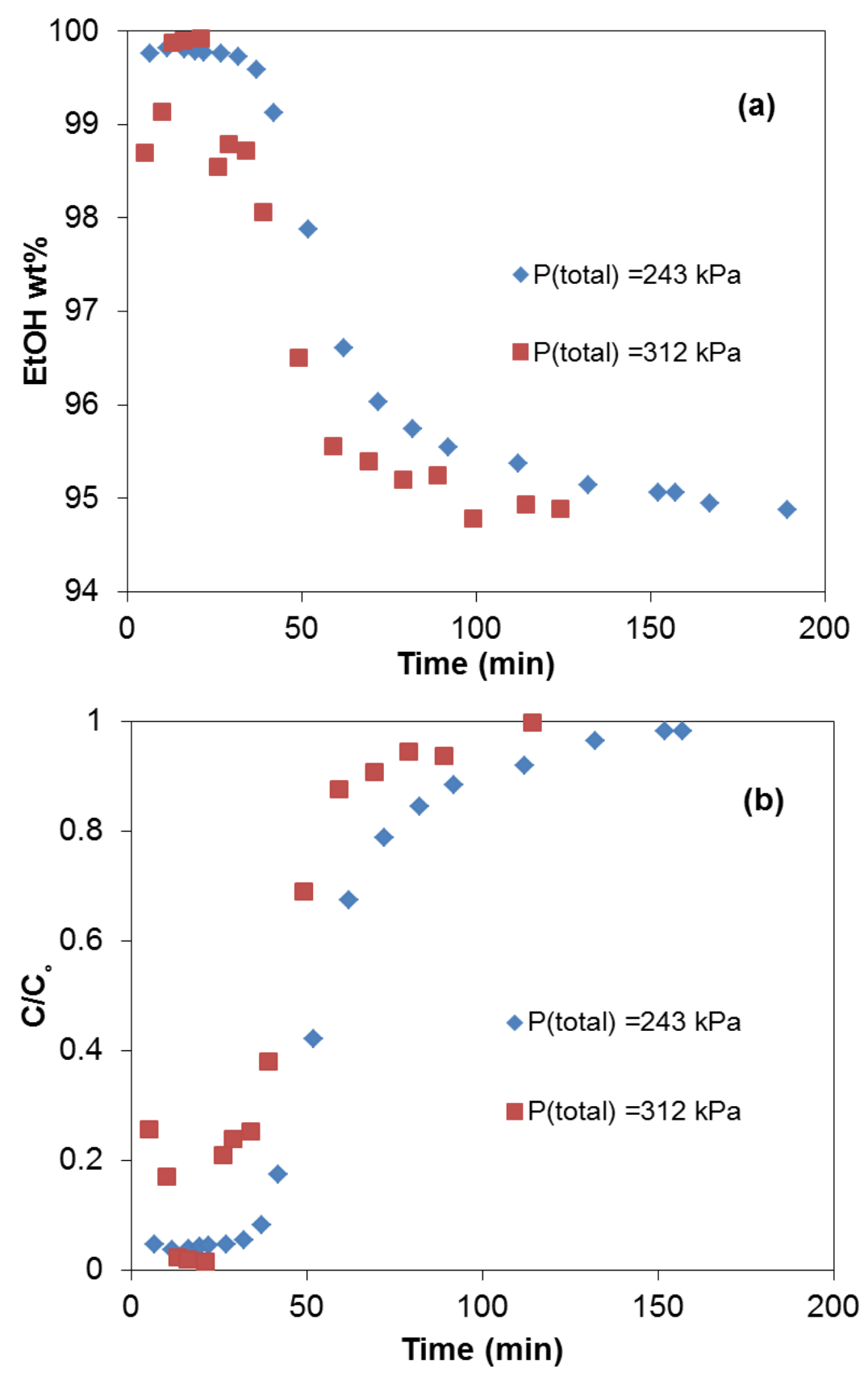

Figure 4.12 (a) Ethanol production profiles, (b) Water breakthrough curves. Operating conditions: $\mathrm{T}=110^{\circ} \mathrm{C}, \mathrm{u}_{0}=0.9 \mathrm{~cm} / \mathrm{s}, \mathrm{d}_{\mathrm{p}}=0.425-1.18 \mathrm{~mm}, \mathrm{P}_{\mathrm{w}}=24 \mathrm{kPa}$. 
Table 4.9. Experimental results of water/ethanol uptake for different total pressures at $110^{\circ} \mathrm{C}$ and $\mathrm{d}_{\mathrm{p}}=0.43-1.18 \mathrm{~mm}$.

\begin{tabular}{|c|c|c|c|c|c|c|c|c|c|c|}
\hline \multicolumn{4}{|c|}{ Operating condition } & \multicolumn{3}{|c|}{ Equilibrium adsorption } & \multicolumn{4}{|c|}{$\begin{array}{l}\text { Adsorption until breakthrough } \\
\text { point }(99 \% \text { wt EtOH) }\end{array}$} \\
\hline $\begin{array}{l}\mathrm{P}_{\text {total }} \\
(\mathrm{kPa})\end{array}$ & $\begin{array}{c}\mathrm{u}_{0} \\
(\mathrm{~cm} / \mathrm{s})\end{array}$ & $\begin{array}{c}\mathrm{Pw} \\
(\mathrm{kPa})\end{array}$ & $\begin{array}{c}\mathrm{P}_{\mathrm{Et}} \\
(\mathrm{kPa})\end{array}$ & $\begin{array}{c}\mathrm{H}_{2} \mathrm{O} \\
\text { uptake* }\end{array}$ & $\begin{array}{l}\text { EtOH } \\
\text { uptake* }\end{array}$ & $\alpha^{* *}$ & $\begin{array}{c}\mathrm{H}_{2} \mathrm{O} \\
\text { uptake* }\end{array}$ & $\begin{array}{l}\text { EtOH } \\
\text { uptake* }\end{array}$ & $\alpha^{* *}$ & $\begin{array}{c}\mathrm{EtOH} \\
\text { mass } \\
* * *\end{array}$ \\
\hline 243 & 0.9 & 24 & 178 & 1.10 & 2.52 & 3.34 & 0.58 & 1.16 & 3.65 & 4.0 \\
\hline 312 & 0.9 & 24 & 178 & 0.68 & 1.49 & 3.25 & 0.30 & 0.77 & 2.87 & 1.5 \\
\hline
\end{tabular}
point (mol EtOH/kg adsorbent).

Figure 4.13, depicts the simulation of water breakthrough curves for runs at total pressure of 243 and $312 \mathrm{kPa}$. The corresponding values for $\mathrm{R}^{2}$ are 0.99 and 0.95 . By modeling water breakthrough curves, it was observed that as the total pressure was increased the overall mass transfer coefficient decreased and consequently the overall mass transfer resistance increased. Table 4.10 also shows that the external mass transfer coefficient, $\mathrm{k}_{\mathrm{c}}$, decreased with an increase in the total pressure. This happened because $\mathrm{k}_{\mathrm{c}}$ is proportional to the molecular diffusivity of water in the gas mixture which in turn is inversely proportional to total pressure. This led the external mass transfer resistance to increase as total pressure was increased.

Simo and his co-workers studied water/ethanol adsorption on $3 \mathrm{~A}$ zeolite and found that the overall mass transfer coefficient decreased as the total pressure was increased. Moreover, they reported that approximately $90 \%$ of the overall mass transfer resistance at elevated pressure is due to the internal regions (Simo et al., 2009), which is similar to the results of this work.

Diffusion in macropores changes with alterations in total pressure, while diffusion in the micropores is independent of the total pressure (Simo et al., 2009). Molecular diffusion, Knudsen diffusion, Poiseuille flow, and surface diffusion are recognized as the mechanisms of diffusion in macropores. Among these, molecular diffusion is the only diffusion mechanism that is inversely proportional to total pressure (Simo et al., 2009; Ruthven 1984). Knudsen diffusion coefficient itself is not dependent on total pressure and Poiseuille flow is directly proportional to total pressure (Ruthven 1984). Therefore, it may be concluded that molecular diffusion in macropores is likely to govern the water adsorption rate as was concluded in Simo's work (Simo et al., 2009). 
Table 4.10. Mass transfer coefficients for different total pressures with equilibrium constant $\mathrm{K}=157$.

\begin{tabular}{cccccccccc}
\hline $\begin{array}{c}\mathrm{P}_{\text {total }} \\
(\mathrm{kPa})\end{array}$ & $\begin{array}{c}\mathrm{D}_{\mathrm{m}} \times 10^{6} \\
\left(\mathrm{~m}^{2} / \mathrm{s}\right)\end{array}$ & $\mathrm{Re}$ & $\mathrm{Sc}$ & $\mathrm{Sh}$ & $\begin{array}{c}\mathrm{k}_{\mathrm{LDF}} \\
(\times 101 / \mathrm{s})\end{array}$ & $\begin{array}{c}\mathrm{k}_{\mathrm{c}} \\
(\times 10 \mathrm{~m} / \mathrm{s})\end{array}$ & $\begin{array}{c}\mathrm{R}_{\mathrm{T}} \\
(\mathrm{s})\end{array}$ & $\begin{array}{c}\mathrm{R}_{\text {ex }} \\
(\mathrm{s})\end{array}$ & $\begin{array}{c}\mathrm{R}_{\text {in }} \\
(\mathrm{s})\end{array}$ \\
\hline 243 & 9.53 & 3.45 & 0.33 & 3.61 & 0.04 & 0.67 & 250 & 0.20 & 249.80 \\
312 & 8.12 & 3.38 & 0.40 & 3.68 & 0.03 & 0.58 & 333.33 & 0.23 & 333.10 \\
\hline
\end{tabular}

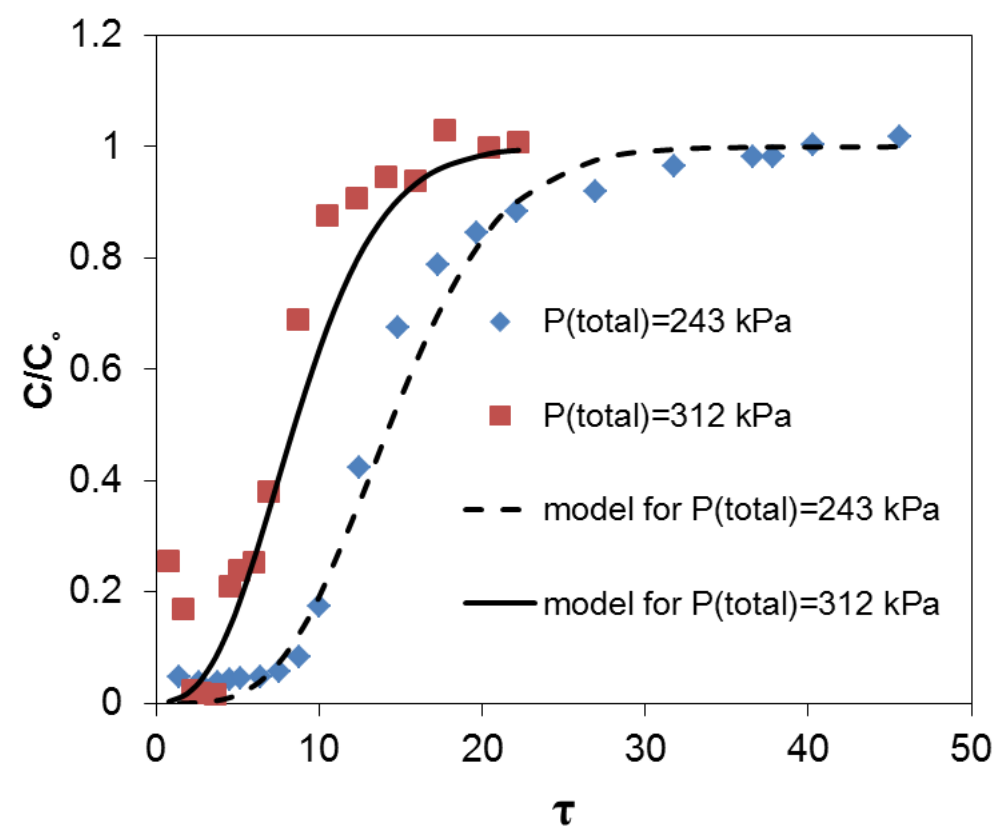

Figure 4.13 Simulation of water breakthrough curves for runs at total pressures 243 and $312 \mathrm{kPa}$. Operating conditions: $\mathrm{P}_{\mathrm{w}}=24 \mathrm{kPa}, \mathrm{d}_{\mathrm{p}}=0.425-1.18 \mathrm{~mm}, \mathrm{~T}=110^{\circ} \mathrm{C}, \mathrm{u}_{0}=0.9 \mathrm{~cm} / \mathrm{s} . \tau$ is the dimensionless time coordinate corrected for displacement $\left(\tau=k\left(t-\frac{z}{u}\right)\right)$.

\subsubsection{Particle Size Effect}

The performance of adsorption can be affected by the particle size of the adsorbents by changing the packing density, bed porosity and mass transfer resistance (Simo et al., 2009). Experimental runs using particles of sizes $0.425-1.18$ and $5 \mathrm{~mm}$ were conducted to investigate the effect of particle size on water/ethanol adsorption. The remaining operating conditions were kept constant at $\mathrm{T}=100^{\circ} \mathrm{C}, \mathrm{P}_{\text {total }}=243 \mathrm{kPa}, \mathrm{u}_{0}=0.9 \mathrm{~cm} / \mathrm{s}$, and $\mathrm{P}_{\mathrm{w}}=45 \mathrm{kPa}$.

As it can be seen from Figure 4.14 (a), the breakthrough time decreased slightly when canola meal with smaller particle size was used for ethanol dehydration. Consequently, the amount of produced ethanol (99 wt\%) slightly decreased from 3.5 (mol EtOH/kg adsorbent) for adsorbent pellets of size $5 \mathrm{~mm}$ to 3.4 for particles of size in the range $0.425-1.18 \mathrm{~mm}$ (Table 4.11). Further, the separation factors at breakthrough decreased as the adsorbent with $5 \mathrm{~mm}$ 
particle size was applied. This conforms to the results obtained by Kim et al., (2011); Vareli et al., (1998), where it was shown that adsorbents with smaller particle sizes had better separation capacity.

Water uptake at breakthrough was 1.37 (mol/ $\mathrm{kg}$ adsorbent) for a run using particles of size $0.425-1.18 \mathrm{~mm}$ and 1.49 ( $\mathrm{mol} / \mathrm{kg}$ adsorbent) for $5 \mathrm{~mm}$ pellets. In the case of ethanol, the corresponding values were 1.53 and 1.91 (mol/kg adsorbent). Similarly, a trend of slight increase in water/ethanol uptake at equilibrium was observed when the particle size was increased (Table 4.11). This increase in water/ethanol uptake could be justified by the fact that packing density raised from 499.78 to $543.17 \mathrm{~kg} / \mathrm{m}^{3}$ as the particle size was increased, since through the pellet making process canola meal particles are compressed together to prepare pellets with $5 \mathrm{~mm}$ diameter. The increase of the packing density may improve the contact between the adsorbate and the adsorbent. The fact that water uptake on $5 \mathrm{~mm}$ canola meal pellets was not reduced compared to the case of $0.425-1.18 \mathrm{~mm}$ particles is a positive result towards applying canola meal adsorbent in the industrial process for ethanol dehydration.

Table 4.11. Experimental results of water/ethanol uptake at $100^{\circ} \mathrm{C}, \mathrm{u}_{0}=0.9 \mathrm{~cm} / \mathrm{s}$ and different particle size.

\begin{tabular}{|c|c|c|c|c|c|c|c|c|c|c|}
\hline \multicolumn{4}{|c|}{ Operating condition } & \multicolumn{3}{|c|}{ Equilibrium adsorption } & \multicolumn{4}{|c|}{$\begin{array}{l}\text { Adsorption until breakthrough point } \\
\text { (99\%wt Et.) }\end{array}$} \\
\hline $\begin{array}{l}\mathrm{P}_{\text {total }} \\
(\mathrm{kPa})\end{array}$ & $\begin{array}{c}\mathrm{Pw} \\
(\mathrm{kPa})\end{array}$ & $\begin{array}{l}\mathrm{P}_{\text {Et. }} \\
(\mathrm{kPa})\end{array}$ & $\begin{array}{c}\mathrm{dp} \\
(\mathrm{mm})\end{array}$ & $\begin{array}{l}\mathrm{H}_{2} \mathrm{O} \\
\text { uptake* }\end{array}$ & $\begin{array}{c}\text { EtOH } \\
\text { uptake* }\end{array}$ & $\alpha^{* *}$ & $\begin{array}{c}\mathrm{H}_{2} \mathrm{O} \\
\text { uptake* }\end{array}$ & $\begin{array}{c}\text { EtOH } \\
\text { uptake* }\end{array}$ & $\alpha^{* *}$ & $\begin{array}{c}\mathrm{EtOH} \\
\text { mass*** }\end{array}$ \\
\hline 243 & 45 & 160 & $\begin{array}{c}0.43- \\
1.18\end{array}$ & 2.92 & 3.38 & 3.06 & 1.37 & 1.53 & 3.18 & 3.4 \\
\hline 243 & 45 & 160 & 5 & 3.38 & 4.15 & 2.95 & 1.49 & 1.91 & 2.78 & 3.5 \\
\hline
\end{tabular}



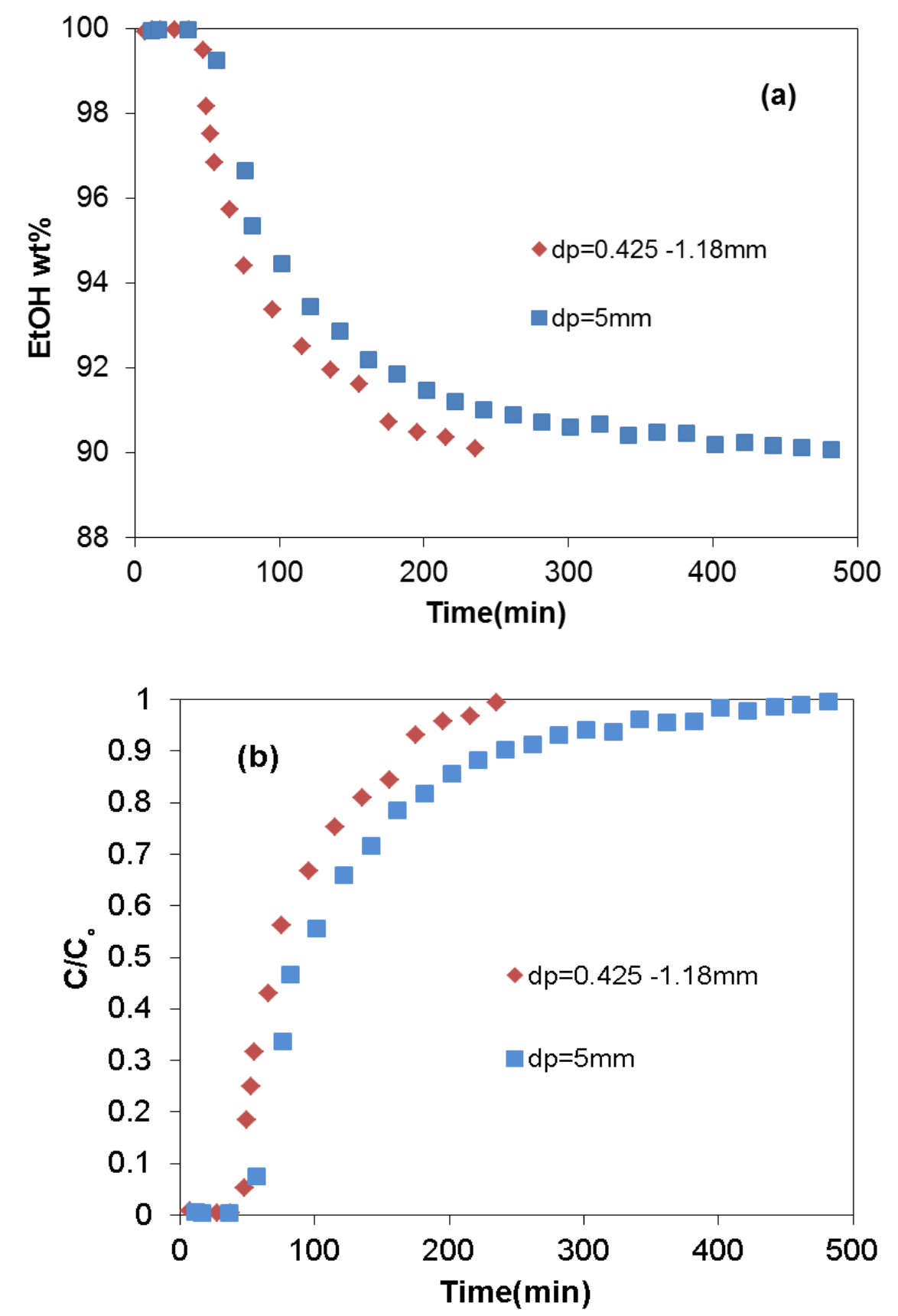

Figure 4.14 (a) Ethanol production profiles, (b) Water breakthrough curves. Operating conditions: $\mathrm{T}=100^{\circ} \mathrm{C}, \mathrm{u}_{0}=0.9 \mathrm{~cm} / \mathrm{s}$, and $\mathrm{P}_{\mathrm{w}}=45 \mathrm{kPa}$.

The simulation of water breakthrough curves for runs with different particle sizes is represented in Figure 4.15. The correlation coefficient $\mathrm{R}^{2}$ for the fitted lines was calculated to be 0.97 and 0.97 for runs with particle size of 0.425-1.18 and $5 \mathrm{~mm}$, respectively. 
The slope of water breakthrough curves slightly decreased as the particle size was increased which indicates a slight decrease in the mass transfer rate (Figure $4.14 \mathrm{~b}$ ). This decrease of the adsorption rate is due to the fact that the overall mass transfer coefficient $\mathrm{k}_{\mathrm{LDF}}$ decreased with the increasing particle size which caused an increase in the overall mass transfer resistance which is inverse proportional to $\mathrm{k}_{\mathrm{LDF}}$.

The equivalent diameter $D_{p}$ of $0.425-1.18 \mathrm{~mm}$ canola particles was calculated using equation (4.26), in which $\mathrm{D}$ was taken to be $\mathrm{D}(\mathrm{v}, 0.5)$. For the cylindrical pellets, $D_{p}$ was calculated from equation (4.27), in which D was considered to be $5 \mathrm{~mm}$. The estimated values of $\mathrm{R}_{\mathrm{p}}$ for both adsorbent types are shown in Table 4.12. The values show that increasing the particle size to $5 \mathrm{~mm}$ pellets led to a decrease in the estimated values for the external mass transfer coefficient, thus the external mass transfer resistance increased significantly. Moreover, the internal mass transfer resistance also increased by increasing the adsorbent size. The contribution of the internal to the overall mass transfer resistance was much higher than the external one, thus the internal mass transfer resistance was again recognized as the mechanism governing the adsorption process. Similar results were reported by Simo et al., (2009) where by decreasing the particle size of zeolite to a half the overall mass transfer resistance increased up to 5 times.

Table 4.12. Mass transfer coefficients for runs at $100^{\circ} \mathrm{C}$ with different particle size.

\begin{tabular}{cccccccccc}
\hline $\begin{array}{c}\mathrm{R}_{\mathrm{p}} \\
(\mathrm{mm})\end{array}$ & $\begin{array}{c}\mathrm{D}_{\mathrm{m}} \times 10^{6} \\
\left(\mathrm{~m}^{2} / \mathrm{s}\right)\end{array}$ & $\mathrm{Re}$ & $\mathrm{Sc}$ & $\mathrm{Sh}$ & $\begin{array}{c}\mathrm{k}_{\mathrm{LDF}} \\
\left(\times 10^{2} 1 / \mathrm{s}\right)\end{array}$ & $\begin{array}{c}\mathrm{k}_{\mathrm{c}} \\
(\times 10 \mathrm{~m} / \mathrm{s})\end{array}$ & $\begin{array}{c}\mathrm{R}_{\mathrm{T}} \\
(\mathrm{s})\end{array}$ & $\begin{array}{c}\mathrm{R}_{\mathrm{ex}} \\
(\mathrm{s})\end{array}$ & $\begin{array}{c}\mathrm{R}_{\mathrm{in}} \\
(\mathrm{s})\end{array}$ \\
\hline 0.26 & 10.03 & 3.34 & 0.32 & 3.56 & 0.13 & 0.70 & 769.23 & 0.33 & 768.90 \\
5.73 & 10.03 & 41.13 & 0.32 & 9.01 & 0.09 & 0.16 & 1111.11 & 16.51 & 1094.59 \\
\hline
\end{tabular}




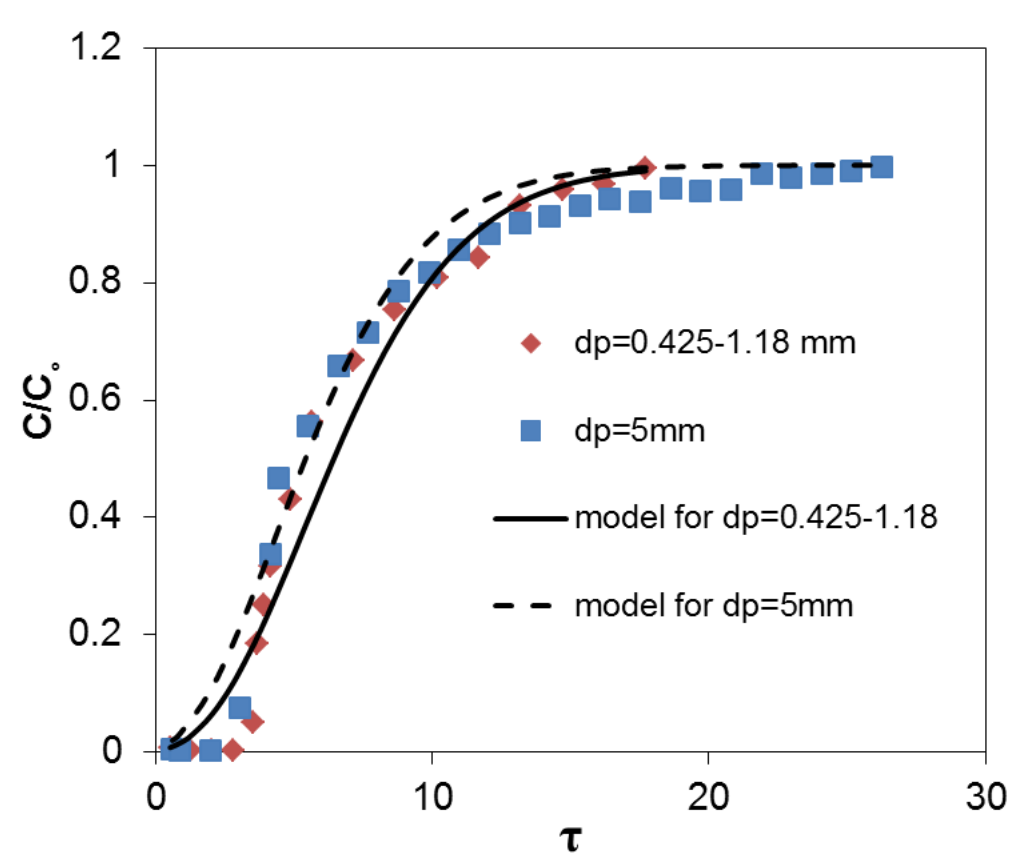

Figure 4.15 Simulation of water breakthrough curves for runs at different particles size. Operating conditions: $\mathrm{P}_{\mathrm{w}}=45 \mathrm{kPa}, \mathrm{T}=100^{\circ} \mathrm{C}, \mathrm{u}_{0}=0.9 \mathrm{~cm} / \mathrm{s} . \tau$ is the dimensionless time coordinate corrected for displacement $\left(\tau=k\left(t-\frac{z}{u}\right)\right)$.

\subsubsection{Superficial Velocity Effect}

To investigate the effect of superficial velocity on the adsorption performance, both feed and gas flow rate were increased up to 1.5 times. As a result, the superficial velocity increased from 0.9 to $1.5 \mathrm{~cm} / \mathrm{s}$ while the other operating conditions remained constant.

Water breakthrough curves and ethanol production profiles are shown in Figure 4.16. From the ethanol production profile in Figure 4.16 (a), it is evident that breakthrough (99 wt\% EtOH) occurred earlier when the flow rates were increased. Consequently, the amount of produced ethanol (99 wt\%) was reduced. The ethanol production (99 wt\%) was 4 (mol EtOH/kg adsorbent) for a run at superficial velocity $0.9 \mathrm{~cm} / \mathrm{s}$, while it dropped to $2.7(\mathrm{~mol} \mathrm{EtOH} / \mathrm{kg}$ adsorbent) at $1.5 \mathrm{~cm} / \mathrm{s}$ superficial velocity (see Table 4.13 ).

Figure 4.16 (b) shows that the breakthrough time decreased from 42 to $31 \mathrm{~min}$ and the bed saturated faster as the superficial velocity was increased. The results conformed to the ones obtained by Wang et al., (2010), where an increase in the vapor superficial velocity led to a decrease in concentration of ethanol in the product. In addition, curves became sharper which 
may be explained by the fact that film mass transfer resistance decreases by increasing flow rate (Simo et al., 2009).

Table 4.13 summarizes the water/ethanol uptake at breakthrough and equilibrium points for runs at different superficial velocity. Water uptake of 0.58 and ethanol uptake of 1.16 (mol/kg adsorbent) were achieved at breakthrough point for a run at $0.9 \mathrm{~cm} / \mathrm{s}$. The corresponding values for a run at velocity $1.5 \mathrm{~cm} / \mathrm{s}$ were 0.495 and 1.15 (mol/ $\mathrm{kg}$ adsorbent).

From Table 4.13, at both runs, it can be noticed that separation factors at breakthrough are slightly greater than the ones at equilibrium. This is because the extent of increase in the ethanol uptake in comparison to the uptake of water is much greater at equilibrium than that at breakthrough point. The calculated separation factors at breakthrough and equilibrium were 3.65 and 3.34 for the run at superficial velocity $0.9 \mathrm{~cm} / \mathrm{s}$. The corresponding values for $1.5 \mathrm{~cm} / \mathrm{s}$ run were 3.07 and 2.81 .

Table 4.13. Experimental results of water/ethanol uptake for different superficial velocities at $\mathrm{T}=110^{\circ} \mathrm{C}$ and $\mathrm{P}_{\text {total }}=243 \mathrm{kPa}$.

\begin{tabular}{ccccccccccc}
\hline \multicolumn{3}{c}{ Operating condition } & \multicolumn{3}{c}{ Equilibrium adsorption } & \multicolumn{3}{c}{$\begin{array}{c}\text { Adsorption until breakthrough point } \\
(99 \% \text { wt EtOH })\end{array}$} \\
\hline $\begin{array}{c}\mathrm{u}_{0} \\
(\mathrm{~cm} / \mathrm{s})\end{array}$ & $\begin{array}{c}\mathrm{Pw} \\
(\mathrm{kPa})\end{array}$ & $\begin{array}{c}\mathrm{P}_{\mathrm{Et}} \\
(\mathrm{kPa})\end{array}$ & $\begin{array}{c}\mathrm{dp} \\
(\mathrm{mm})\end{array}$ & $\begin{array}{c}\mathrm{H}_{2} \mathrm{O} \\
\text { uptake* }\end{array}$ & $\begin{array}{c}\text { EtOH } \\
\text { uptake* }\end{array}$ & $\alpha$ & $\begin{array}{c}\mathrm{H}_{2} \mathrm{O} \\
\text { uptake* }\end{array}$ & $\begin{array}{c}\text { EtOH } \\
\text { uptake* }\end{array}$ & $\alpha$ & $\begin{array}{c}\text { EtOH } \\
\text { mass** }\end{array}$ \\
\hline 0.9 & 24 & 178 & $\begin{array}{c}0.43- \\
1.18\end{array}$ & 1.10 & 2.52 & 3.34 & 0.58 & 1.16 & 3.65 & 4 \\
1.50 & 24 & 178 & $\begin{array}{c}0.43- \\
1.18\end{array}$ & 0.94 & 2.40 & 2.81 & 0.49 & 1.15 & 3.07 & 2.7 \\
\hline
\end{tabular}

*mol/kg adsorbent; **ethanol production (99 wt\%) until breakthrough point (mol EtOH/kg adsorbent). 

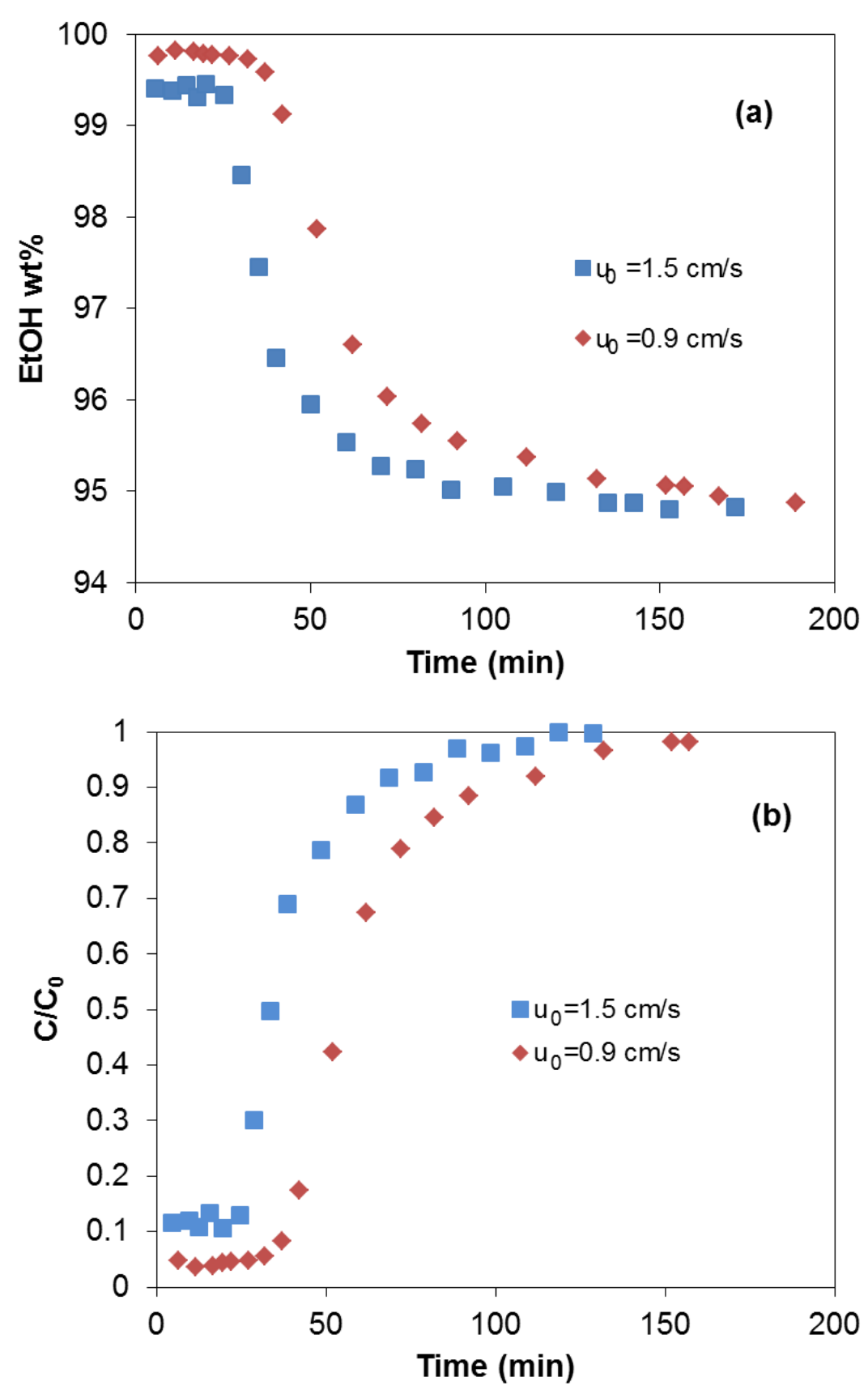

Figure 4.16 (a) Ethanol production profiles, (b) Water breakthrough curves. Operating conditions: $\mathrm{T}=110^{\circ} \mathrm{C}, \mathrm{d}_{\mathrm{p}}=0.425-1.18 \mathrm{~mm}, \mathrm{P}_{\mathrm{w}}=24 \mathrm{kPa}$.

The simulation of water breakthrough curves at runs with superficial velocity of 0.9 and $1.5 \mathrm{~cm} / \mathrm{s}$ is represented in Figure 4.17. The calculated values as $\mathrm{R}^{2}$ were 0.99 and 0.98 for velocities 0.9 and $1.5 \mathrm{~cm} / \mathrm{s}$, respectively. The values for the parameters in the proposed mathematical model were calculated and summarized in Table 4.14. 
Table 4.14 shows the overall mass transfer coefficient increased by increasing the superficial velocity which caused the overall mass transfer resistance to decrease. From the calculated values of the mass transfer resistances for both runs, it can be observed that $\mathrm{R}_{\mathrm{T}} \approx \mathrm{R}_{\text {in }}$ $\gg \mathrm{R}_{\mathrm{ex}}$. This means that the contribution of the external mass transfer resistance to the overall one is not significant even at elevated flow rates, thus the internal mass transfer resistance governs the adsorption process.

Table 4.14. Mass transfer coefficients for different superficial velocities with $K=157$.

\begin{tabular}{cccccccccc}
\hline $\mathrm{u}_{0}(\mathrm{~cm} / \mathrm{s})$ & $\begin{array}{c}\mathrm{D}_{\mathrm{m}} \times 10^{6} \\
\left(\mathrm{~m}^{2} / \mathrm{s}\right)\end{array}$ & $\mathrm{Re}$ & $\mathrm{Sc}$ & $\mathrm{Sh}$ & $\begin{array}{c}\mathrm{k}_{\mathrm{LDF}} \\
\left(\times 10^{2} 1 / \mathrm{s}\right)\end{array}$ & $\begin{array}{c}\mathrm{k}_{\mathrm{c}} \\
(\times 10 \mathrm{~m} / \mathrm{s})\end{array}$ & $\begin{array}{c}\mathrm{R}_{\mathrm{T}} \\
(\mathrm{s})\end{array}$ & $\begin{array}{c}\mathrm{R}_{\mathrm{ex}} \\
(\mathrm{s})\end{array}$ & $\begin{array}{c}\mathrm{R}_{\mathrm{in}} \\
(\mathrm{s})\end{array}$ \\
\hline 0.9 & 9.53 & 3.45 & 0.33 & 3.61 & 0.40 & 0.67 & 250.00 & 0.20 & 249.80 \\
1.50 & 9.55 & 5.80 & 0.33 & 4.19 & 0.43 & 0.78 & 232.56 & 0.17 & 232.39 \\
\hline
\end{tabular}

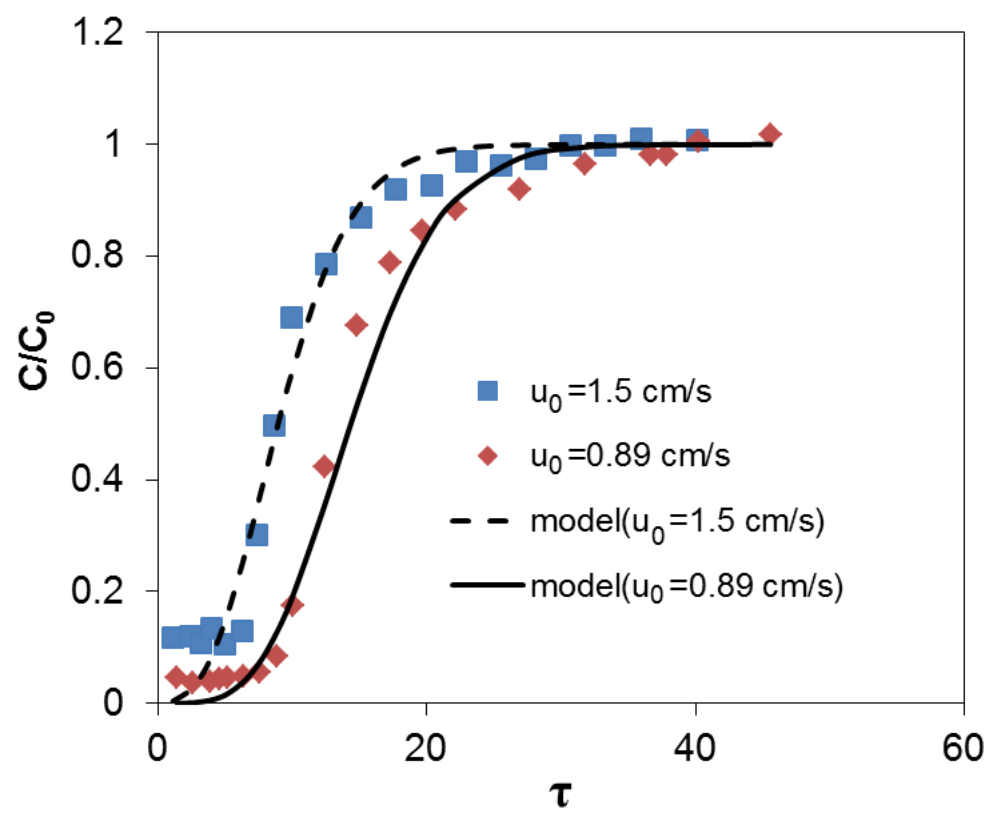

Figure 4.17 Simulation of breakthrough curve for runs at $\mathrm{u}_{0}$ of 1.5 and $0.9 \mathrm{~cm} / \mathrm{s}$. Operating conditions: $\mathrm{P}_{\mathrm{w}}=24 \mathrm{kPa}, \mathrm{d}_{\mathrm{p}}=0.425-1.18 \mathrm{~mm}, \mathrm{~T}=110^{\circ} \mathrm{C} . \tau$ is the dimensionless time coordinate corrected for displacement $\left(\tau=k\left(t-\frac{z}{u}\right)\right)$.

\subsection{Equilibrium Adsorption}

Breakthrough runs were carried out and equilibrium data for adsorbable components were calculated through the mass balance once the bed reached the equilibrium conditions. As mentioned earlier, at equilibrium, the concentration of water in the outlet becomes equal to the 
one in the feed stream (saturation condition) and also the bed temperature has restored its initial value. Indeed, the bed was initially clean and then exposed to the vapor feed. After the bed reached equilibrium, the water uptake was calculated as the ratio of the difference between the accumulated mass of water in the effluent and total mass of water introduced to the column, and the dry net weight of the canola meal in the column.

\subsubsection{Adsorption Isotherm Modeling}

The equilibrium isotherms for water adsorption on canola meal were generated by plotting water uptake versus water activity at different temperatures. There are a number of models describing water adsorption phenomena including Dubinin-Polanyi (potential theory), Brunauer-Emmelt-Teller (BET), Guggenheim-Andrson-de-Boer (GAB) and Frenkel-Halsey-Hill (FHH) model (Al-Asheh et al., 2009; Ruthven 1984). The BET model is a two-parameter isotherm which covers water activity $a_{w}$ from 0 up to 0.3 or 0.4 (Timmermann et al., 2001). Considering that the experiments in this work were carried out in a wider range of water activity (0.23-0.84), the BET was not used to simulate the experimental data of water adsorption on canola meal. However, the rest of the models were used and below follows a description of how they were applied.

The GAB isotherm is a three-parameter model defined based on the same theory as of the BET model, but the GAB model covers a wider range of water activity from 0 to 0.9 (Al-Asheh et al., 2009; Timmermann et al., 2001). The BET isotherm is applied for multilayer adsorption and postulates that sorbate molecules in the second and subsequent layers behave the same as saturated liquid. In the BET model, the equilibrium constant for the first layer of adsorbed molecules is considered to be different from the subsequent layers due to the fact that sorbent molecules in the first layer are in contact with the surface of the adsorbent and other molecules in the next layer (Ruthven 1984). The GAB model introduced a second well-differentiated sorption stage for the adsorbate which brings an additional degree of freedom and consequently an additional parameter, compared to the BET model (Al-Asheh et al., 2009). The GAB equation is:

$X=\frac{X_{m} \dot{C} \dot{K} a_{w}}{\left[\left(1-\dot{K} a_{w}\right)\left(1+(\dot{C}-1) \hat{K} a_{w}\right)\right]}$

where $X$ is the water uptake on the adsorbent (mol $\mathrm{H}_{2} \mathrm{O} / \mathrm{kg}$ adsorbent), $X_{m}$ is the monolayer capacity (mol $\mathrm{H}_{2} \mathrm{O} / \mathrm{kg}$ adsorbent), $a_{w}$ is the water activity, $\dot{C}$ is the energy constant related to the 
difference between the chemical of the adsorbate in the upper layers and in the monolayer, $K$ is a dimensionless energy constant (Al-Asheh et al., 2009; Zhang and Qiu 2007). The water activity $a_{w}$ was calculated by:

$a_{w}=\frac{P_{w}}{P^{s}}$

where $P_{w}$ is the partial pressure of water in the feed stream and $P^{s}$ is the saturation pressure of water at the isotherm temperature. $P^{S}$ was determined by the Antoine equation:

$\ln P^{s}=A-\frac{B}{T-C}$

where $A, B$, and $C$ are constants. The values of $A, B$, and $C$ for water vapor are $16.29,3816.44$, and 46.13, respectively (Timmermann et al., 2001).

The GAB model was applied to the experimental data and the results are shown in Figure 4.18. Non-linear least square regression was applied using MATLAB to evaluate the parameters of the GAB model; the results are summarized in Table 4.15. The obtained values for $\mathrm{R}^{2}$ being 1 confirm that the GAB model fits the experimental data very well at all temperatures. In the previous section, a linear model was used to fit the water adsorption isotherm which provided reasonable fitting with $\mathrm{R}^{2}$ being 0.97 . That treatment is only for the sake of simplifying the model (equation 4.3) so as to achieve an analytical solution (equation 4.11). The GAB model here is more complicate than the linear one, however, provided better fitting results.

Table 4.15 shows that the monolayer capacity $X_{m}$ slightly decreased as the temperature was increased which indicates that water adsorption becomes more difficult and limited at higher temperature. This could be due to the fact that water adsorption is exothermic and at higher temperature the vibration energy of molecules are elevated which leads to the adsorption of a smaller net number of molecules at equilibrium (Okewale et al., 2011). Al-Muhtaseb et al., (2004) concluded that the monolayer capacity values obtained for potato, highly amylopectin and highly amylose starch powders decreased with an increase in the temperature, which supports the results of this work. Parameters $K$ and $C$ was reported to incorporate the temperature effect in the work done by Van den Berg (1984). In addition, $C$ is known to be more enthalpic while $K$ is entropic in nature (Al-Muhtaseb et al., 2004). 
Table 4.15. The GAB parameters for water vapor adsorption on canola meal at different temperatures.

\begin{tabular}{ccccc}
\hline $\mathrm{T}\left({ }^{\circ} \mathrm{C}\right)$ & $\begin{array}{c}\text { Monolayer capacity } \\
X_{m}\left(\mathrm{~mol} \mathrm{H}_{2} \mathrm{O} / \mathrm{kg} \text { adsorbent }\right)\end{array}$ & Energy constant, $\dot{C}$ & Energy Constant, $K$ & $\mathrm{R}^{2}$ \\
\hline 100 & 5.93 & 1.60 & 0.59 & 1 \\
105 & 5.91 & 1.52 & 0.62 & 1 \\
110 & 2.39 & 3.76 & 0.92 & 1 \\
\hline
\end{tabular}

The FHH model is another equilibrium isotherm used in this work to simulate the equilibrium data. The FHH model is described by Gatta and Lee (2007):

$X=X_{m}\left[-\ln a_{w}\right]^{-1 / r}$

where the exponent $1 / r$ is associated with the nature of the gas solid interaction, while the other variables are same as above. According to this model, if $r$ is small, the attraction between solid and vapor is not very large, thus forces are more of physical type and can act at a greater distance. However, when $r$ is very large, the attraction between vapor and solid becomes very large which cannot act far from the surface (Al-Asheh et al., 2009). Generally, if $r \leq 3$, the attraction between vapor and solid is more typically Van der Waals, while values of $r$ greater than 3 imply great attraction between vapor and solid (Al-Asheh et al., 2009).

Representations of isothermal data for water vapor adsorption on canola meal at different temperature using FHH model are shown in Figure 4.18. The FHH model parameters were determined using non-linear regression method and are shown in Table 4.16 along with the obtained values for $\mathrm{R}^{2}$. It can be seen that the FHH model gave a less accurate fit to the experimental results compared to the $\mathrm{GAB}$ model at 100 and $105^{\circ} \mathrm{C}$.

Table 4.16. Parameter values for the FHH model.

\begin{tabular}{cccc}
\hline $\mathrm{T}\left({ }^{\circ} \mathrm{C}\right)$ & $R$ & $X_{m}\left(\mathrm{~mol} \mathrm{H}_{2} \mathrm{O} / \mathrm{kg}\right.$ adsorbent $)$ & $\mathrm{R}^{2}$ \\
\hline 100 & 1.49 & 2.26 & 0.99 \\
105 & 1.09 & 2.18 & 0.99 \\
110 & 0.99 & 2.24 & 1 \\
\hline
\end{tabular}

Table 4.16 shows that the obtained values for $r$ for all temperatures were less than 3 . This means that the attraction forces between water vapor and solid are consistent with Van der Waals forces. Similarly, $r$ was also shown to be smaller than 3 for phillipsite (natural zeolite) in the work of (Al-Asheh et al., 2009). 

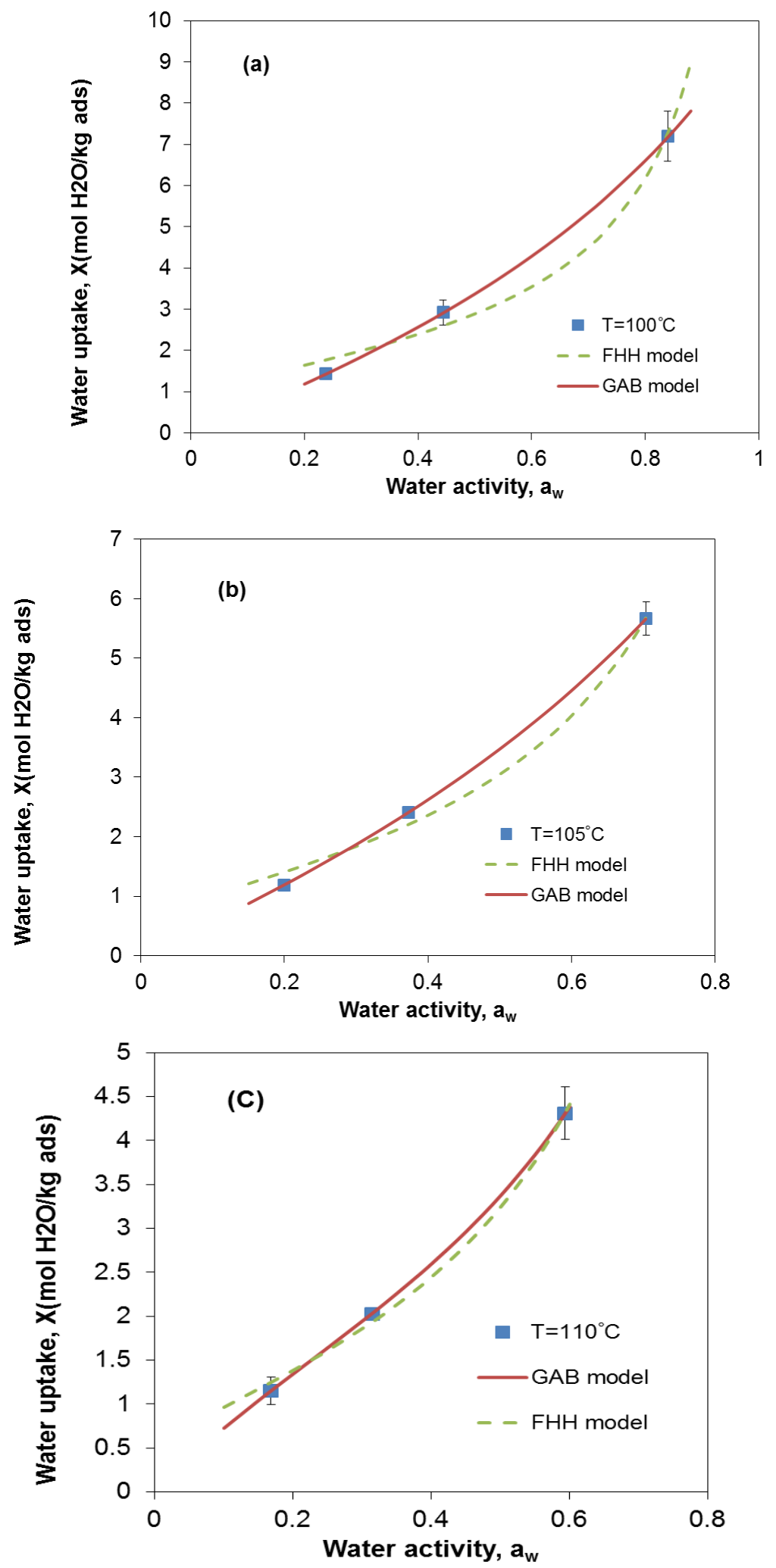

Figure 4.18 GAB and $\mathrm{FHH}$ isotherms of water adsorption on canola meal at $100,105,110^{\circ} \mathrm{C}$. Error bars represent the range of the obtained highest and lowest values for each data point. 
The Dubinin-Polanyi theory proposed a correlation of adsorption equilibria for microporous and macroporous materials based on the adsorption potential theory which is used to represent adsorption equilibrium data at different temperatures (Chang et al., 2006a; Ruthven 1984). According to the adsorption potential theory, the adsorption potential is correlated to the volume of fluid adsorbed on the adsorbent through a temperature independent relation referred to as the characteristic curve (Chang et al., 2006a; Ruthven 1984). The adsorption potential $\varepsilon$ is given by:

$\varepsilon=-R T \ln \left(\frac{f}{f^{s}}\right)=-R T \ln \left(\frac{P}{P^{s}}\right)$

where $f_{s}$ and $P^{S}$ are the saturation fugacity and pressure for the liquid sorbate, while $f$ and $P$ are referred to the corresponding equilibrium quantities for the adsorbed phase. The characteristic curve can be described by the following correlation:

$q=f(\varepsilon)=f\left(R T \ln \left(P^{s} / P\right)\right)$

The proposed correlations by Dubinin-Polanyi theory are both function of the adsorption characteristic curve (Ruthven 1984). The expression for microporous and macroporous materials are described by equations (4.34) and (4.35), respectively (Chang et al., 2006a).

$$
\begin{aligned}
& \ln q=\ln q_{0}-\frac{k_{1}}{\beta}\left[R T \ln \left(\frac{P^{S}}{P}\right)\right]^{2} \\
& \ln q=\ln q_{0}-\frac{k_{2}}{\beta}\left[R T \ln \left(P^{s} / P\right)\right]
\end{aligned}
$$

where $q$ is the water uptake ( $\mathrm{mol} \mathrm{H}_{2} \mathrm{O} / \mathrm{kg}$ adsorbent), $q_{0}$ is the limiting mass for adsorption (mol $\mathrm{H}_{2} \mathrm{O} / \mathrm{kg}$ adsorbent) and $\beta$ is an affinity coefficient characterizing the polarizability of the adsorbate. In addition, constants $k_{1}$ and $k_{2}$ is related to the distribution of pore volume and referred to as pore constants for micropore and large pore materials, respectively (Chang et al., 2006a).

Equations (4.34) and (4.35) were applied to equilibrium water uptake data at all tested temperatures $\left(100,105\right.$, and $\left.110^{\circ} \mathrm{C}\right)$ and the results are shown in Figure 4.19. The parameters for the Dubinin-Polanyi model were evaluated by the linear regression method using Microsoft Excel 2010. The estimated values for the model parameters are displayed in Table 4.17 along with the corresponding values for the correlation coefficient $\mathrm{R}^{2}$. 
Table 4.17. Values of parameters in Dubinin-Polanyi model for equilibrium water adsorption.

\begin{tabular}{ccccc}
\hline Dubinin-Polanyi Model & $\ln q_{0}$ & $\frac{k_{1}}{\beta} \times 10^{8}$ & $\frac{k_{2}}{\beta} \times 10^{4}$ & $\mathrm{R}^{2}$ \\
\hline Microporous adsorbent & 1.6 & 6 & N/A* & 0.89 \\
Large pore adsorbent & 2.1 & N/A* & 4 & 0.99 \\
\hline
\end{tabular}

*Not applicable

As it can be seen from Table 4.17, the $\mathrm{R}^{2}$ values of 0.89 and 0.99 were obtained for the microporous and large pore adsorbent model, respectively. Dubinin-Polanyi equation (4.37) for the macroporous type of adsorbent, gave a better fitting to the experimental results compared to equation (4.36), which may indicate that canola meal is a large pore material. This result is similar to the result reported by Chang et al., (2006a) where the Dubinin-Polanyi model was used to investigate the adsorption capacity of water and ethanol on cornmeal at temperatures from 82 to $100^{\circ} \mathrm{C}$ and reported that cornmeal is a large pore (or nonporous) material. 

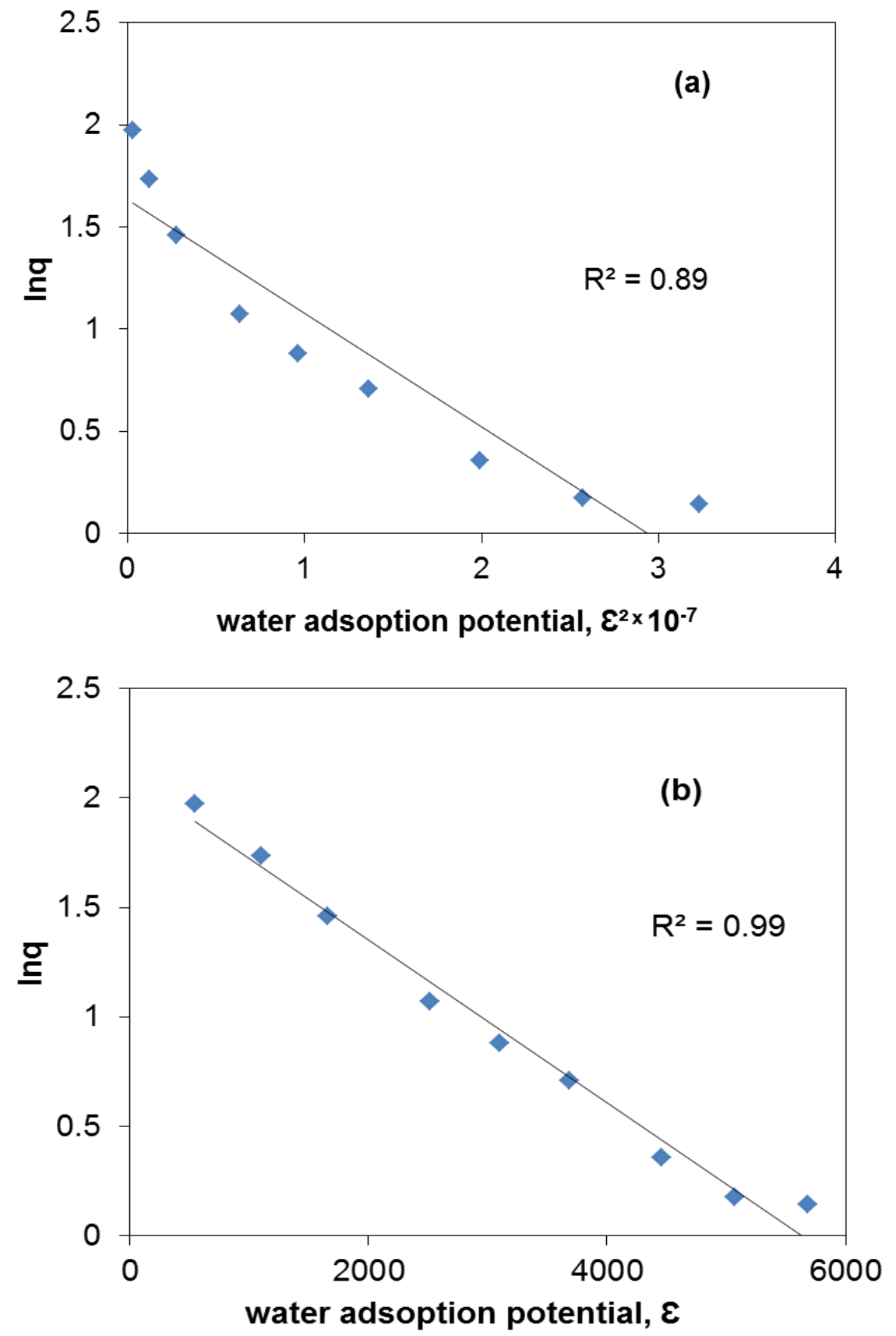

Figure 4.19 (a) Dubinin-Polanyi model for the microporous adsorbent (b) Dubinin-Polanyi model for large pore adsorbent.

\subsubsection{Heat of Adsorption}

As mentioned earlier, less water uptake was obtained at runs with greater temperatures. From the equilibrium isotherms, as a consequence, less heat of adsorption is expected to be generated at elevated temperatures. In view of this, it is important to determine the heat of 
adsorption. For this purpose, it is necessary to determine the thermodynamic equilibrium constant $K_{0}$ (or thermodynamic distribution coefficient) at different temperatures. For an adsorption process, $K_{0}$ can be defined by:

$$
K_{0}=\frac{a_{s}}{a_{e}}=\frac{\gamma_{s}}{\gamma_{e}} \frac{C_{s}}{C_{e}}
$$

where $a_{s}$ is the activity of the adsorbed component, $a_{e}$ the activity of the component in the feed at equilibrium conditions, $C_{s}$ the surface concentration of water in mol/kg adsorbent and $C_{e}$ the concentration of water in the vapor feed under equilibrium conditions (mol/L), $\gamma_{s}$ is the activity coefficient of adsorbed component and $\gamma_{e}$ the activity coefficient of the adsorbate in vapor feed at equilibrium. The constant $K_{0}$ is determined by plotting $\ln \left(C_{s} / C_{e}\right)$ versus $C_{e}$ and extrapolating to zero $C_{e}$ (Khan and Singh 1987). For this reason, the value of $\ln K_{0}$ is given by the intersection of the vertical axis with the straight line fitted to the points.

Standard free energy changes $\Delta \mathrm{G}^{\circ}$ are calculated from:

$\Delta G^{0}=-R T \ln K_{0}$

where $R$ is the universal gas constant and $T$ is temperature in Kelvin. The standard enthalpy changes $\Delta H^{\circ}$ (heat of adsorption) are evaluated from the Van't Hoff equation:

$\frac{d \ln K_{0}}{d \frac{1}{T}}=-\frac{\Delta H^{\circ}}{R}$

Thus, a plot of $\ln K_{0}$ vs. $1 / T$ gives a straight line. Then $\Delta H^{\circ}$, was determined by the slope of that line and the results are presented in Figure 4.20 (b). The standard entropy changes $\left(\Delta S^{\circ}\right)$ were calculated using the following equation:

$\Delta G^{\circ}=\Delta H^{\circ}-T \Delta S^{\circ}$

The calculated values for $\Delta H^{\circ}$ and $\Delta S^{\circ}$ were $-32.11 \mathrm{~kJ} / \mathrm{mol}$ and $-44 \mathrm{~J} / \mathrm{mol} * \mathrm{~K}$, respectively. Moreover, values of $-15.69,-15.49$ and $-15.25 \mathrm{~kJ} / \mathrm{mol}$ for $\Delta G^{\circ}$ were evaluated in runs at temperatures 100,105 and $110^{\circ} \mathrm{C}$. From this information it is again confirmed that the adsorption process is an exothermic phenomena due to the negative values obtained for $\Delta H^{\circ}$. The heat of adsorption in the range of $20-80 \mathrm{~kJ} / \mathrm{mol}$ indicates physical adsorption, while a higher value in the range of $80-400 \mathrm{~kJ} / \mathrm{mol}$ is expected for a chemical adsorption process (Ruthven 1984). The negative values for $\Delta G^{\circ}$ indicate that the adsorption process is feasible and spontaneous. 

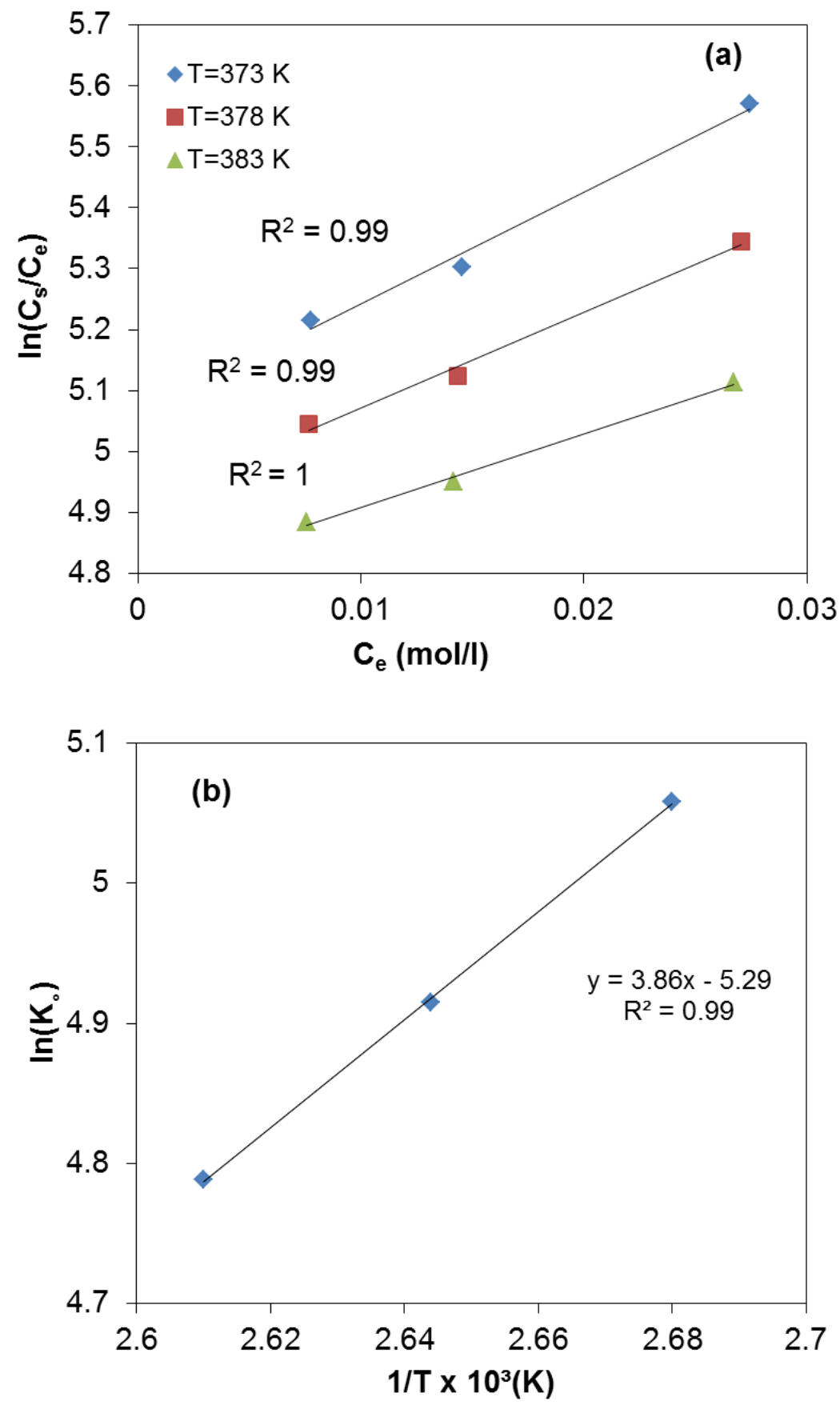

Figure 4.20 (a) Plots of $\ln \left(C_{s} / C_{e}\right)$ vs $C_{e}$, (b) Plot of $\ln K_{0}$ vs $1 / T$. Particle size $\mathrm{d}_{\mathrm{p}}=0.43-1.18$ $\mathrm{mm}$.

\subsection{Comparison with Other Adsorbents}

A comparison of water uptake by canola meal and other adsorbents is presented in Table 4.18. It was shown that canola meal has much higher water uptake than other types of cellulosic 
materials such as wood pulp, but has similar water uptake to that of corn meal. It was also found that corn meal has significant ethanol uptake which is higher than that reported in Chang et al., (2006b); Lee et al., (1991). Corn meal contains 75\% starch (Chang et al., 2006b; Lee et al., 1991) and water molecules diffuse into the starch matrix during adsorption which causes starch granules to swell (gelatinization). This in turn may decrease adsorption capacity of corn meal (Beery and Ladisch 2001). In the regeneration step, some adsorbates are trapped in the starch matrix due to the shrinking starch structure. Hence, trapped adsorbates make the desorption process longer. As a consequence, this phenomenon increases energy consumption (Kim et al., 2011; Beery and Ladisch 2001; Westgate and Ladisch 1993b). However, canola meal is mainly made of protein and cellulosic components and it was reported that no significant differences were observed in the least gelation concentration of canola meal by neither boiling nor roasting canola meal (Aider and Barbana 2011). Thus, it is possible to mix canola meal with corn meal to make pellets with higher selective water adsorption and lower gelatinization properties compared to canola and corn meal, respectively.

A comparison in equilibrium water/ethanol adsorption between zeolite and canola meal is summarized in Table 4.18. It was shown that zeolite has a higher water adsorption than canola meal, while its ethanol uptake is lower. The water uptake achieved for zeolite in this work is similar to that reported by Simo et al., (2009), however, the ethanol uptake was lower compared to this work. Future study is required to further enhance the water uptake and selectivity of canola meal. 
Table 4.18. Experimental results of water/ethanol uptake on different adsorbents.

\begin{tabular}{|c|c|c|c|c|c|c|c|}
\hline Adsorbent & $\begin{array}{c}\mathrm{T} \\
\left({ }^{\circ} \mathrm{C}\right)\end{array}$ & $\begin{array}{c}\mathrm{u}_{0} \\
(\mathrm{~cm} / \mathrm{s})\end{array}$ & $\begin{array}{c}\mathrm{P}_{\mathrm{w}} \\
(\mathrm{kPa})\end{array}$ & $\begin{array}{c}\mathrm{d}_{\mathrm{p}} \\
(\mathrm{mm})\end{array}$ & $\begin{array}{l}\text { feed } \\
\text { Con. }{ }^{1}\end{array}$ & $\begin{array}{c}\mathrm{H}_{2} \mathrm{O} \\
\text { uptake }^{2}\end{array}$ & $\begin{array}{c}\text { EtOH } \\
\text { uptake }^{2}\end{array}$ \\
\hline canola meal (this work) & 100 & 0.9 & 24 & $0.43-1.18$ & 95 & 1.43 & 3.17 \\
\hline canola meal (this work) & 100 & 0.9 & 24 & 5 & 95 & 1.56 & 3.63 \\
\hline corn meal (this work) & 100 & 0.9 & 24 & $0.43-1.18$ & 95 & 1.68 & 2.63 \\
\hline $\begin{array}{l}\text { corn meal (Chang et al., } \\
2006 \mathrm{c})\end{array}$ & 100 & 1.5 & 14 & $<0.45$ & 94 & 1.43 & 0.35 \\
\hline zeolite (this work) & 100 & 0.9 & 34 & 3 & 93 & 9.21 & 2.21 \\
\hline $\begin{array}{l}\text { zeolite (Simo et al., } \\
\qquad 2009)\end{array}$ & 100 & 8.3 & 23 & 3 & 0 & 9.10 & N/A \\
\hline $\begin{array}{l}\text { zeolite (Simo et al., } \\
\text { 2009) }\end{array}$ & 167 & 8.3 & N/A & 3 & 100 & N/A & 0.03 \\
\hline $\begin{array}{c}(\text { zeolite }+ \text { canola })(\text { this } \\
\text { work })\end{array}$ & 100 & 0.9 & 35 & $3 \& 5$ & 93 & 6.72 & 3.25 \\
\hline $\begin{array}{l}\text { cassava pearl (Kim et al., } \\
\text { 2011) }\end{array}$ & 90 & 20.0 & N/A & 1 & 95 & 1.40 & 0.16 \\
\hline $\begin{array}{l}\text { bleached wood pulp } \\
\text { (Benson and George }\end{array}$ & 78 & 0.3 & 12 & N/A & 95 & 0.64 & N/A \\
\hline 2005) & & & & & & & \\
\hline
\end{tabular}

${ }^{1}$ Feed concentration (wt\% EtOH), ${ }^{2}$ equilibrium uptake in (mol/kg adsorbent)

\subsection{Regeneration and Repeatability}

After the adsorption step, the water saturated bed was regenerated. For the regeneration step, the temperature of the bed was adjusted at $110^{\circ} \mathrm{C}$, and then the pressure was reduced and kept at $25 \mathrm{kPa}$ (-11 psig) with the aid of vacuum. Then, the column was purged by nitrogen gas from the bottom at flow rate $756 \mathrm{~cm}^{3} / \mathrm{min}$ until the bed was completely dried and the bed temperature resorted. It took around $4.5 \mathrm{hrs}$ for canola meal to dry completely. Furthermore, the weight of the canola meal packed in the bed was measured after desorption and compared with the initial weight; the difference in weight was about $0.44 \%$ which confirms the bed was completely dried. Then the regenerated bed was re-used for ethanol dehydration. The repeated runs are presented in Figure 4.21 (a) in terms of water breakthrough curves. The temperature 
profile is shown in Figure 4.21 (b). The repeated run had similar water breakthrough behavior as the original one. The canola meal was used for over 32 cycles without deteriorated quality, demonstrating that canola meal is stable and reusable in the application for ethanol dehydration.

Furthermore, CHNS analysis was performed on fresh canola meal and on used canola meal (after 32 cycles), and the results are displayed in Table 4.19 .

Table 4.19. Experimental results on CHNS analysis of fresh and used canola meal samples.

\begin{tabular}{rcccc}
\hline Adsorbent & $\mathrm{N} \%$ & $\mathrm{C} \%$ & $\mathrm{~S} \%$ & $\mathrm{H} \%$ \\
\hline Fresh CM & 6.5 & 48 & 0.6 & 6.3 \\
Used CM* & 6.6 & 47 & 0.6 & 6.2 \\
\hline
\end{tabular}

*canola meal used after 32 cycles

The results demonstrated that the contents of the major elements in canola meal, after being used for 32 cycles, are almost the same as the ones of fresh canola meal, indicating that canola meal is a stable material for ethanol dehydration. 

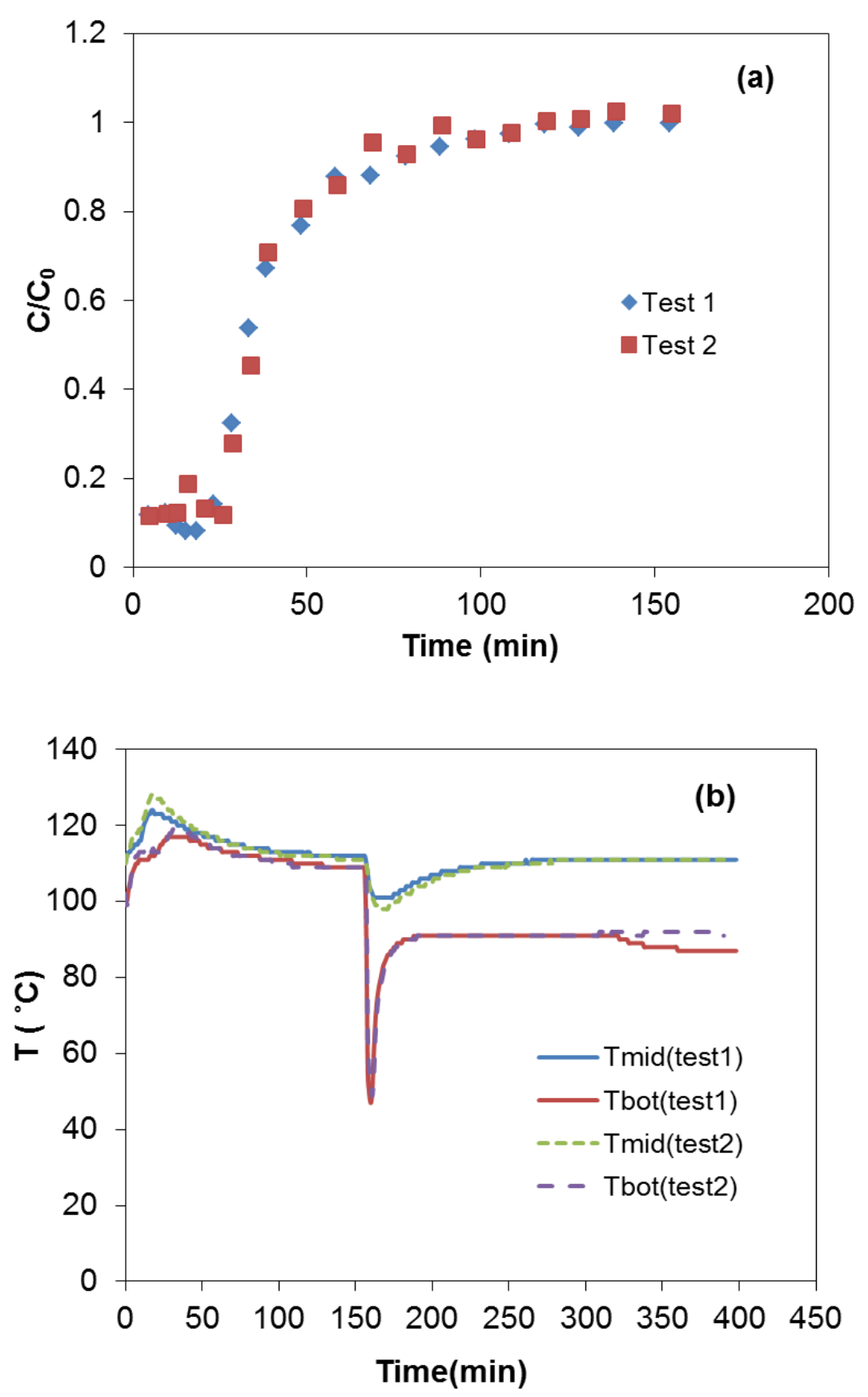

Figure 4.21 (a) Water breakthrough curves, (b) Temperature profiles. Operating conditions: $\mathrm{T}=110^{\circ} \mathrm{C}, \mathrm{P}_{\mathrm{w}}=24 \mathrm{kPa}, \mathrm{u}_{0}=0.9 \mathrm{~cm} / \mathrm{s}, \mathrm{d}_{\mathrm{p}}=0.425-1.18 \mathrm{~mm}$.

In Section 4.1.2, the functional groups of cellulosic and starchy components were observed at FTIR spectrums of canola meal. Due to this observation, the content of carbon and hydrogen may indicate the presence of these two groups in canola meal. Figure 4.22 shows that the functional groups of canola meal did not change through the adsorption cycles; FTIR 
spectrums of canola meal were relatively identical for fresh and used canola meal samples, which confirms the stability of canola meal usage as the adsorbent in ethanol dehydration.

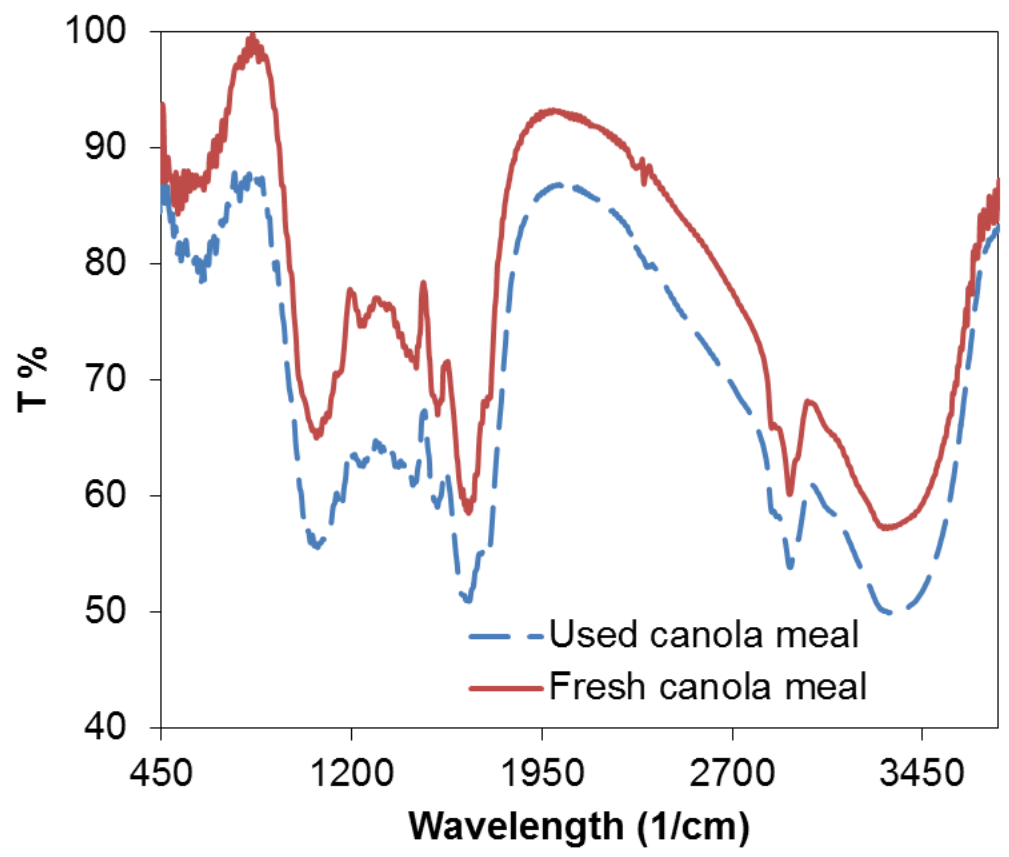

Figure 4.22 Fourrier transform infrared (FTIR) spectra of fresh and used canola meal. 


\section{CONCLUSIONS AND RECOMENDATIONS}

In summary, the lab scale pressure swing adsorption process (PSA) apparatus was designed and built to investigate water and ethanol adsorption behaviors on canola meal. Canola meal showed a good potential for water adsorption and it can be used for the separation of waterethanol mixture. Through experimental runs, it was shown that canola meal was able to break the azeotropic point $(95.6 \mathrm{wt} \%$ ) and produce ethanol with concentration over $99 \mathrm{wt} \%$ in the effluent. The highest ethanol production (ethanol with concentration over $99 \mathrm{wt} \%$ ) was 4.7 (mol EtOH/kg adsorbent), achieved at $100^{\circ} \mathrm{C}$, total pressure of $243 \mathrm{kPa}$, feed concentration of $95 \mathrm{wt} \% \mathrm{EtOH}$, and particle size of $0.43-1.118 \mathrm{~mm}$.

The water/ethanol adsorption dynamic study, investigated the effects of the pressure, temperature, particle size, feed concentration, and the superficial velocity on the water breakthrough curves and ethanol production profile. Through the simulation of water breakthrough curves, the overall mass transfer coefficient was determined in all experiments. Subsequently, the external, internal and overall mass transfer resistances were evaluated and the relevant mass transfer mechanisms were identified. The temperature dependency was discovered by observing a slight increase in the slope of water breakthrough curves with an increase in temperature. Through the simulation it was found that more than $95 \%$ of the total mass transfer resistance belongs to the internal resistances. In the case of superficial velocity effect, the slope of water breakthrough curves showed a tendency to increase with an increase in the velocity of vapor stream which caused the overall mass transfer coefficient to increase and reduce the overall mass transfer resistance. Although the contribution of external mass transfer resistance to the overall mass transfer resistance increased significantly as the velocity was increased, the internal mass transfer resistances still showed the greatest contribution. However, in total

pressure and pellet size experiments the overall mass transfer coefficient decreased with increases in total pressure and pellet size, respectively. The presence of macropore diffusion mechanism was identified in the total pressure experiments. Eventually, the internal mass transfer resistance was identified to have the most significant contribution to the overall mass transfer residences in all cases including the experimental runs at higher velocity. Thus, the internal mass transfer resistance was determined as the mechanism governing the adsorption 
process with respect to the assumption that the intrinsic water adsorption rate is faster than the mass transfer rate (external plus internal transport).

Equilibrium isotherms including Dubinin-Polanyi (potential theory), GuggenheimAndrson-de-Boer (GAB) and Frenkel-Halsey-Hill (FHH) were applied to describe the equilibrium water adsorption data. The GAB and FHH models were able to reasonably simulate the experimental data. From the FHH model results, the values obtained for $r$ were less than 3 in all temperatures confirming that the attraction forces between water vapor and solid resemble Van der Waals forces which can act at a greater distance. This can explain the mechanism of the intrinsic water adsorption, which is the adsorption of water molecules on the surface of the adsorbent (mono layer moisture content). Van der Waals forces form weaker bonds in comparison to hydrogen bonds which is known as the mechanism of water adsorption in the mono-layer on the starchy materials. The Dubinin-Polanyi model for large pore materials showed a better fit to the equilibrium data in comparison to Dubinin-Polanyi model for the microporous materials confirming that canola meal is a large pore (non-porous) material.

By using the Van't Hoff equation, the heat of adsorption on canola meal with particle size of $0.43-1.18 \mathrm{~mm}$ was determined to be $-32.11 \mathrm{~kJ} / \mathrm{mol}$. The result confirmed that the adsorption process is an exothermic phenomenon and is of physical type.

The equilibrium water uptake on canola meal was similar to that reported for starchy and cellulosic adsorbents, while the ethanol uptake was higher. At equilibrium, water uptake of canola meal was $1.43 \mathrm{~mol} \mathrm{H}_{2} \mathrm{O} / \mathrm{kg}$ adsorbent at the feed concentration of about $95 \mathrm{wt} \% \mathrm{EtOH}$ which is comparable to the one obtained by corn meal (1.43 mol $\mathrm{H}_{2} \mathrm{O} / \mathrm{kg}$ adsorbent), and cassava pearl (1.43 mol $\mathrm{H}_{2} \mathrm{O} / \mathrm{kg}$ adsorbent), and is higher than bleached wood pulp (0.644 mol $\mathrm{H}_{2} \mathrm{O} / \mathrm{kg}$ adsorbent). The saturated bed (canola meal) was successfully regenerated by passing nitrogen at $110^{\circ} \mathrm{C}$ which is lower than that for molecular sieves commonly used in industry for ethanol dehydration plants. The canola meal was re-used for more than 32 cycles without deteriorated quality.

Based on the observed relatively high ethanol uptake on canola meal, additional study should be beneficial to improve the selective water adsorption on canola meal by combining this bio-adsorbent with other materials. One could perform chemical treatments on canola meal before using it for ethanol dehydration processes to create more pores which will result in an increase in the surface area of the adsorbent. To obtain better equilibrium isotherm models, one 
should include the effects of ethanol uptake in the equilibrium isotherms since adsorption of ethanol was observed along with water adsorption during the ethanol dehydration process. To be able to conduct the adsorption experiments in a wider range of flow rates, one should modify the experimental apparatus design accordingly. To investigate the dynamic adsorption of either water or ethanol on canola meal, one should apply the online methods to measure the concentration of the components in the effluent. 


\section{REFERENCES}

Aider, M., C. Barbana. "Canola Proteins: Composition, Extraction, Functional Properties, Bioactivity, Applications as a Food Ingredient and allergenicity-A Practical and Critical Review." Trends in Food Science \& Technology 22, 1 (2011): 21-39.

Al-Asheh, S., F. Banat, N. Al-Lagtah. "Separation of ethanol-water Mixtures using Molecular Sieves and Biobased Adsorbents." Chemical Engineering Research and Design 82, 7 (2004): 855-64.

Al-Asheh, S., F. Banat, A. A. Fara. "Dehydration of Ethanol-Water Azeotropic Mixture by Adsorption through Phillipsite Packed-Column." Separation Science and Technology 44, 13 (2009): 3170-88.

Al-Muhtaseb, AH, WAM McMinn, TRA Magee. "Water Sorption Isotherms of Starch Powders: Part 1: Mathematical Description of Experimental Data." Journal of Food Engineering 61, 3 (2004): 297-307.

Arumugam, B. K., J. F. Banks, P. C. Wankat. "Pressure Effects in Adsorption Systems." Adsorption 5, 3 (1999): 261-78.

Baylak, T., P. Kumar, C. H. Niu, A. Dalai. "Ethanol Dehydration in a Fixed Bed using Canola Meal." Energy \& Fuels 26, 8 (2012): 5226-31.

Beery, K. E., M. R. Ladisch. "Chemistry and Properties of Starch Based Desiccants." Enzyme and microbial technology 28, 7 (2001): 573-81.

Beery, K. E., M. Gulati, E. P. Kvam, M. R. Ladisch. "Effect of Enzyme Modification of Corn Grits on their Properties as an Adsorbent in a Skarstrom Pressure Swing Cycle Dryer." Adsorption 4, 3 (1998): 321-35.

Beery, K. E., M. R. Ladisch. "Adsorption of Water from Liquid-Phase Ethanol-Water Mixtures at Room Temperature using Starch-Based Adsorbents." Industrial \& Engineering Chemistry Research 40, 9 (2001): 2112-5.

Benson, T. J., C. E. George. "Cellulose Based Adsorbent Materials for the Dehydration of Ethanol using Thermal Swing Adsorption." Adsorption 11 (2005): 697-701. 
Black, C., D. Distler. "Dehydration of Aqueous Ethanol Mixtures by Extractive Distillation." Extractive and azeotropic distillation (1972): 1-15.

Boonfung, Chontrita, Panarat Rattanaphanee. "Pressure Swing Adsorption with Cassava Adsorbent for Dehydration of Ethanol Vapor." World Academy of Science, Engineering and Technology 71 (2010).

"Canola Council of Canada." < http://www.canolacouncil.org/>, 2012 (2011).

Carmo, M. J., J. C. Gubulin. "Ethanol-Water Separation in the PSA Process." Adsorption 8, 3 (2002): 235-48.

Carrier, M., A. Loppinet-Serani, D. Denux, J. M. Lasnier, F. Ham-Pichavant, F. Cansell, C. Aymonier. "Thermogravimetric Analysis as a New Method to Determine the Lignocellulosic Composition of Biomass." Biomass and Bioenergy 35, 1 (2011): 298-307.

Chahbani, MH, D. Tondeur. "Mass Transfer Kinetics in Pressure Swing Adsorption." Separation and purification technology 20, 2 (2000): 185-96.

Chang, H., X. G. Yuan, H. Tian, A. W. Zeng. "Experimental Investigation and Modeling of Adsorption of Water and Ethanol on Cornmeal in an Ethanol-Water Binary Vapor System." Chemical Engineering \& Technology 29, 4 (2006a): 454-61.

Chang, H., X. G. Yuan, H. Tian, A. W. Zeng. "Experimental Study on the Adsorption of Water and Ethanol by Cornmeal for Ethanol Dehydration." Industrial \& Engineering Chemistry Research 45, 11 (2006b): 3916-21.

Chang, Hua, Xi-Gang Yuan, Hua Tian, Ai-Wu Zeng. "Experiment and Prediction of Breakthrough Curves for Packed Bed Adsorptin of Water Vapor on Cornmeal." Chemical Engineering and Processing 45 (2006c): 747-54.

Fogler, H. Elements of chemical reaction engineering Upper Saddle River, NJ: Upper Saddle River, NJ : Prentice Hall PTR, 1999.

Frolkova, A., V. Raeva. "Bioethanol Dehydration: State of the Art." Theoretical Foundations of Chemical Engineering 44, 4 (2010): 545-56. 
Gatta, G., Y. Lee. "Anisotropic Elastic Behaviour and Structural Evolution of Zeolite Phillipsite at High Pressure: A Synchrotron Powder Diffraction Study." Microporous and Mesoporous Materials 105, 3 (2007): 239-50.

Ghose, TK, RD Tyagi. "Rapid Ethanol Fermentation of Cellulose Hydrolysate. II. Product and Substrate Inhibition and Optimization of Fermentor Design." Biotechnology and bioengineering 21, 8 (1979): 1401-20.

Glueckauf, E., JI Coates. "241. Theory of Chromatography. Part IV. the Influence of Incomplete Equilibrium on the Front Boundary of Chromatograms and on the Effectiveness of Separation." Journal of the Chemical Society (Resumed) (1947): 1315-21.

Glueckauf, E. "Theory of Chromatography. Part 10.-Formula for Diffusion into Spheres and their Application to Chromatography." Transactions of the Faraday Society 51 (1955): 1540-51.

Gomis, V., A. Font, R. Pedraza, MD Saquete. "Isobaric vapor-liquid and vapor-liquid-liquid Equilibrium Data for the System Water Ethanol Cyclohexane." Fluid Phase Equilibria 235, 1 (2005): 7-10.

Gorbach, A., M. Stegmaier, G. Eigenberger. "Measurement and Modeling of Water Vapor Adsorption on Zeolite 4A-Equilibria and Kinetics." Adsorption 10, 1 (2004): 29-46.

Han, X., X. Ma, J. Liu, H. Li. "Adsorption Characterisation of Water and Ethanol on Wheat Starch and Wheat Gluten using Inverse Gas Chromatography." Carbohydrate Polymers 78, 3 (2009): 533-7.

Hassas-Roudsari, M., P. R. Chang, R. B. Pegg, R.. T. Tyler. "Antioxidant capacity of bioactives extracted from canola meal by subcritical water, ethanolic and hot water extraction." Food Chemistry 114, 2 (2009): 717-726.

Hong, J., M. Voloch, MR Ladisch, GT Tsao. "Adsorption of ethanol-water Mixtures by Biomass Materials." Biotechnology and bioengineering 24, 3 (1982): 725-30.

$\mathrm{Hu}, \mathrm{X} ., \mathrm{W}$. Xie. "Fixed-Bed Adsorption and Fluidized-Bed Regeneration for Breaking the Azeotrope of Ethanol and Water." Separation Science and Technology 36, 1 (2001): 125-36.

Huang, H. J., S. Ramaswamy, UW Tschirner, BV Ramarao. "A Review of Separation Technologies in Current and Future Biorefineries." Separation and Purification Technology 62, 1 (2008): 1-21. 
Jeong, J. S., B. U. Jang, Y. R. Kim, B. W. Chung, G. W. Choi. "Production of Dehydrated Fuel Ethanol by Pressure Swing Adsorption Process in the Pilot Plant." Korean journal of chemical engineering 26, 5 (2009): 1308-12.

Kapoor, A., T. Viraraghavan. "Heavy Metal Biosorption Sites in Aspergillus Niger." Bioresource technology 61, 3 (1997): 221-7.

Khan, A. A., RP Singh. "Adsorption Thermodynamics of Carbofuran on Sn (IV) Arsenosilicate in H , Na and Ca 2 Forms." Colloids and surfaces 24, 1 (1987): 33-42.

Kim, Y., R. Hendrickson, N. Mosier, A. Hilaly, M. R. Ladisch. "Cassava Starch Pearls as a Desiccant for Drying Ethanol." Industrial \& Engineering Chemistry Research 50, 14 (2011): 8678-85.

Klinkenberg, A. "Heat Transfer in Cross-Flow Heat Exchangers and Packed Beds." Industrial \& Engineering Chemistry 46, 11 (1954): 2285-9.

Kumar, S., N. Singh, R. Prasad. "Anhydrous Ethanol: A Renewable Source of Energy." Renewable and Sustainable Energy Reviews 14, 7 (2010): 1830-44.

Kupiec, K., J. Rakoczy, L. Zieliński, A. Georgiou. "Adsorption-Desorption Cycles for the Separation of Vapour-Phase Ethanol/Water Mixtures." Adsorption Science \& Technology 26, 3 (2008): 209-24.

Ladisch, M. R., K. Dyck. "Dehydration of Ethanol- New Approach Gives Positive Energy Balance." Science 205, 4409 (1979): 898-900.

Lee, J. Y., P. J. Westgate, M. R. Ladisch. "Water and Ethanol Sorption Phenomena on Starch." AICHE Journal 37, 8 (1991): 1187-95.

Liu, Y. W., T. Tang, T. W. Chung, C. Huang, Y. S. Lin. "Equilibrium Isotherms of Water and Ethanol Vapors on Immobilized Starch Sorbents." Journal of Chemical \& Engineering Data 55, 12 (2010): 5807-11.

Mahmoodi, N. M., M. Arami, H. Bahrami, S. Khorramfar. "Novel Biosorbent ( Canola Hull): Surface Characterization and Dye Removal Ability at Different Cationic Dye Concentrations." Desalination 264, 1 (2010): 134-42. 
Wajira Asanga Manamperi, Scott W. Pryor,Sam K. C. Chang. Separation and Evaluation of Canola Meal and Protein for Industrial Bioproducts, North Dakota State University, October 1213, $2007,2007$.

Okewale, AO, BR Etuk, PK Igbokwe. "COMPARATIVE STUDIES ON SOME STARCHY ADSORBENTS FOR THE UPTAKE OF WATER FROM ETHANOL-WATER MIXTURES." International Journal of Engineering \& Technology IJET-IJENS 11 (2011).

Pavia, DL, GM Lampman, DL Kriz. "Introduction to Spectroscopy: A Guide for Students." Saunders College Publishing (2000).

Pleeth, SJW. Alcohol, a fuel for internal combustion engines Chapman \& Hall, 1949.

Poling, Bruce E., John M. Prausnitz, and John P. O'Connell. The Properties of Gases and Liquids Fifth ed. McGRAW-HILL, 2001.

Pruksathorn, P., T. Vitidsant. "Production of Pure Ethanol from Azeotropic Solution by Pressure Swing Adsorption." Korean journal of chemical engineering 26, 4 (2009): 1106-11.

Quintero, J. A., C. A. Cardona. "Ethanol Dehydration by Adsorption with Starchy and Cellulosic Materials." Industrial \& Engineering Chemistry Research 48, 14 (2009): 6783-8.

Ribeiro, A. M., T. P. Sauer, C. A. Grande, R. F. P. M. Moreira, J. M. Loureiro, A. E. Rodrigues. "Adsorption Equilibrium and Kinetics of Water Vapor on Different Adsorbents." Industrial \& Engineering Chemistry Research 47, 18 (2008): 7019-26.

Ruthven, Douglas M. Principles of adsorption and adsorption processes New York: New York : Wiley, 1984.

Seader, J. D.,E. J. Henley. Separation process principles New York: New York : Wiley, 1998.

Sereno, C., A. Rodrigues. "Can Steady-State Momentum Equations be used in Modelling Pressurization of Adsorption Beds?" Gas separation \& purification 7, 3 (1993): 167-74.

Simo, M., Christopher J. Brown, Vladimir Hlavacek. "Simulation of Pressure Swing Adsorption in Fuel Ethanol Production Process." Computers \& Chemical Engineering 32, 7 (2008): 1635-49. 
Simo, M., S. Sivashanmugam, C. J. Brown, V. Hlavacek. "Adsorption/desorption of Water and Ethanol on 3A Zeolite in Near-Adiabatic Fixed Bed." Industrial \& Engineering Chemistry Research 48, 20 (2009): 9247-60.

Sowerby, B., BD Crittenden. "An Experimental Comparison of Type A Molecular Sieves for Drying the Ethanol-Water Azeotrope." Gas Separation \& Purification 2, 2 (1988): 77-83.

Sun, N., C. Okoye, C. H. Niu, H. Wang. "Adsorption of Water and Ethanol by Biomaterials." International Journal of Green Energy 4, 6 (2007): 623-34.

Timmermann, EO, J. Chirife, HA Iglesias. "Water Sorption Isotherms of Foods and Foodstuffs: BET Or GAB Parameters?" Journal of Food Engineering 48, 1 (2001): 19-31.

B. M. Tindall,R. S. Natarajan. Production of anhydrous ethnaol by pressure swing adsorption, New York, NY, Minneapolis, MN, 1987 , 1987.

Van den Berg, C. "Description of Water Activity of Foods for Engineering Purposes by Means of the GAB Model of Sorption." Engineering and food 1 (1984): 311-21.

Vareli, G. D., P. G. Demertzis, K. Akrida-Demertzi. "Effect of Adsorbent Particle Size and Temperature on Water-Ethanol Separation by Starchy and Cellulosic Substrates." Zeitschrift für Lebensmitteluntersuchung und -Forschung A 207, 2 (1998): 122-7.

Vareli, G. D., P. G. Demertzis, K. Akrida-Demertzi. "Water and Ethanol Adsorption on Starchy and Cellulosic Substrates as Biomass Separation Systems." Zeitschrift für Lebensmitteluntersuchung und-Forschung A 205, 3 (1997): 204-8.

Wang, Y., C. Gong, J. Sun, H. Gao, S. Zheng, S. Xu. "Separation of ethanol/water Azeotrope using Compound Starch-Based Adsorbents." Bioresource technology 101, 15 (2010): 6170-6.

Westgate, P. J., M. R. Ladisch. "Sorption of Organics and Water on Starch." Industrial \& Engineering Chemistry Research 32, 8 (1993a): 1676-80.

Westgate, P. J., M. R. Ladisch. "Air Drying using Corn Grits as the Sorbent in a Pressure Swing Adsorber." AICHE Journal 39, 4 (1993b): 720-3. 
Wetzel, DL, AJ Eilert, LN Pietrzak, SS Miller, JA Sweat. "Ultraspatially-Resolved Synchrotron Infrared Microspectroscopy of Plant Tissue in Situ." Cellular and molecular biology (Noisy-leGrand, France) 44, 1 (1998): 145.

Yu, P., C. R. Christensen, D. A. Christensen, J. J. McKinnon. "Ultrastructural-Chemical Makeup of Yellow-Seeded (Brassica Rapa) and Brown-Seeded (Brassica Napus) Canola within Cellular Dimensions, Explored with Synchrotron Reflection FTIR Microspectroscopy." Canadian journal of plant science 85, 3 (2005): 533-41.

Zhang, XJ, LM Qiu. "Moisture Transport and Adsorption on Silica gel-calcium Chloride Composite Adsorbents." Energy conversion and management 48, 1 (2007): 320-6. 


\section{APPENDIX A}

Chapman and Enskog equation (Poling et al., 2001) was used to evaluate the diffusion coefficient $\left(\mathrm{D}_{\mathrm{AB}}\right)$ in binary gas mixtures:

$\mathrm{D}_{\mathrm{AB}}=\frac{0.00266 \mathrm{~T}^{\frac{3}{2}}}{\mathrm{PM}_{\mathrm{AB}}^{\frac{1}{2}} \sigma_{\mathrm{AB}}^{2} \Omega_{\mathrm{D}}}$

where $\mathrm{M}_{\mathrm{A}}, \mathrm{M}_{\mathrm{B}}$ denotes molecular weights of $\mathrm{A}$ and $\mathrm{B}, \mathrm{P}$ is pressure in bar, $\mathrm{T}$ is temperature in kelvin, $\sigma_{\mathrm{AB}}$ is characteristic length of the intermolecular force law ( ${ }^{\circ} \mathrm{A}$ ), and $\Omega_{\mathrm{D}}$ is diffusion collision integral.

$\mathrm{M}_{\mathrm{AB}}$ and $\sigma_{\mathrm{AB}}$ were determined by using equations (2) and (3):

$\mathrm{M}_{\mathrm{AB}}=2\left[\left(1 / \mathrm{M}_{\mathrm{A}}\right)+\left(1 / \mathrm{M}_{\mathrm{B}}\right)\right]^{-1}$

$\sigma_{\mathrm{AB}}=\left(\sigma_{\mathrm{A}} \sigma_{\mathrm{B}}\right)^{\frac{1}{2}}$

where $\sigma$ is the characteristic Lennard-Jones length which is evaluated by equation (Poling et al., 2001):

$\sigma=\left(\frac{1.585 \mathrm{~V}_{\mathrm{b}}}{1+1.3 \delta^{2}}\right)^{\frac{1}{3}}$

where $V_{b}$ is the liquid molar volume at the normal boiling point $\left(\mathrm{cm}^{3} / \mathrm{mol}\right) . \delta$ and $V_{b}$ were calculated using equations (5) and (6) (Poling et al., 2001):

$\delta=\frac{1.94 * 10^{3} \mu_{\mathrm{p}}^{2}}{\mathrm{~V}_{\mathrm{b}} \mathrm{T}_{\mathrm{b}}}$

$\mathrm{V}_{\mathrm{b}}=0.285 \mathrm{~V}_{\mathrm{c}}^{1.048}$

where $V_{c}$ is the critical volume $\left(\mathrm{cm}^{3} / \mathrm{mol}\right), T_{b}$ is normal boiling point (kelvin) at the atmospheric pressure, and $\mu_{\mathrm{p}}$ is dipole moment in debye.

$\Omega_{\mathrm{D}}$ was evaluated by the correlation of Neufield et al. (1972) (Poling et al., 2001) as follows:

$\Omega_{\mathrm{D}}=\frac{\mathrm{A}}{\left(\mathrm{T}^{*}\right)^{\mathrm{B}}}+\frac{\mathrm{C}}{\exp \left(\mathrm{DT}^{*}\right)}+\frac{\mathrm{E}}{\exp \left(\mathrm{FT}^{*}\right)}+\frac{\mathrm{G}}{\exp \left(\mathrm{HT}^{*}\right)}+\frac{0.19 \delta_{\mathrm{AB}}^{2}}{\mathrm{~T}^{*}}$

where

$$
\begin{array}{lcc}
T^{*}=K T / \varepsilon_{A B} & A=1.06036 & B=0.15610 \\
C=0.19300 & D=0.47635 & E=1.03587
\end{array}
$$




$$
F=1.52996 \quad G=1.76474 \quad H=3.89411
$$

Equation (8) was applied to identify $\varepsilon_{A B} / \mathrm{k}$ :

$\frac{\varepsilon_{\mathrm{AB}}}{\mathrm{K}}=\left(\frac{\varepsilon_{\mathrm{A}}}{\mathrm{K}} \frac{\varepsilon_{\mathrm{B}}}{\mathrm{K}}\right)^{1 / 2}$

where $\varepsilon / K$ was determined by the following equation (Poling et al., 2001):

$\frac{\varepsilon}{\mathrm{K}}=1.18\left(1+1.3 \delta^{2}\right) \mathrm{T}_{\mathrm{b}}$

Blanc's law (Poling et al., 2001) was used to determine the diffusion coefficient for a ternary mixture as follows:

$D_{i m}=\left(\sum_{\substack{j=1 \\ j \neq i}}^{n} \frac{X_{j}}{D_{i j}}\right)^{-1}$

where $i$ is the trace component, and $X j$ is the mole fraction of component $j$. Water was considered as the trace component in this case. First, binary gas phase diffusivities was calculated according to equation (1). Then, the overall diffusivity was evaluated by equation (10). 